\title{
Recycling veneer-mill residues into engineered products with improved torsional rigidity
}

\author{
Brad McGraw \\ West Virginia University
}

Follow this and additional works at: https://researchrepository.wvu.edu/etd

\section{Recommended Citation}

McGraw, Brad, "Recycling veneer-mill residues into engineered products with improved torsional rigidity" (2009). Graduate Theses, Dissertations, and Problem Reports. 2801.

https://researchrepository.wvu.edu/etd/2801

This Thesis is protected by copyright and/or related rights. It has been brought to you by the The Research Repository @ WVU with permission from the rights-holder(s). You are free to use this Thesis in any way that is permitted by the copyright and related rights legislation that applies to your use. For other uses you must obtain permission from the rights-holder(s) directly, unless additional rights are indicated by a Creative Commons license in the record and/ or on the work itself. This Thesis has been accepted for inclusion in WVU Graduate Theses, Dissertations, and Problem Reports collection by an authorized administrator of The Research Repository @ WVU. For more information, please contact researchrepository@mail.wvu.edu. 
Recycling Veneer-Mill Residues into Engineered Products with Improved Torsional Rigidity

\author{
Brad McGraw
}

Thesis submitted to the College of Agriculture, Forestry and Consumer Sciences at West Virginia University

in partial fulfillment of the requirements

for the degree of

Master of Science

in

Forestry

\author{
Elemer M. Lang, Ph.D., Chair \\ Julio F. Davalos, Ph.D. \\ Dr. Levente Denes, Ph.D. \\ Dr. Benjamin Dawson-Andoh, Ph.D. \\ Department of Wood Science
}
Morgantown, West Virginia
2009

Keywords: Veneer-Mill Residues; Structural Wood Composites; Engineered Wood Composites; I-Joists 


\section{ABSTRACT \\ Recycling Veneer-Mill Residues into Engineered Products with Improved Torsional Rigidity}

\section{Brad McGraw}

The purpose of this research was to recycle veneer-mill residues from underutilized hardwood species into a value-added composite. These residues come from high quality logs and currently, are treated as waste. This study included the development of production methods of this new product. Using standard ASTM testing methods, an assessment into the physical and mechanical properties of the composite was performed.

The intended end use of these panels is as a web material in prefabricated I-joists. Composite I-joists were produced using flanges of structural composite lumber and a corrugated web. The purpose of the corrugated web was to increase the buckling capacity and in-plane stability of the joists. To manufacture structural size samples panels were joined in length. The strength of the web-to-web connection and two different flange-to-web connections were explored. A basic investigation into the bending performance of the I-joists was carried out.

This research was carried out as a preliminary investigation into the production methods and characterization of composite panels of hardwood decorative veneer clippings. This will lead to an adjoining thesis into the characterization and buckling capacity of l-joists with a corrugated web of these veneer-mill residue composite panels. 


\section{AKNOWLEDGEMENTS}

Funding for this project was provided by the Wood Utilization Project, the WVU Division of Forestry and Natural Resources, and the WVU Department of Civil and Environmental Engineering. I would like to thank Spencer Veneer LLC in Spencer, WV and Charles "Spike" Mancuso and International Timber \& Veneer in Jackson Center, PA for providing the residues used in this research. I would also like to thank John Noffsinger and Weyerhaeuser of Heaters, WV for their generous contribution of materials. In addition, I would also like to thank Brian Wilson and Weyerhaeuser of Buckhannon, WV and Steve Wendler and the Arclin Company for their donations.

I would like to express my sincerest gratitude and appreciation to Dr. Elemer M. Lang for providing me with this opportunity. His knowledge, support, encouragement, and advice were a driving force behind the completion of this project. I especially must thank Dr. Levente Denes for all of his guidance and support. Without Levente I could not have completed this project. I also must thank Dr. Julio F. Davalos, Dr. An Chen, and the Civil and Environmental Engineering Department. I would like to specifically thank Dr. Benjamin Dawson-Andoh, Dr. James Armstrong, Dr. Joseph F. McNeel, and Dr. Jingxing Wang. I also must thank Paul Ludrosky, Jody Gray, the entire faculty and staff of the Wood Science Department, the Division of Forestry and Natural Resources, and the Appalachian Hardwood Center. Also, I must express my gratitude towards Colin Dougherty, Hannes Plackner, Mike Merit, Colin Hotalen, Todd Mills, and my fellow graduate students. 
Finally, I cannot give enough thanks to my family and friends for all the love, support, and encouragement they provided . Thanks again to all I have mentioned and those whom I may have left ou 


\section{TABLE OF CONTENTS}

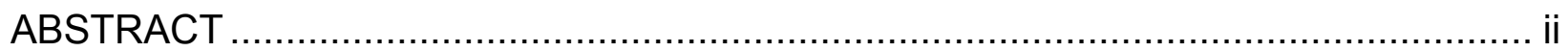

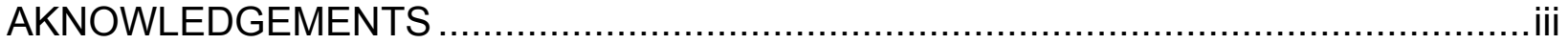

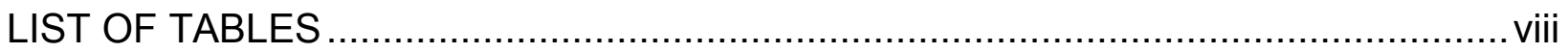

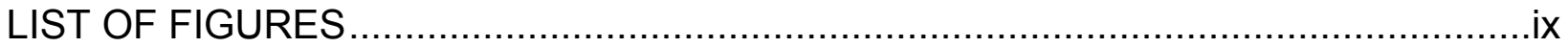

\section{Chapter 1}

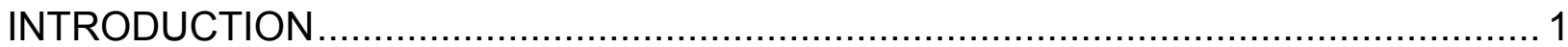

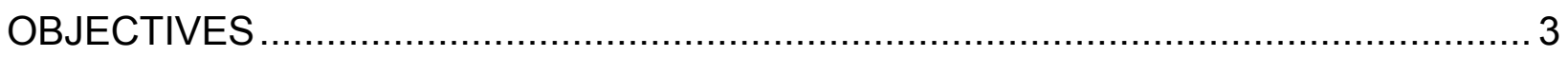

\section{Chapter 2}

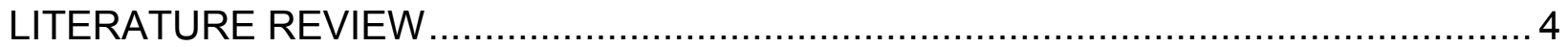

$2.1 \quad$ Wood-based Composites ............................................................................. 4

2.2 Structural Composite Lumber (SCL) …...................................................... 5

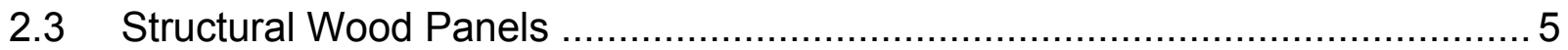

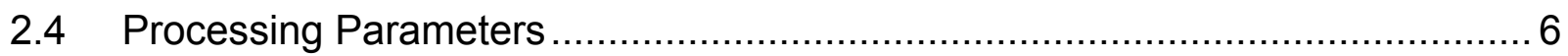

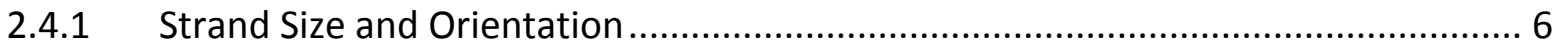

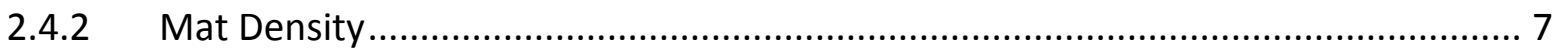

2.4.3 Influence of Moisture Content …………………............................................... 8

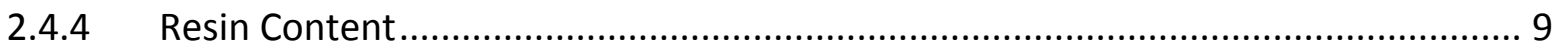

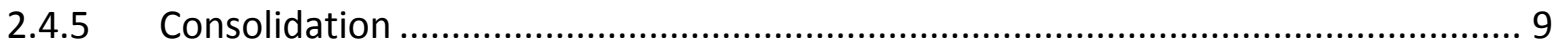

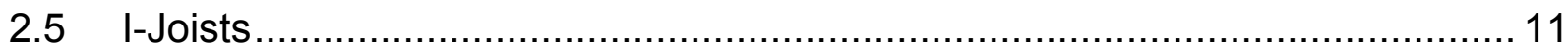

\section{Chapter 3}

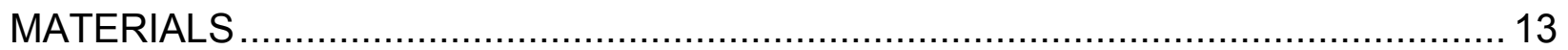

3.1 Decorative Hardwood Veneer .............................................................. 13

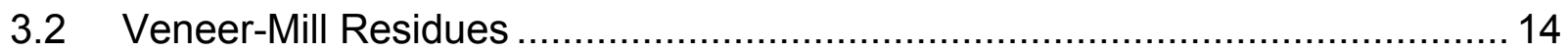

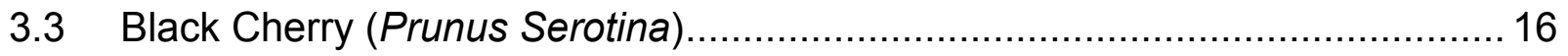

3.4 Liquid Phenol-Formaldehyde ............................................................. 16

\section{Chapter 4}

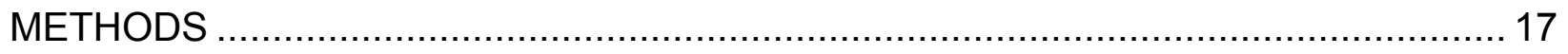

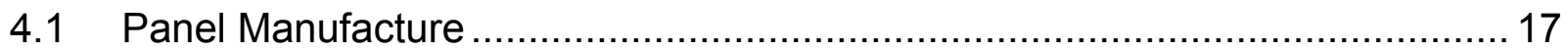




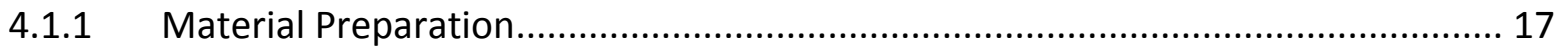

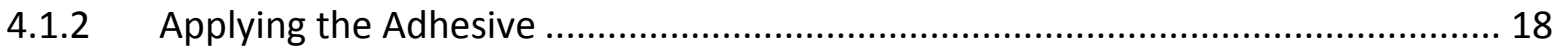

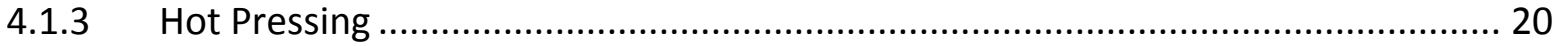

4.1.4 Flat Panel Manufacture .................................................................................. 21

4.1.5 Corrugated Panel Manufacture .................................................................. 24

4.1.6 Optimization of Press Schedule ........................................................................ 28

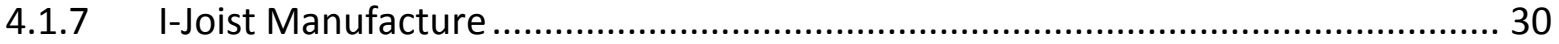

4.2 Mechanical Testing of Small Scale Specimens ....................................... 31

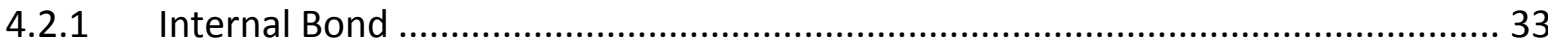

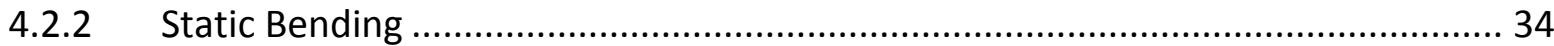

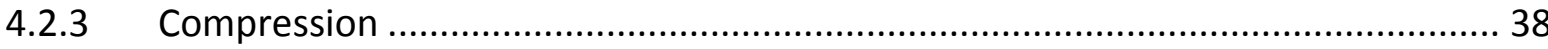

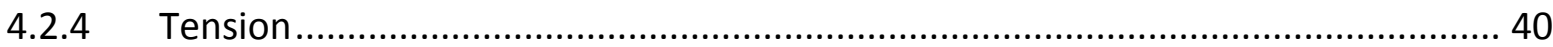

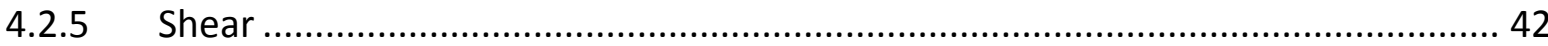

4.2.6 Water Absorption and Thickness Swell ........................................................... 43

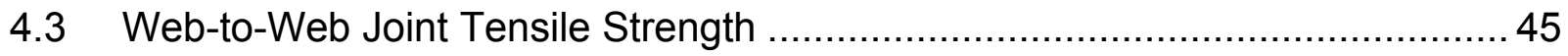

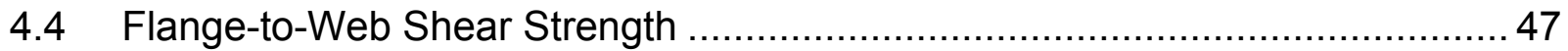

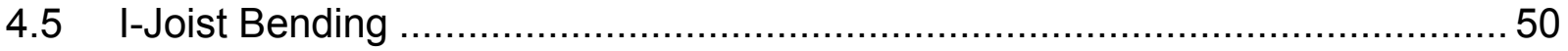

\section{Chapter 5}

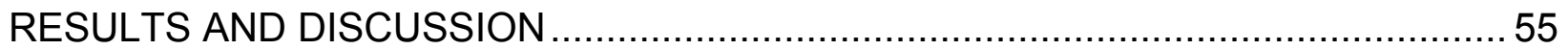

5.1 Mechanical Testing of Small Scale Specimens ..................................... 55

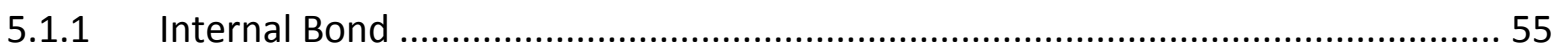

5.1.2 Water Absorption and Thickness Swell ........................................................... 56

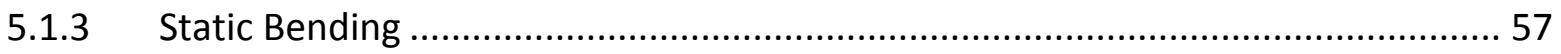

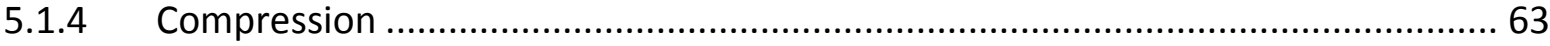

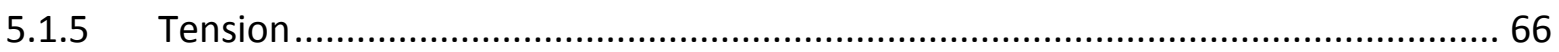

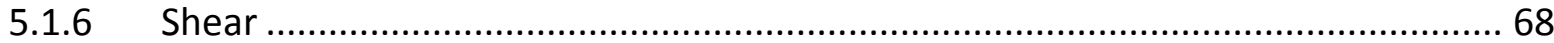

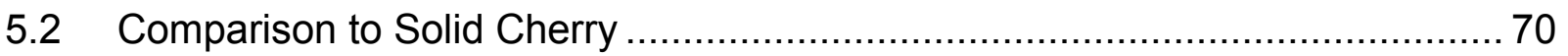

5.3 Comparison to Structural Wood Panels .......................................... 71

5.4 Comparison to Structural Composite Lumber ................................. 74

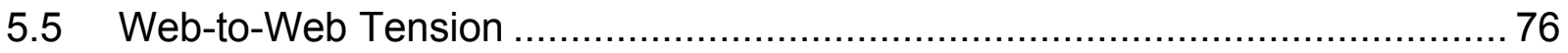




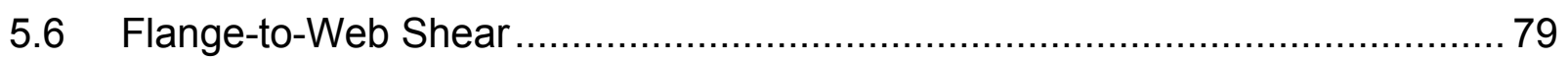

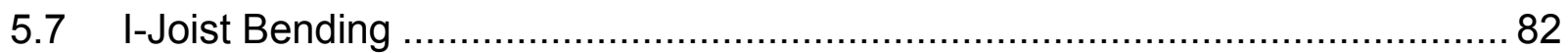

\section{Chapter 6}

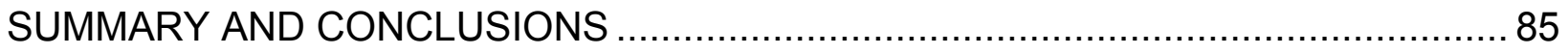

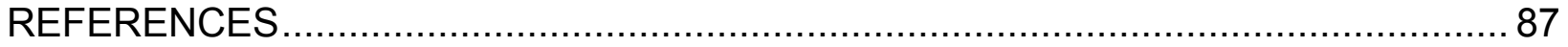

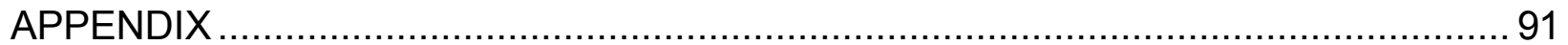




\section{LIST OF TABLES}

TABLE

Page

5.1 Summary of internal bond tests .56

5.2 Summary of water absorption and thickness swell testing ................ 57

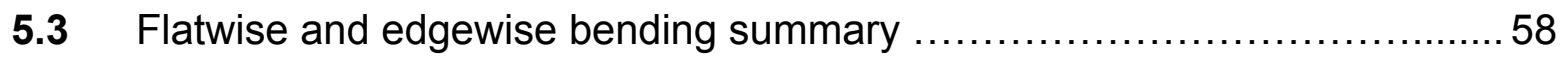

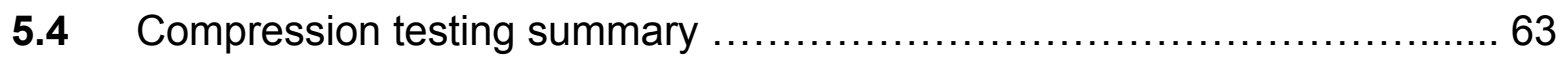

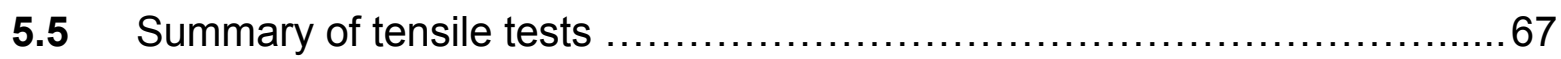

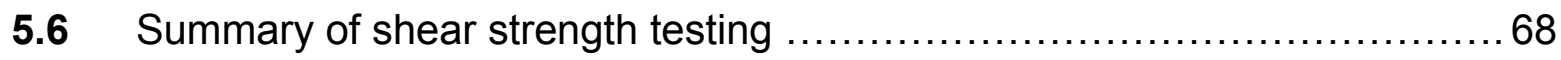

5.7 Comparison of the mechanical properties of the veneer strand

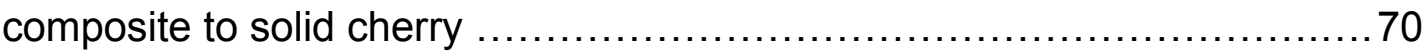

5.8 Comparison of the mechanical properties of the veneer strand composite to sheathing-grade OSB and plywood 71

5.9 Comparison of the mechanical properties of the veneer strand composite to LVL and PSL .74

5.10 Summary of preliminary web-to-web joint tensile strength tests with panels made from Ash 77

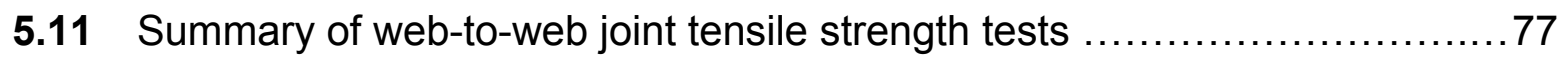

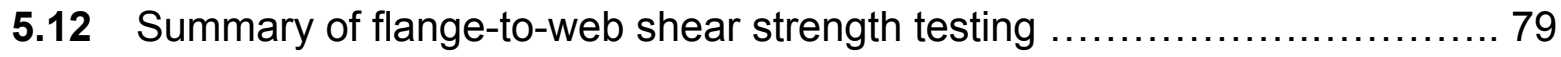

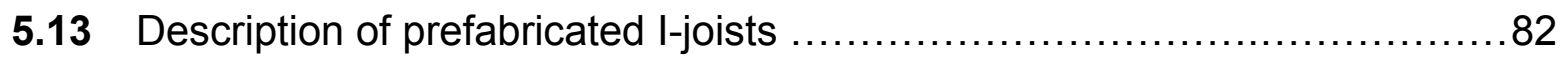

5.14 Mechanical properties of prefabricated I-joists ............................ 83 


\section{LIST OF FIGURES}

Figure

Page

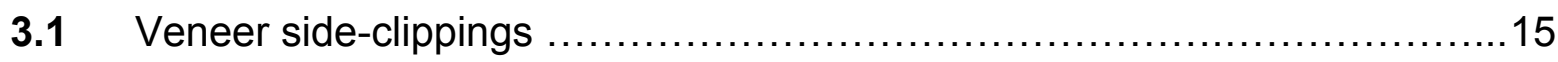

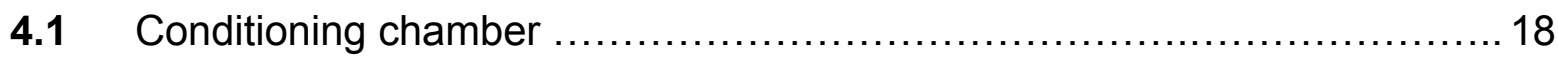

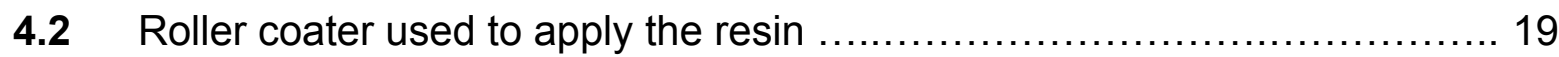

$4.3 \quad$ (a) Hot press and (b) press control console ............................... 20

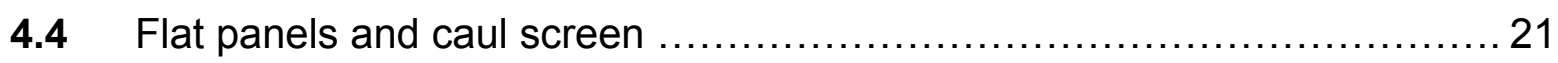

4.5 (a) Press schedule for flat panels and (b) PressMAN graph ................. 23

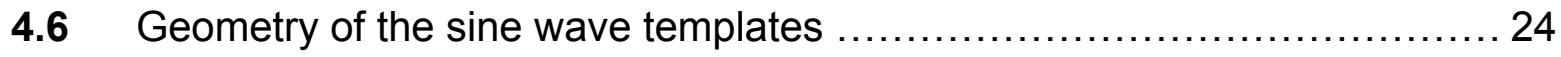

4.7 Thickness variations in sine wave templates ............................ 25

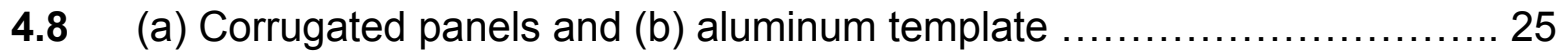

4.9 (a) Press schedule for corrugated panels and (b) PressMAN graph ........ 27

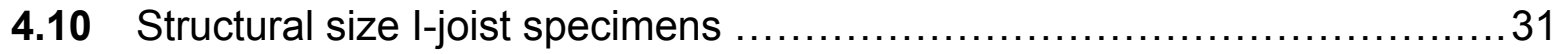

4.11 Parallel to strand alignment $(\|)$ and perpendicular to strand

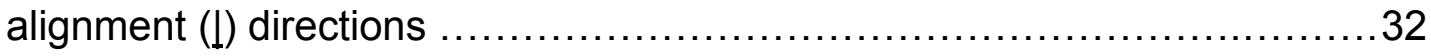

4.12 Internal bond (tensile strength perpendicular to surface) test setup ......... 33

4.13 Static bending test setup (a) front view and (b) side view ...................35

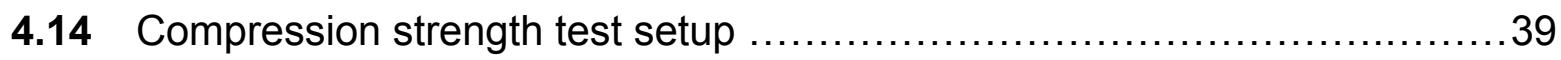

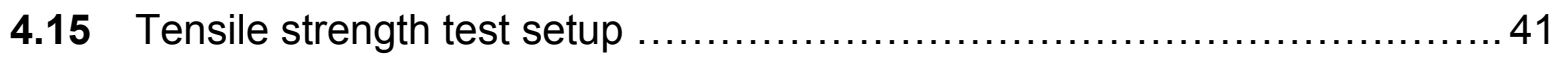

4.16 Shear strength in the plane of the board test setup ........................42

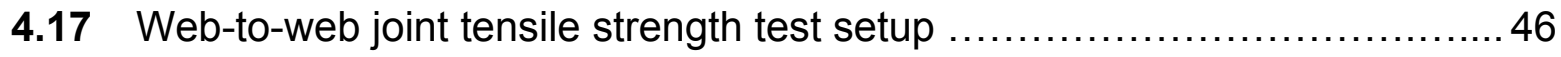




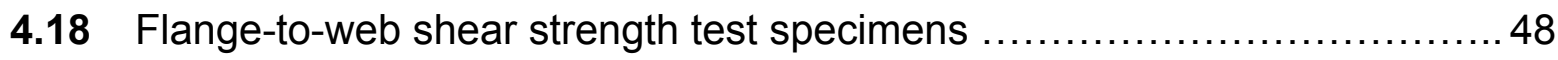

4.19 Flange-to-web shear strength test configuration ......................... 48

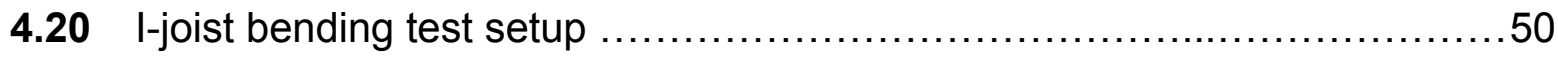

5.1 Comparison of flatwise and edgewise MOE about both the \|

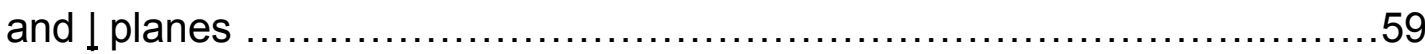

5.2 Relationship between density and the bending MOE about

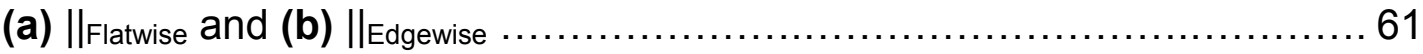

5.3 Relationship between density and the bending MOE about

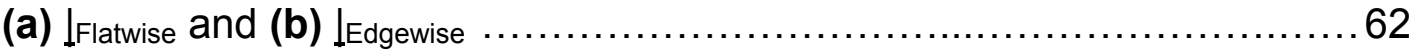

5.4 Comparison of the compressive MOE about the $\|$ and $\rfloor$ planes ..............64

5.5 Relationship between density and the compressive MOE about

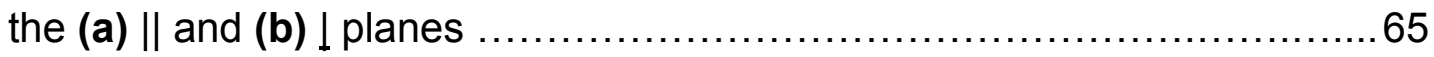

5.6 Comparison of the tensile MOE about the $\|$ and $\downarrow$ planes ...................67

5.7 Comparison of the shear strength in the $\|$ and $\downarrow$ planes .....................69

5.8 Comparison of MOR in flexure of the veneer strand composite,

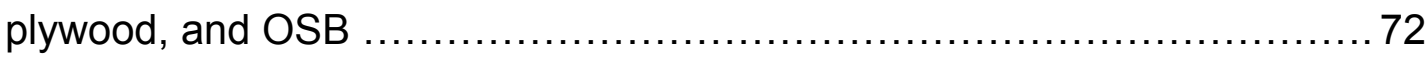

5.9 Comparison of MOE in flexure of the veneer strand composite,

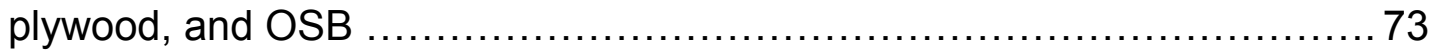

5.10 Comparison of tensile and compressive strength of the veneer strand composite, plywood, and OSB …............................... 73

5.11 Comparison of flatwise and edgewise MOE parallel to strand alignment of the veneer strand composite, LVL, and PSL 75

5.12 Comparison of compressive MOE parallel and perpendicular to 
strand alignment of the veneer strand composite, LVL, and PSL

5.13 Comparison of shear strength parallel and perpendicular to strand alignment of the veneer strand composite, LVL, and PSL .76

5.14 Comparison of tensile strength of solid panels and panels joined in length using ash and cherry 78

5.15 Typical failure modes of flange-to-web shear tests .80

5.16 Comparison of shear strength of flange-to-web joints 81

5.17 Typical failure modes of I-joists 84 


\section{LIST OF SYMBOLS AND ABBREVIATIONS}

\begin{tabular}{|c|c|}
\hline$A$ & area $\left(\mathrm{in}^{2}\right)$ \\
\hline$C_{v}$ & coefficient of variation (\%) \\
\hline$M O E$ & modulus of elasticity (psi) \\
\hline$E_{A P P}$ & apparent modulus of elasticity (psi) \\
\hline$f t$ & feet \\
\hline$I_{x}$ & moment of inertia $\left(\mathrm{in}^{4}\right)$ \\
\hline in (") & inch \\
\hline ksi & kilo-pounds per square inch \\
\hline$I_{0}$ & initial gauge length (in) \\
\hline$L$ & span length (in) \\
\hline Ib & pound \\
\hline M & moment (lb-in) \\
\hline$\|$ & parallel to strand alignment orientation \\
\hline 1 & perpendicular to strand alignment orientation \\
\hline$P$ & load (lbs) \\
\hline psi & pounds per square inch \\
\hline MOR & modulus of rupture (psi) \\
\hline$S_{x}$ & section modulus $\left(\mathrm{in}^{3}\right)$ \\
\hline $\mathrm{t}$ & thickness of specimen (in) \\
\hline$w$ & width of specimen (in) \\
\hline$\delta$ & displacement (in) \\
\hline$\Delta$ & deflection (in) \\
\hline$\epsilon$ & strain (in/in) \\
\hline$\sigma$ & stress (psi) \\
\hline$\tau$ & shear stress (psi) \\
\hline
\end{tabular}




\section{INTRODUCTION}

Solid wood, typically coniferous species, has been the most commonly used building material for residential and light framed construction in the U.S. Over the last few decades the quality and quantity of available raw timber resources has been on the decline. The increasing need for construction materials together with the lack of suitable raw materials has lead to the research and development of new composite products. Some hardwood species have now been introduced as load carrying members and into manufacturing of structural composite products.

Structural composites have risen to meet the demand of this changing market. Composites have been shown to exhibit more consistent physical and mechanical properties and sometimes higher strength and stiffness than solid wood (Lang et al. 2008). By breaking down raw materials into smaller pieces and then reforming them into composite products defects can be minimized, and products can be manufactured which are much more homogenous, predictable, and typically stronger than the raw materials. Also, the dimensions of these structural composites are only limited by manufacturing constraints.

Composite wood members are becoming more common in structural system design, and are expected to become even more important as demand continues to force improved utilization of available resources (Leichti et al. 1990). Having a highly 
efficient design, prefabricated wood I-joists are an attractive economical alternative to solid-sawn lumber. I-joists are lightweight load carrying members shaped to maximize stiffness while minimizing materials used. Prefabricated wood I-joists are used for longspan applications such as floor or roof systems in both residential and commercial light framed construction.

When discussing I-joists bucking is a limiting factor and always of primary concern especially with increasing span length. When under heavy concentrated loading and not properly braced in the lateral direction the joist will suddenly fail due to lateral buckling of the compression flange. Also, l-joists with slender webs and increasing depth-to-thickness or span-to-depth ratios are much more prone to lateral buckling. 


\section{OBJECTIVES}

The primary goal of this project was to characterize the mechanical and physical properties of a new composite product made from hardwood veneer-mill residues. The intention is to use this new product as a corrugated web material in I-joists for home and light-frame construction. The results of this research are to be used in simulation modeling. The specific objectives of this phase of the project were:

1. Development of production technologies that include preprocessing of the constituents, adhesive-strand blending technique, mat lay-up, and the hot pressing/consolidation process.

2. Manufacturing of small-scale and structural-size samples.

3. Investigation of the physical and mechanical properties of the new composite using small scale specimens and standard ASTM testing procedures.

4. Investigation of the strengths of the web-to-web and flange-to-web connections using the corrugated web.

5. Investigation of the mechanical properties of structural size I-joist specimens with a corrugated web. 


\section{LITERATURE REVIEW}

\subsection{Wood-based Composites}

The availability of the size, quality, and quantity of timber resources is declining while the demand for higher quality wood composite products is on the rise. Composite materials have evolved out of the increasing demand for construction materials which are not only of large dimension but are durable and reliable as well.

Wood-based composite products have many advantages over ordinary timber. These advantages include higher strength properties than solid wood, high yield from the wood source, use of underutilized wood species, low grade logs, small diameter logs, and waste materials. Solid wood cannot match reconstituted wood in the range of properties that can be controlled in processing. When the processing variables are properly selected, composites can outperform solid wood (Forest Products Laboratory 1999). 


\subsection{Structural Composite Lumber (SCL)}

Structural composite lumber is a group of engineered wood products formed by combining veneer sheets, strands, or other particles with an adhesive to form structural products. Strength and stiffness properties of SCL can outperform those of the highest grades of lumber as it is uniform and defect free. When compared to other structural products such as steel, concrete, and other composites on a performance vs. cost basis SCL does very well (Edgar 2002). Because SCL is composed of reconstituted wood it is available in dimensions larger than solid lumber, with size only being limited by manufacturing constraints. The primary uses of these products are as beams and columns therefore the general orientation of the wood fiber is along the long axis of the member. The most common SCL products are laminated veneer lumber (LVL), parallel strand lumber (PSL), and laminated strand lumber (LSL).

\subsection{Structural Wood Panels}

Structural wood panels are the most widely used engineered wood products (Temperate Forest Foundation 2001). Plywood and oriented strand board (OSB) are the two types of wood structural panels most commonly used in construction. These panels are manufactured by orienting and laminating different layers of veneer sheets, strands, or flakes to improve strength, stiffness, and stability. The uses of these panels range from siding, sheathing, and flooring to web material for wood I-joists. 


\subsection{Processing Parameters}

The process of manufacturing structural wood composite panels involves four basic steps. The raw material is gathered and then dried to a predetermined moisture content. Adhesive is applied to the surface of the wood elements being used. A mat is loosely formed and placed in a large press under heat and pressure until the adhesive cures. The product is cooled and finally cut to desired size.

The properties of these products are governed by wood species, the size of particles or strands, the adhesive used, and the production process. Besides the aforementioned factors, Xu and Suchsland (1998) found that compaction ratio and density significantly influence bending strength. By controlling the constituent materials and processing parameters manufactured composite products can exhibit much more consistent properties than solid lumber.

\subsubsection{Strand Size and Orientation}

Two of the primary features that influence wood strand composite properties are strand geometry and orientation. The strands used will vary in shape, size, and thickness from one product to another. Most SCL products use full size sheets, long strands, or large strands with the orientation of the wood fiber along the long axis of the member. Composite panel products, such as oriented strand board (OSB), align multiple layers of strands in both longitudinal and transverse directions balancing the properties in both directions. 
Barnes (2000) stated that increasing the strand length increases the strength properties of composite wood products. A larger strand will better maintain wood's natural axial strength properties. Edgar (2002) found that, regardless of strand geometry, larger strands are significantly stiffer than smaller strands. Slenderness ratio, or the ratio of strand length to thickness, is an important issue related to strand size. Increasing slenderness ratios results in improved properties in the composite (Barnes 2002). Nishimura et al. (2004) found that long, slender strands produce panels that are significantly stiffer and stronger in bending. Although as strand size increases the harder it becomes to efficiently consolidate the composite. With a larger strand size it is more difficult to achieve a constant density throughout the mat and areas of low density and voids are formed.

Strand orientation has a strong effect on the bending properties of a composite. The strength and stiffness properties of veneer strand products decrease with increasing angles to the applied stress (Barnes 2000). One drawback of aligning all strands along one axis is that if it is not carefully controlled density can be uneven along the width of the product.

\subsubsection{Mat Density}

Initial mat density must be determined so that adequate final panel density will be reached. If the density is too low, voids and low strength and stiffness will result. On the other hand density can be too high as well. Higher density can result in crushing of the fibers which leads to loss in strength and stiffness. Also, internal steam pressure can 
build during hot pressing which can lead to undesired "blows" in the panel if there is no way for gas to escape the mat. A blow is a term that describes uncontrolled gas pressure build up inside of a panel leading to large bubbles or tears in the final product that significantly reduces quality.

Mat density has a strong relationship with mechanical performance. Cai et al. (2006) found that increasing panel density has a substantial influence on both MOE and MOR. Increasing panel density also shows a positive correlation with increasing internal bond strength. But, increasing density leads to high cost and can result in other undesirable properties, such as loss of dimensional stability and lowered mechanical properties after the fibers have been damaged.

\subsubsection{Influence of Moisture Content}

Along with panel density moisture content has significant effects on internal steam pressure as well as internal bonding. Mat moisture content shows a positive relationship with internal steam pressure and maximum core temperature (Cai et al. 2006). High moisture content will result in a build-up of steam pressure inside the mat during hot-pressing causing blows and damage in the final product. To avoid blows, control of the initial moisture content of the wood constituents is necessary. Another factor to consider is press time. The moisture content of the panel after pressing increased with decreasing press times (Heebink et al. 1972). Therefore, the higher the initial moisture content of the mat, the longer the required pressing time. 


\subsubsection{Resin Content}

The amount of resin applied to the constituent materials and the resin spread have a significant effect on the quality of the bonds formed. Resin should be uniformly spread over the surface of the strands or flakes which are to be in contact with one another. The amount of resin applied to these surfaces is crucial. Too little resin will result in insufficient bonding, while too much resin will actually reduce the strength of the panel.

Increasing the resin content of composite wood products increases the strength properties until it reaches a maximum. After the maximum is reached the strength will begin to decline. Barnes (2000) stated that increasing the phenol-formaldehyde (PF) content of strand wood composites rapidly increases the strength properties of the composite up to about 3 percent, reaching a maximum at about 5 percent.

\subsubsection{Consolidation}

Hot-pressing is the most critical step in the manufacturing process. Wood composites gain most of their final characteristics through the pressing process. Hotpressing consolidates the mat by applying heat and mechanical pressure. The thermal energy or heat is necessary for curing of the resin. Pressure is applied to ensure maximum element to element contact, thus reducing voids and improving consolidation.

Most pressing operations rely on a conduction process where heat is transferred through the platens to the mat surface. The rate of temperature increase and maximum 
temperature significantly affects the curing process. As mat density increases permeability decreases and gas pressure builds allowing internal temperature to rise at a quicker rate. This will eventually push steam outwards towards the edge of the panel where it will be allowed to escape safely. When enough moisture is evaporated from the surface layers heat transfer slows. Eventually, this leads to a temperature plateau where the internal temperature will remain fairly constant.

Press cycles are often based off a minimum core temperature of $212^{\circ} \mathrm{F}\left(100^{\circ} \mathrm{C}\right)$ and the time necessary for the resin to cure above this temperature (Forest Products Laboratory 2004). In the structural wood panel industry, the trial-and-error method is used to determine optimal press cycle for a given product. Press cycles which are too long are inefficient and drive manufacturing costs higher. If the press cycle is too short and the cure time is not met, the panel may delaminate and optimal strength and stiffness of the panel will certainly not be achieved.

After the desired internal temperature has been reached and the adhesive has cured the venting process begins. The venting process allows the mat to expand slowly which leads to further release of gas pressure and reduces the potential for blows and panel delamination. Once the mat has been properly vented the final product can be removed from the hot press and allowed to cool and cut to the final dimensions. 


\section{$2.5 \quad$ I-Joists}

The large, high quality timber needed for roof and floor framing in residential and commercial light frame construction are becoming rarer and more expensive. The lack of suitable building materials lead to the rise of the engineered wood I-Joist industry. Ijoists are designed to be straighter, stiffer, stronger, and exhibit more consistent mechanical properties than solid wood. I-joists require $50 \%$ less wood to manufacture than a solid beam with the same strength (Temperate Forest Foundation 2001).

Wood I-joists are load carrying members with an I-shaped cross section. The design of the beams allows the manufacturer to take best advantage of material properties. In general flanges will provide most of the moment capacity while shear forces are resisted through the web.

Flanges are glued to a web which is typically an engineered wood product, such as plywood or oriented strand board (OSB). The flanges are usually made of LVL, though some manufacturers will use PSL or solid sawn lumber. Two of the most important features of the joists are the flange-to-web and web-to-web joints. Phenolresorcinol cold setting resin is typically used to bond both of these connections. Producers will often protect the flange-to-web joints with patents. Tongue and groove joints are to be the most common, providing sufficient contact area between the flanges and the web. To join the adjacent panels in the web butt joints, scarf joints, or tongue and groove joints are typically used.

Wood I-joists have many advantages over solid sawn dimensional lumber. I-joists can be produced in many different spans and depths making them useful for a variety of 
applications. By varying the species, grade, thickness of the web, and depth of the beam very high strength and stiffness can be attained. When compared with solid lumber, structural I-joists have higher strength-to-weight ratios, dimensional stability, and lower variability. Holes can be predrilled through the web to allow for the passage of electrical wires, ductwork, and plumbing. 


\section{MATERIALS}

\subsection{Decorative Hardwood Veneer}

Veneers are thin plates or sheets of high quality wood which are glued to an inferior material. Using veneers allows a small amount of material to be used efficiently in furniture, cabinet, and millwork manufacturing in cases where using solid lumber would be very difficult and/or very expensive. Quality decorative (face) veneers are produced mainly from hardwood logs. These logs are the highest in quality used for industrial purposes.

Hardwood veneer logs are considered to be at the top of the log-quality spectrum. These logs are becoming increasingly more rare, representing less than $1 \%$ of the hardwood saw log market in the northeastern United States (Wiedenbeck 2003). Because these logs are of such high quality and rarity they demand a cost which is 1.5 to 6 times higher than that of grade 1 saw logs (Wiedenbeck 2003).

Typically only the first log cut from the bottom trunk of the tree is used for veneers. A log must contain minimal defects to qualify for use as face veneer. Grade defects are physical abnormalities that reduce the overall quality of the wood. Some of the defects found in lower quality trees are knots, bumps, bulges, holes, canker, and limb stubs. Straightness of grain is also an important qualification. The face veneer industry is concerned with appearance and defects will considerably lower the 
attractiveness of the veneers. While these defects lower the overall attractiveness of the veneer they also correlate with the mechanical properties, the fewer defects in the veneer the higher the strength. However, in some cases defects such as curly grain, birdseye, wide pith rays, and crushed fibers are allowed when they increase the attractiveness of the face veneer.

Decorative veneers are marketed for four major uses: architectural, secondary manufacturing, profile-wrapped mouldings, and paneling. The architectural market requires the highest quality logs and usually long lengths are required. These veneers are used as wall and door paneling in public and office buildings. Secondary manufacturing primarily serves the furniture, flooring, and cabinet making market requiring high quality yet shorter length veneers. Profile-wrapped moulding is used as a substitute to solid wood moulding where the veneers are wrapped around reconstituted products such as fiberboard. The last market is the paneling market where the face veneer is used in eight-foot mismatched wall paneling where some defects are generally allowed.

\subsection{Veneer-Mill Residues}

Residues in the form of bark, cores, and clippings are an inevitable result in the manufacturing of veneers. In both rotary cutting and slicing of hardwoods, less than half of the volume of the log may be recovered as veneer (Forest Products Laboratory 1962). Coarse residues, such as cores, are mainly used to make pulp and other fiber products. Bark and also fine residues, such as clippings, are used for industrial fuel. 
Side and end clippings used in this research were produced exclusively from flat slicing operations. The finest decorative face veneers are produced from flat slicing (Merker and Hopper 2004). To produce flat sliced veneers logs are cut into halves, quarters, or sometimes other proportions called "flitches". The side of the flitch that has the most aesthetically pleasing face is the side that is then used for slicing sheets. To make the wood easier to slice, the flitches are first softened in a hot water bath. When removed from the water bath the flitch is cleaned and then fixed onto a metal frame. The frame moves rapidly up and down against a stationary knife producing thin veneer sheets.

After the logs are sliced into thin sheets, these are dried and then stacked into bundles of 15 or 20 . The bundles are then cut into rectangular dimensions. This process produces rectangular end-clippings and side-clippings with an average length of 3 to 13 feet and width of 1 to 2 inches. Veneer clippings are shown in Figure 3.1.

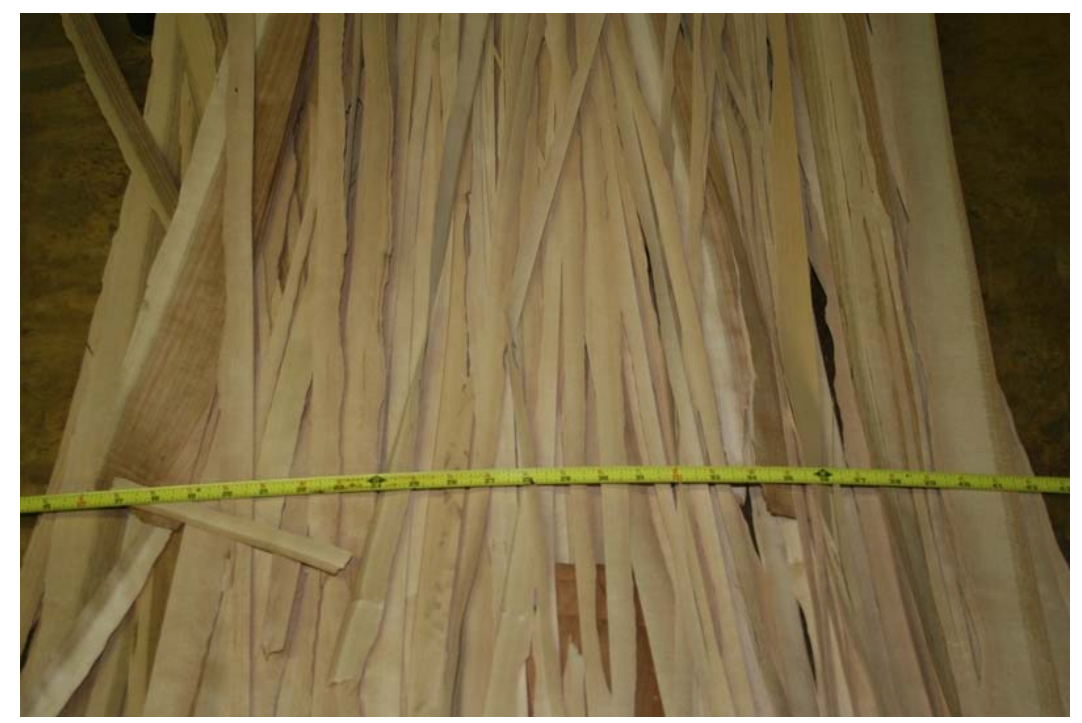

Figure 3.1 Veneer side-clippings. 


\subsection{Black Cherry (Prunus Serotina)}

Black cherry veneer-mill residues were used in the manufacturing of all specimens for small scale mechanical testing. Cherry is one of the most important species in sliced veneer manufacture. Wiedenbeck et al. (2003) stated that in 2000 Cherry accounted for 29 percent of all sliced veneer production, the highest percentage of all species sliced.

Cherry has a medium density allowing easier consolidation into composite panels. It has a high dimensional stability, exhibits good bending properties, and has uniform pore distribution. The wood also has a fairly uniform texture and very good machining properties (Forest Products Laboratory 1999).

\subsection{Liquid Phenol-Formaldehyde}

A liquid phenol-formaldehyde (Ipf) resin was used to bond the strands. The adhesive was formulated with a $50 \%$ solids content and a shelf life of 2 weeks. Due to the short shelf life of the resin it was shipped in 5 gallon containers and stored in a refrigerator when not in use. By storing it in refrigerator the shelf life was increased by about 2 weeks. Before use the desired amount would be removed and allowed to warm to room temperature to decrease viscosity for better resin spread and decrease necessary pressing time. To cure, it is necessary for the resin to reach $212^{\circ} \mathrm{F}$. 


\section{METHODS}

\subsection{Panel Manufacture}

Two types of panels were manufactured for use in this research, flat panels for basic mechanical testing and corrugated panels for manufacture of I-joists. The same species and compaction ratio (ratio of target mat density to raw material density) was used in the manufacture of both geometries of panels. Therefore, the target density of $40 \mathrm{lb} / \mathrm{ft}^{3}$ was equal for both flat and corrugated panels.

\subsubsection{Material Preparation}

Veneer clippings were provided by International Timber and Veneer in Jackson Center, Pennsylvania. The majority of clippings provided were side clippings with an average thickness of $0.015 \mathrm{in}$. Two species of significant quantity were donated, Black cherry and white oak. Black cherry was primarily used for all small scale mechanical testing. White oak was used in the optimization of the press schedule.

The length of raw veneer clippings were anywhere from a few feet to $12 \mathrm{ft}$ in length, with the majority being $12 \mathrm{ft}$ long. The clippings were then cut into short lengths 
due to press size and template restraints. For flat panels the clippings were cut to approximately 30-32" and 34" for corrugated panels.

These clippings were then placed into a chamber in which the humidity was controlled to keep the furnish moisture content around $4-5 \%$ for at least 3 or 4 days before use (Figure 4.1). It was necessary to keep the veneer clippings dry because excess moisture in the raw materials will lead to excess steam build-up during hot pressing which can cause blows in the panel.

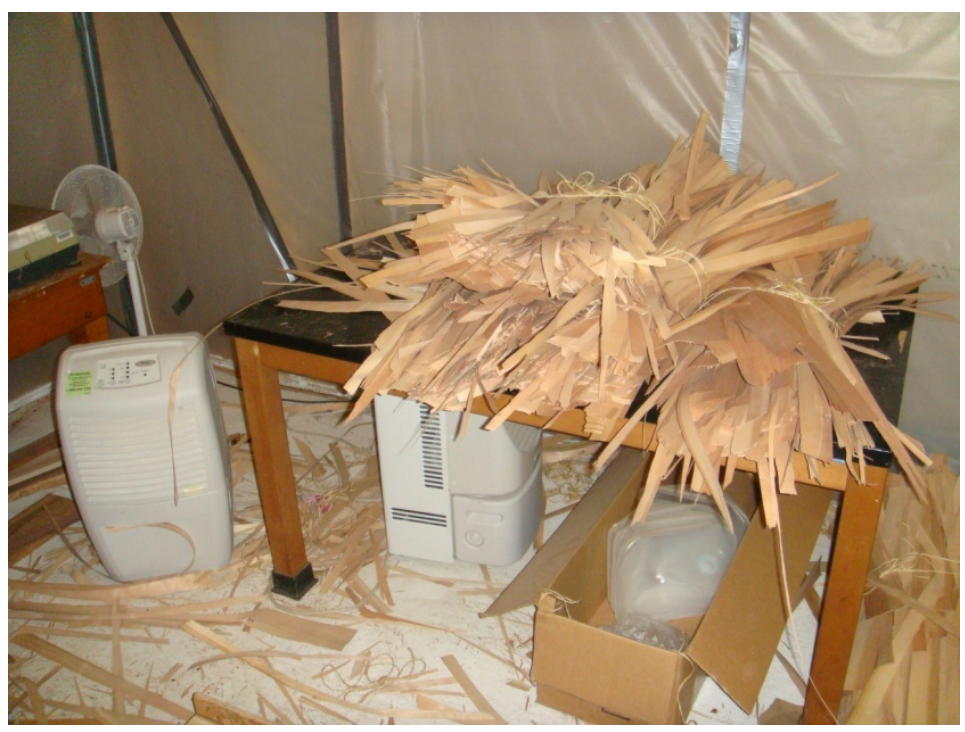

Figure 4.1 Conditioning chamber.

\subsubsection{Applying the Adhesive}

A Black Brothers adhesive spreader and roller coater machine, see Figure 4.2, was used to apply liquid phenol-formaldehyde (LPF) resin to each individual strand going into the mat for panel manufacture. Two 26 " rubber rollers applied resin set at 
approximately 0.015 " apart simultaneously applied resin to both the top and bottom surfaces of the veneer strands.

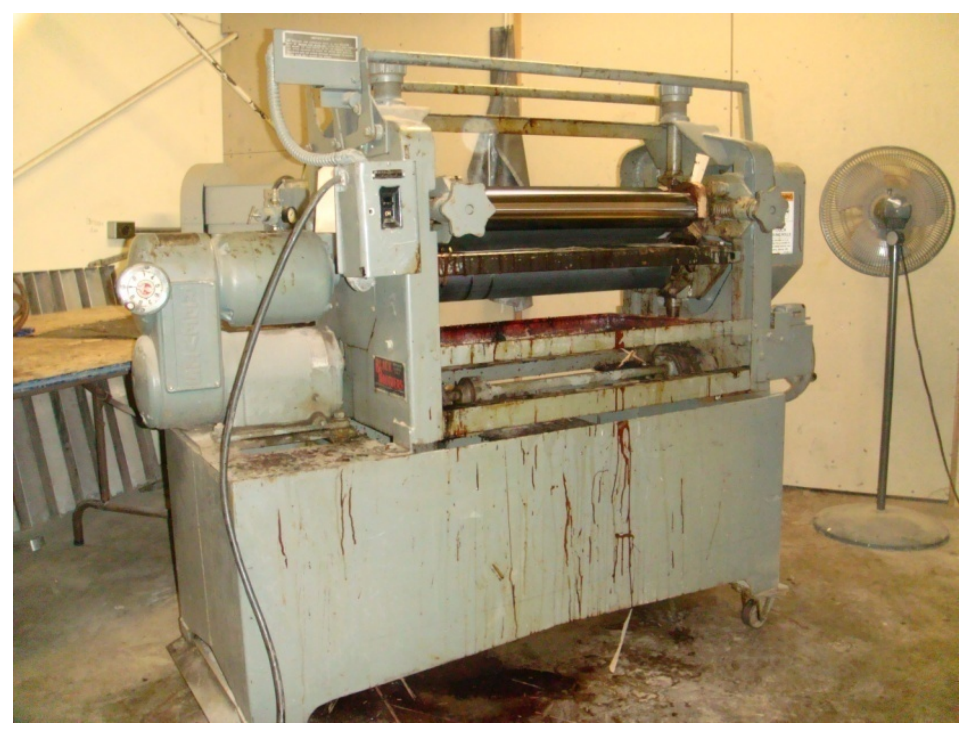

Figure 4.2 Roller coater used to apply the resin.

As previously stated (Barnes 2000) found that for wood-based strand composites strength properties reach a maximum around a resin content of $5 \%$. Hence, a target resin content of $5 \%$ was decided for these panels made of strand-type veneer residues. The LPF used contained a solids content of $50 \%$, the other $50 \%$ being water. Minimizing the resin content also reduced the chance of excess steam pressure building in the mat and blows in the final panel. To achieve this, the horizontal distance between the rollers, where the resin is held, was set to approximately 0.04 " for both the top and bottom sets of rollers. The speed of the rollers was set to roughly 51 revolutions per minute. 


\subsubsection{Hot Pressing}

All panels were manufactured using a 200-ton hot press with 30 " x 30 " heated platens (Figure 4.3 a). For the resin to properly cure, the internal temperature of the panels had to reach $212^{\circ}$ for 60 seconds. In preparing for panel production both top and bottom platens were heated to roughly $350^{\circ}$ Fahrenheit. This temperature in combination with the press schedules for both flat and corrugated panels allowed the resin to adequately cure without burning the outside layers of the panels.

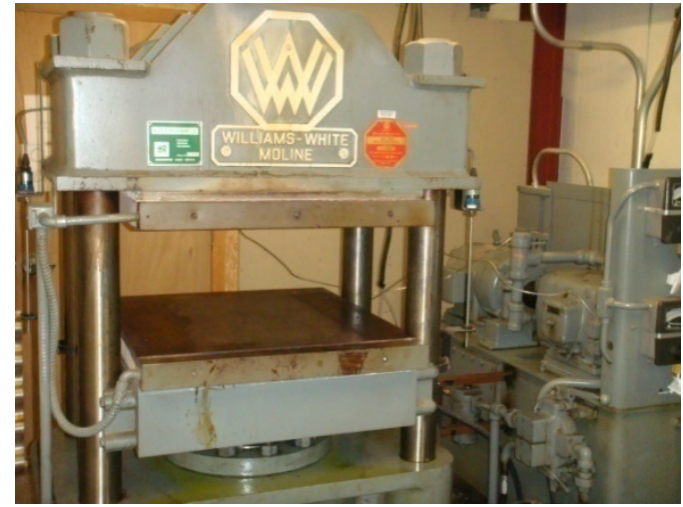

(a)

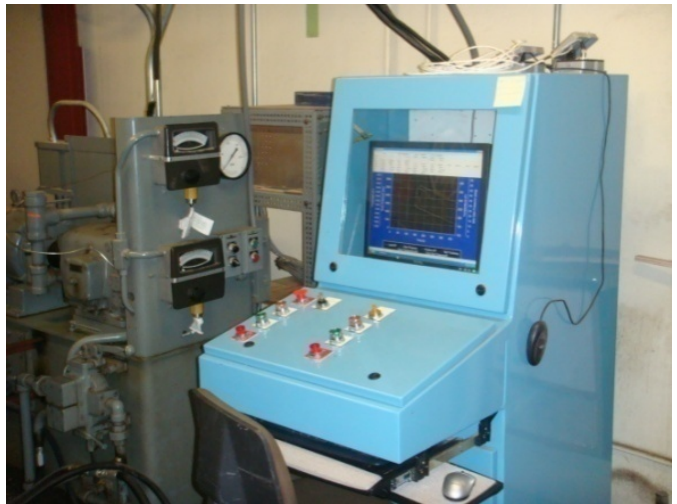

(b)

Figure $4.3 \quad$ (a) Hot press and (b) press control console.

PressMAN v0.78 software was used to design and control the pressing process. The console used to control the press cycle is shown in Figure $4.3 \mathrm{~b}$. For both flat and corrugated panel types the press cycle was controlled by position. In some cases a probe was inserted into the middle of the panel to monitor internal pressure and temperature. 
When the pressing was finished and the platens were opened the panel could be removed. Steel bars were laid on top of the panel while cooling to help reduce warping due to internal thermal stresses. After the panels cooled, loose excess veneer was trimmed off around all four edges.

\subsubsection{Flat Panel Manufacture}

Flat panels were produced for use in small scale mechanical tests. These panels were manufactured in roughly 30 " squares with 0.375 " thickness. Each panel was made from approximately 3500 grams $(7.7 \mathrm{lbs})$ of veneer residues, based on a compaction ratio of 1.2 with a target density of $40 \mathrm{lbs} / \mathrm{ft}^{3}$. Trimmed flat panels are shown in Figure 4.4 .

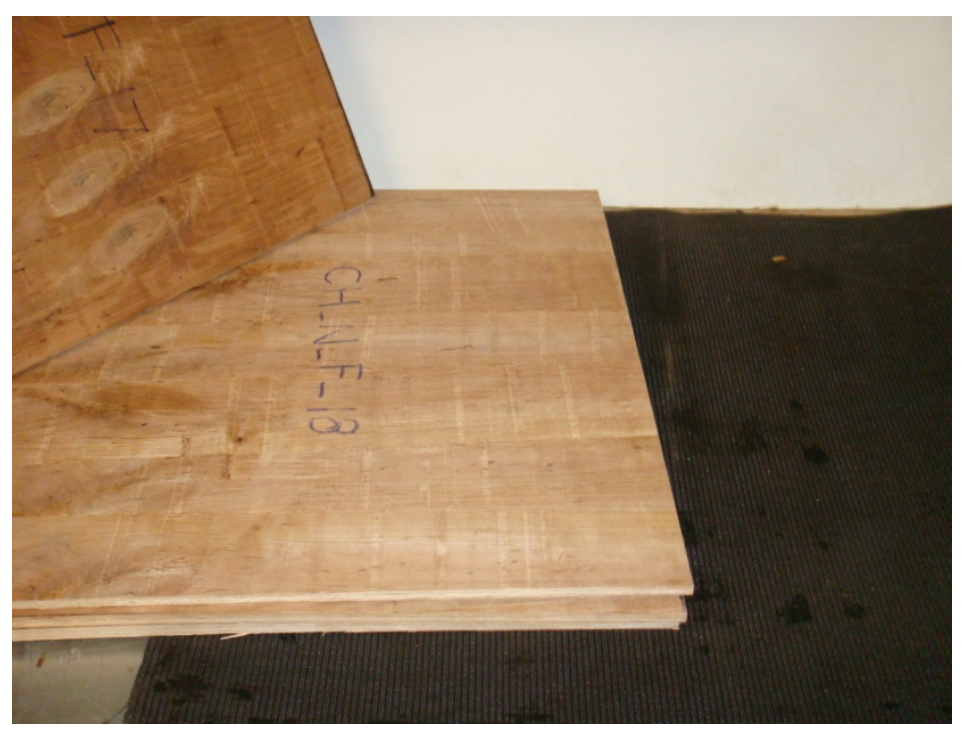

Figure 4.4 Flat panels and caul screen. 
Each strand was run through the roller coater to cover both sides with adhesive. The mat was then laid out on a caul screen made of a thin metal mesh (shown in Figure 4.4). The screens allowed for easy transfer in and out of the press and prevent edthe outside layers of the mat from coming into direct contact with the hot press platens. Before the mat was laid out on the screen, the screen was sprayed with silicon spray to ease in the release of the panel after pressing. Strands were laid out in parallel with one another taking caution to evenly distribute them throughout the width of the panel and to cover the gaps between strands as to not leave openings through the thickness. After all veneer strands were laid out the top mesh was applied and then the mat was moved to the press. The press schedule and a corresponding graph from the PressMAN software are shown in Figure 4.5 a and $\mathbf{b}$. 

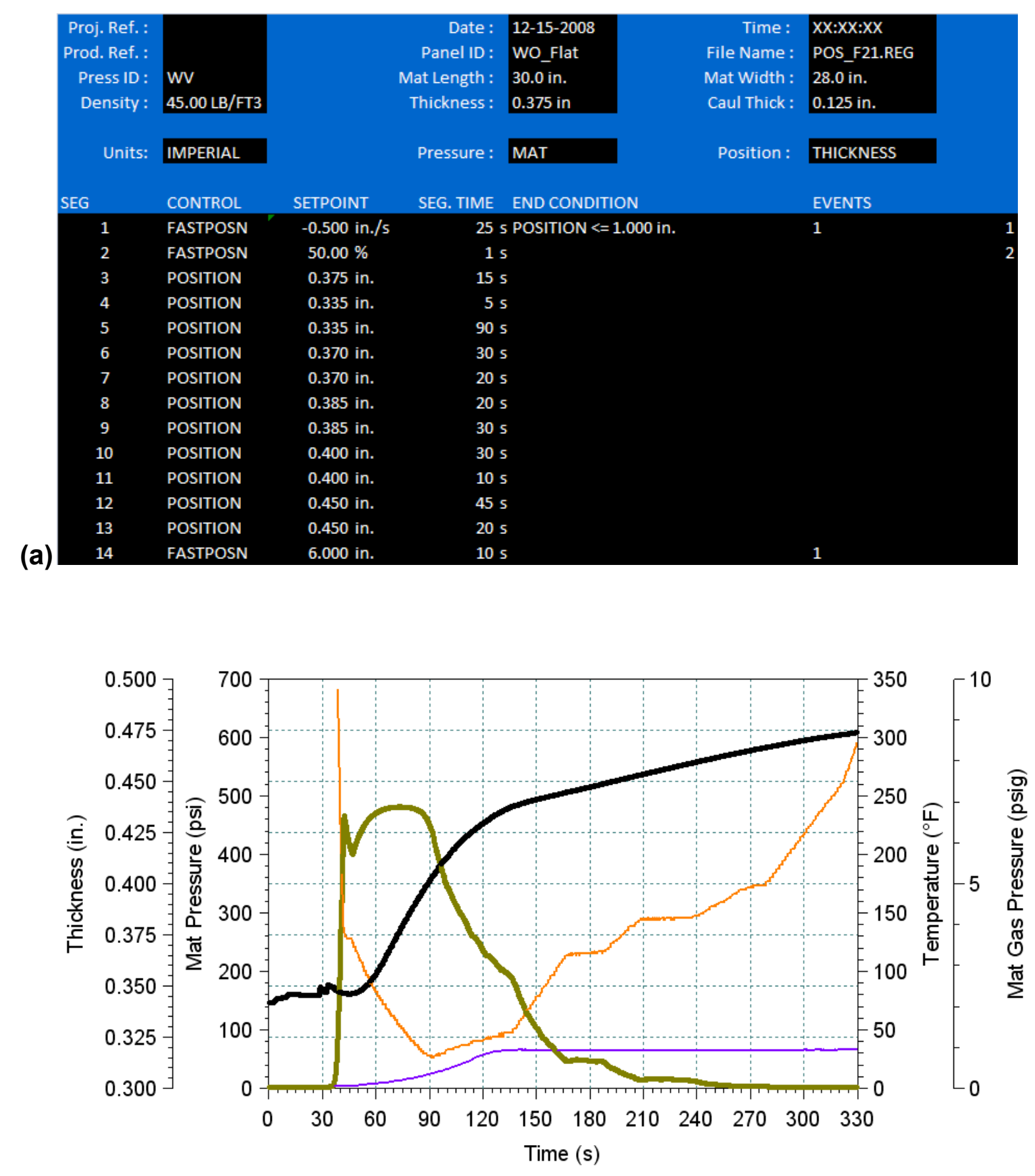

(b)

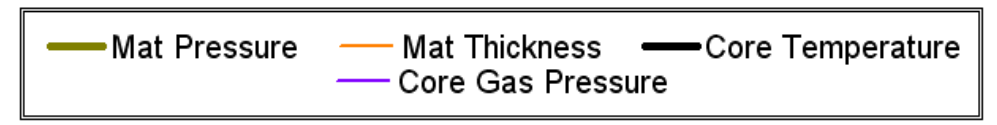

Figure 4.5 (a) Press schedule for flat panels and (b) PressMAN graph. 


\subsubsection{Corrugated Panel Manufacture}

Corrugated panels were manufactured to be used as web material in I-joists. Aluminum templates in the shape of a sine wave were used to form the panels. The geometry of the sine wave templates is shown in Figure 4.6. As seen in Figure 4.7, there is a difference in the distance between the apexes and the distance at the midpoint between the apexes (points in $A$ and $B$ ). When thinner panels are manufactured the difference between these two points is negligible, but as the distance between the apexes increases the difference becomes more significant ( 0.1 " difference between the two points $A$ and $B$ for a panel 0.5 " thick at the apex). Therefore, these sine wave templates can only be used to manufacture thin to medium thickness panels, up to approximately 0.5 " thick at the apex.

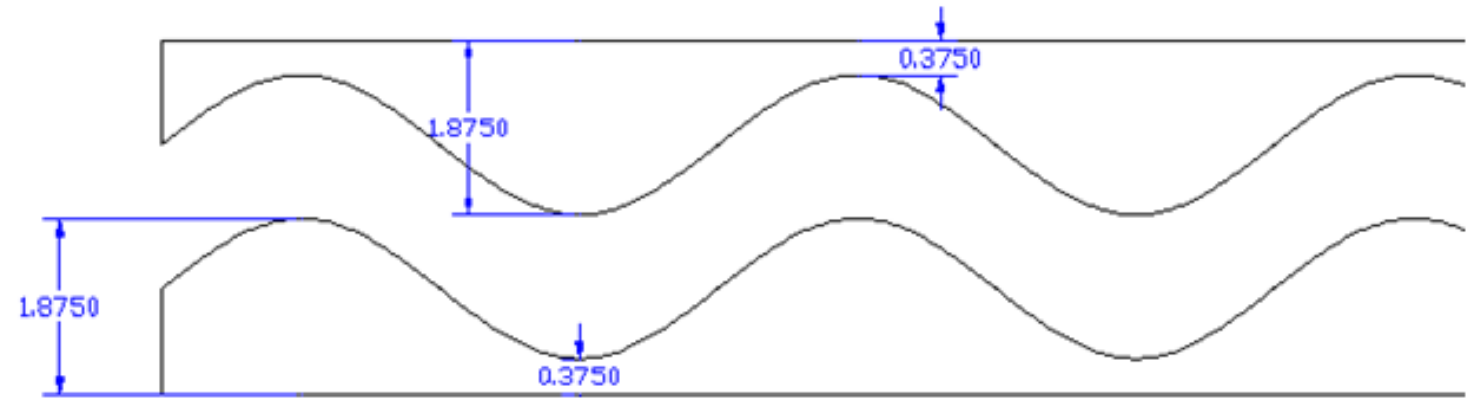

Figure 4.6 Geometry of the sine wave templates. 


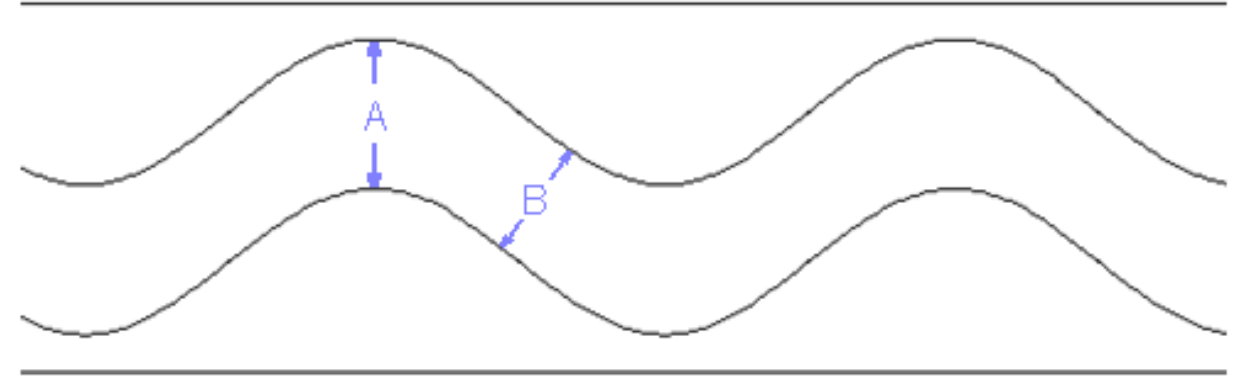

\begin{tabular}{cc}
\hline \hline$A$ (in) & B (in) \\
\hline 0.25 & 0.1968 \\
0.3125 & 0.2462 \\
0.375 & 0.2957 \\
0.4375 & 0.3425 \\
0.5 & 0.3951 \\
\hline \hline
\end{tabular}

Figure 4.7 Thickness variations in sine wave templates.

Corrugated panels were manufactured with 2500 grams (5.5 lbs) of clippings. The compaction ratio of 1.2 and target density of the panels, $40 \mathrm{lb} / \mathrm{ft}^{3}$, were the same as for flat panels. The panels were fabricated at 30 " long by 18 " wide, the dimensions of the templates, with approximately 0.375 " thickness. The finished panels and template are shown in Figure 4.8.

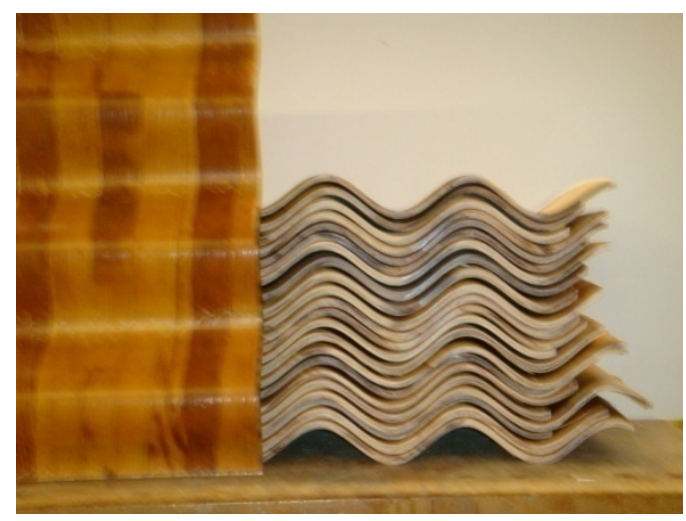

(a)

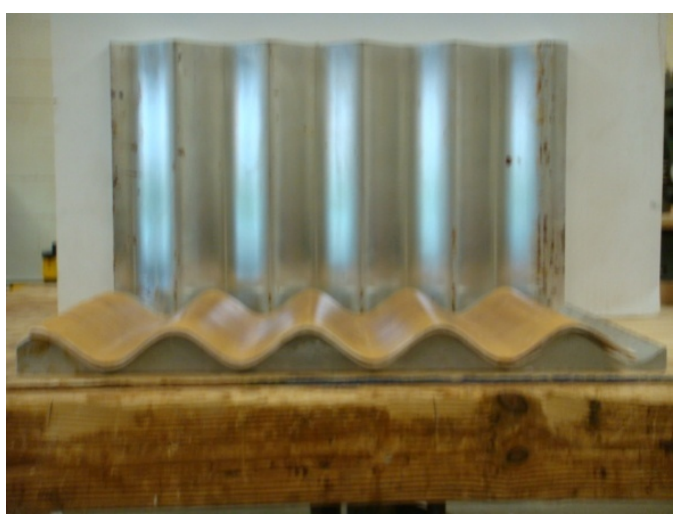

(b)

Figure 4.8 (a) Corrugated panels and (b) aluminum template. 
The veneer clippings were laid out in a mat on impregnated paper. The paper was used to avoid sticking of the panel to the templates and allowed for easier removal. The sine wave templates were set on the press and preheated (with the top template bolted to the top platen of the press). The same basic schedule, with minor variations, was used to consolidate the corrugated panels as the flat, adjusting for the thickness of the templates. The press schedule and and corresponding PressMAN graph are seen in Figure 4.9. 

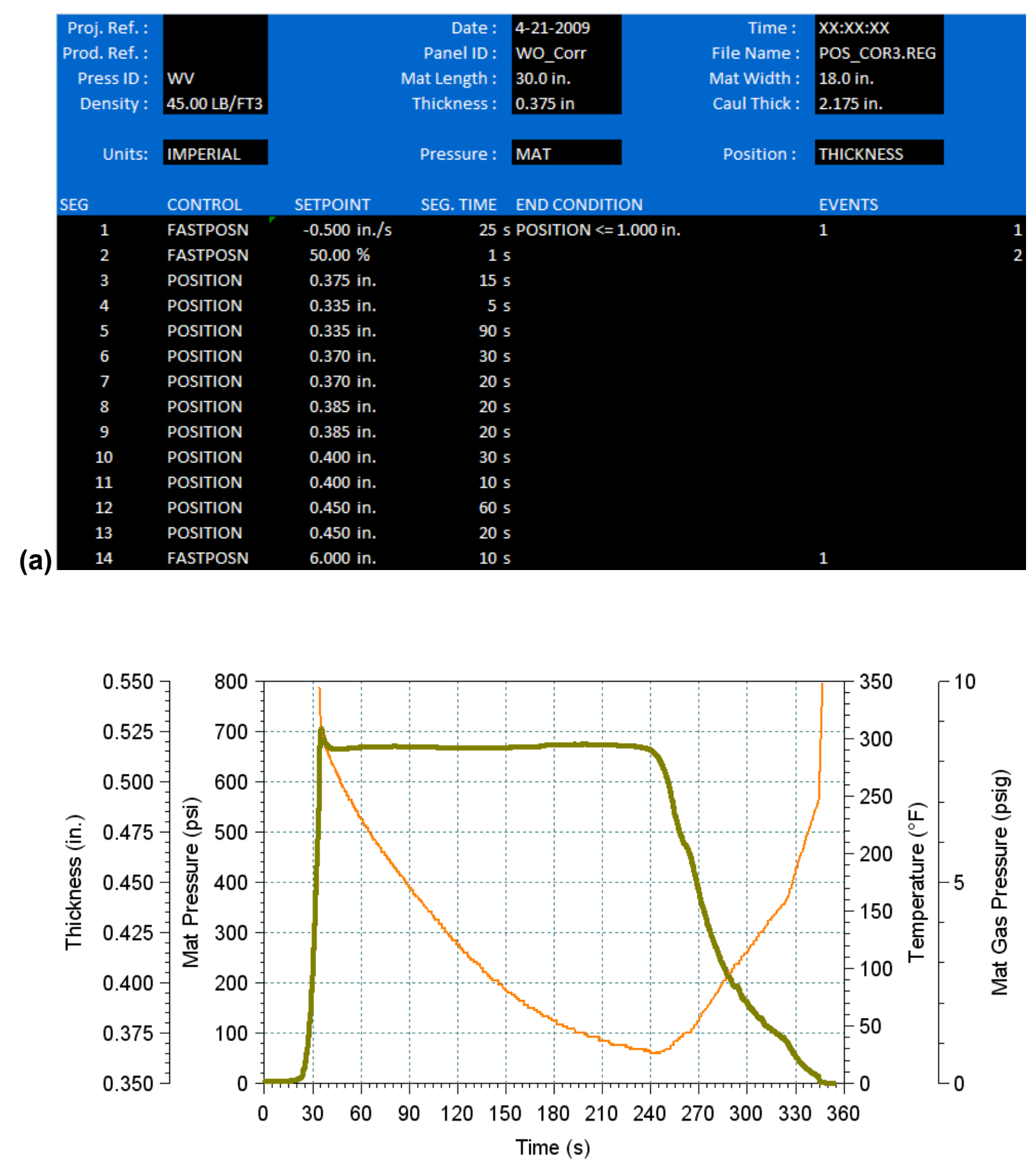

(b)

Figure 4.9 (a) Press schedule for corrugated panels and (b) PressMAN graph. 


\subsubsection{Optimization of Press Schedule}

Veneer-mill residues of white oak (Quercus alba) were first used to manufacture trial panels in an attempt to find an acceptable schedule. After determining a suitable schedule using these white oak residues, it was decided that the research would focus on using black cherry (Prunus Serotina) residues for further panel and joist manufacture and for all coupon testing.

Initially it was decided that position control of the hot press platens will govern the manufacturing of panels. Experts in the wood composites manufacturing industry were consulted to help establish a trial pressing schedule to use as a starting point. After discussing the raw materials, adhesive, and equipment that would be used in this research a schedule similar to that used for manufacture of OSB was considered to be best.

All press schedules were designed to reach a target panel thickness of $0.375 "$ within the lowest reasonable total press time. The internal temperature and pressure was monitored at the center of the mat using a thermocouple. White Oak panels were first made using 3800 grams of strands for a 30 " x 30 " panel. The press was closed to 0.350" and held at this position for 100 seconds to allow the resin to cure. Two opening phases, each opening the press 0.015 " for 10 seconds and holding for another 5 seconds, were used to relieve internal pressure before completely releasing the panel. The schedule had a total pressing time of approximately 3 minutes. But the panels produced were thicker than desired and contained many blows. 
Many more trial panels were produced using variations of this schedule. The initial close position was lowered and additional and slower venting phases were added to the schedule increasing total press time. These schedules produced panels which were closer to the target thickness but blowing was still a major issue. Therefore, a cross layer of approximately $1 / 3$ of the total furnish weight was added to the middle of the mat to try to reduce the internal pressure during consolidation. Also, after observing the compaction ratio was too high, the weight of residues used in the panels was lowered to 3000 grams.

Varying initial close height, hold times, and venting phases 17 different trial panels with cross-layers were created. Panels were now reaching the desired thickness without blowing, but warping was an issue. Panels made with cross layers tended to bow upon cooling. So, cross layers were abandoned and the final schedule was tried using strand orientation in one direction. The schedule was finely tuned adding a few more seconds to the venting phases and acceptable flat unidirectional panels were achieved.

Cherry residues were then acquired and using the same schedule panels were manufactured. Since black cherry is less dense than white oak the panels produced were lower than the desired thickness. After 3 more iterations of the schedule, in which initial close height was raised and venting phases adjusted accordingly, a final schedule was reached in which average thickness was close to the desired value and blows were kept to a minimum. 


\subsubsection{I-Joist Manufacture}

The flange-to-web connection is one of the most crucial steps in manufacturing Ijoists. Due to the corrugated shape of the web new flange-to-web connections needed to be designed and tested. Because of size limitations of the press, the web panels also had to be joined in length to produce full-scale joists.

The web was connected by finger jointing. The panels were first cut at the apex of the wave compensating for the length of the joint. Using a router, fingers were cut into the end of the panel and then the router was offset to cut the fingers into the adjoining panel so that the panels would match.

To connect the flanges to the web two different methods were used, finger jointing and tongue and groove jointing. In the case of finger jointing, fingers were cut through the length of the flanges and the top and bottom of each panel going into the web. For the tongue and groove joints, a template was made and using a router with a 3/8" bit, approximately the thickness of the panels, a groove was cut into flanges in the shape of a sine wave.

A cold setting resin was used to adhere the web-to-web and flange-to-web connections. The resin used was Prefere 4001 and the hardener was Prefere 58305. The resin and hardener were mixed with a weigth ratio of 100 to 35 . The mixture was then applied and the entire joist was clamped and left to dry. I-joist samples are shown in Figure 4.10. 


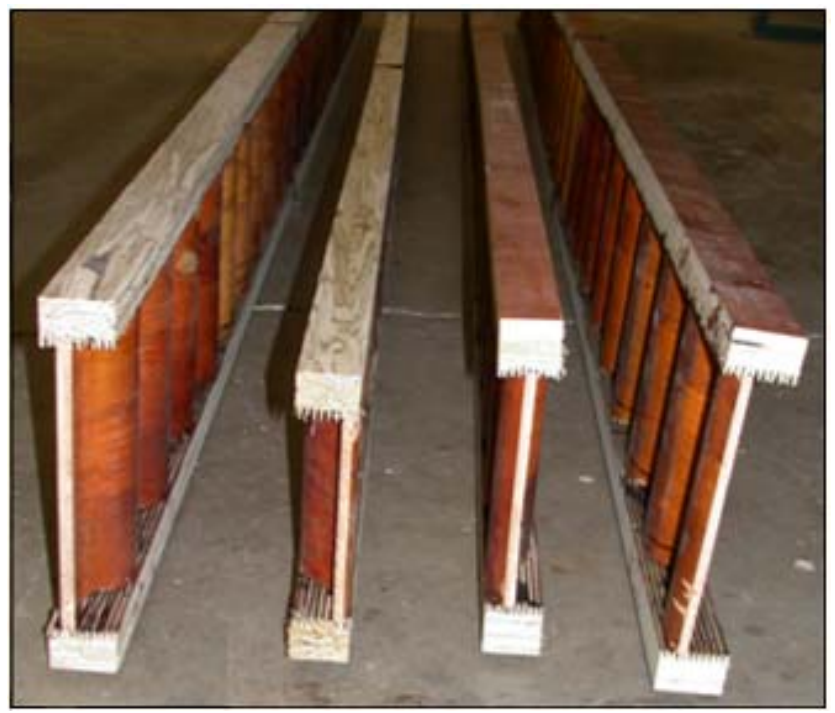

Figure 4.10 Structural size I-joist specimens.

\subsection{Mechanical Testing of Small Scale Specimens}

Testing was performed to determine panel qualities and also material properties both the parallel to strand alignment ( ||$)$ and perpendicular to strand alignment ( $\downarrow$ ) (Figure 4.11). Small scale mechanical testing for internal bond, bending, edgewise bending, shear, compression, and thickness swell were performed following the standards given in ASTM D 1037 - 99. Tension testing was performed in accordance with ASTM D 3500 - 99 due to equipment restraints. 


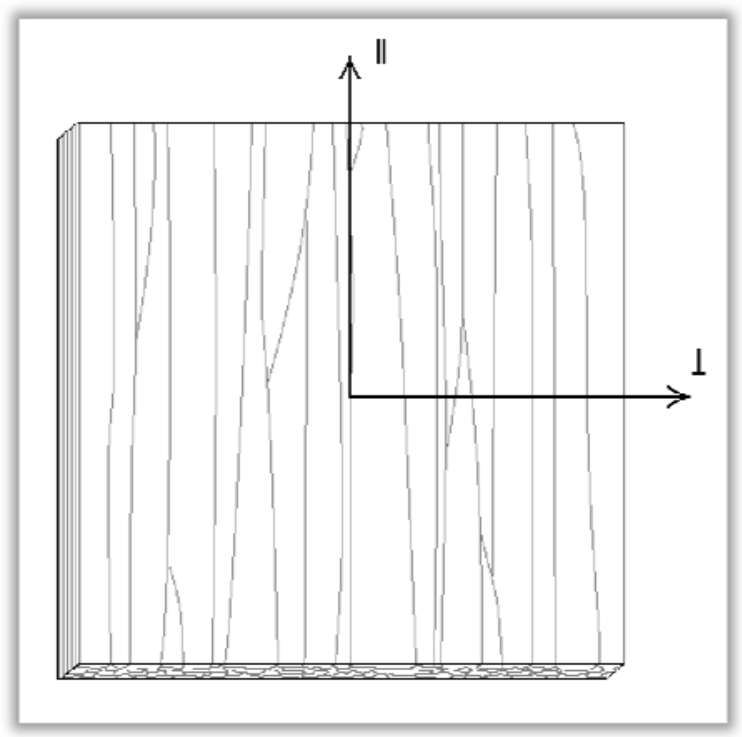

Figure 4.11 Parallel to strand alignment ( ||$)$ and perpendicular to strand alignment ( $(1)$ directions.

The coupon tests including internal bond, tension, compression, flatwise bending, edgewise bending, and shear were performed on a Servo-Hydraulic MTS universal testing machine. This machine had a $20,000 \mathrm{lb}$ capacity and a $20,000 \mathrm{lb}$ or $500 \mathrm{lb}$ load cell was used depending on the test being performed. The $500 \mathrm{lb}$ load cell was necessary for certain tests in the perpendicular to strand alignment where accurate loading values were needed for low maximum loads. Clip on extensometers were used to measure strain and displacement when necessary. Two different extensometers were used, an MTS model 630.12-50 and an MTS model 632.03R-30. Both extensometers had a 1" gauge length and were accurate to 0.00001 inches. Load cell and extensometer data was collected using an Instron 8800 data acquisition system in real time. 


\subsubsection{Internal Bond}

Internal bond testing was performed to evaluate the quality of bond perpendicular to the surface of the panel. The specimens were cut into 2" $\times 2$ " squares. The actual dimensions were measured to the nearest 0.001 inch using a digital caliper so that the stress could be accurately calculated. To improve adhesion to the aluminum loading blocks, the top and bottom surfaces were sanded.

With the specimens glued to the loading blocks they could now be fixed in the testing jig on the MTS machine (Figure 4.12). In accordance with ASTM D 1037 - 99, speed of testing was $0.08 \mathrm{in} / \mathrm{in}$ of thickness per minute. With the average thickness of specimen being approximately 0.375 ", the speed of the crosshead was set to a constant rate of $0.0297 \mathrm{in} / \mathrm{min}$.

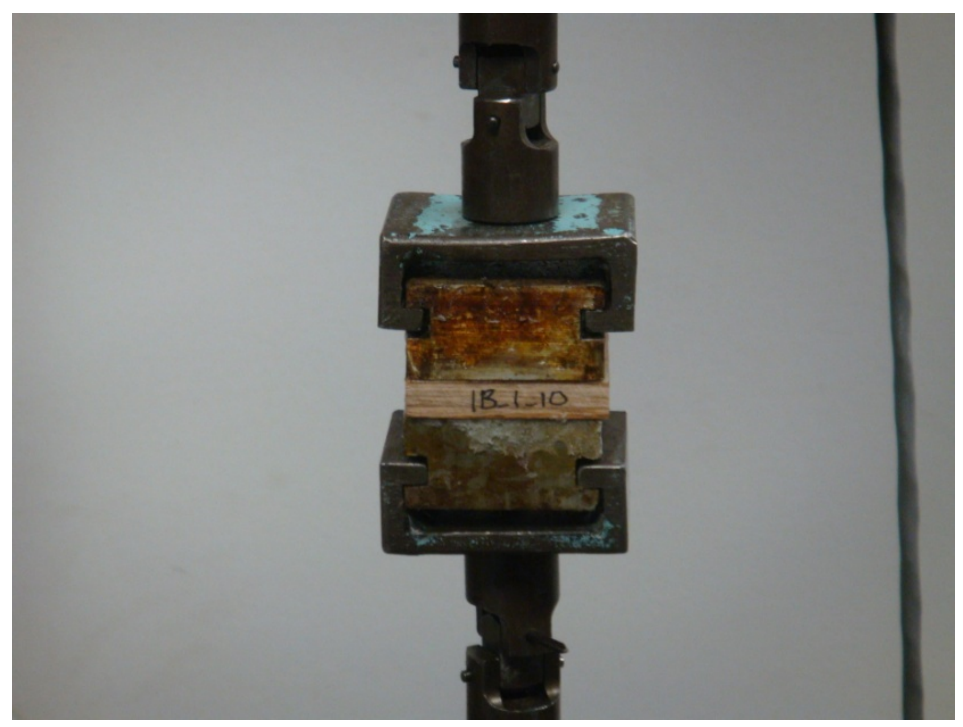

Figure 4.12 Internal bond (tensile strength perpendicular to surface) test setup. 
The samples were tested to failure and the maximum load was recorded. The $20,000 \mathrm{lb}$ load cell measured the loading data. A total of 20 specimens were tested. The maximum stress was calculated using the following formula:

$$
\sigma_{M A X}=\frac{P_{M A X}}{A}
$$

Where:

$$
\begin{aligned}
& \sigma_{\text {MAX }}=\text { Maximum stress }(\mathrm{psi}) \\
& P_{\text {MAX }}=\text { Maximum load }(\mathrm{lbs}) \\
& A=\text { Cross-sectional area perpendicular to applied load }\left(\mathrm{in}^{2}\right)
\end{aligned}
$$

\subsubsection{Static Bending}

Three-point static bending tests were performed to determine the apparent MOE and MOR along both the parallel and perpendicular to strand alignment directions and also in the flatwise and edgewise orientations. The setup for all static bending tests is shown in Figure 4.13. A total of 40 samples were tested in the flatwise orientation, with 20 tests in each the parallel and perpendicular to strand alignments directions. There were 44 total edgewise bending tests performed, with 24 tests parallel to strand alignment and 20 tests perpendicular to strand alignment.

All test samples had a width of 3". Flatwise bending tests with parallel to strand aligment had a total length of 19", while all other orientations had a length of 16 ". However, all bending cases were tested under a span of 12.75". In constructing edgewise panels, five 3 " by approximately 20 " long strips were glued face-to-face, clamped, and left to dry. Then, the excess glue was sanded off and the blocks were cut 
into 16 " long by 0.5 " thick specimens (while maintaining the 3 " width). This method was used for edgewise samples in both directions.

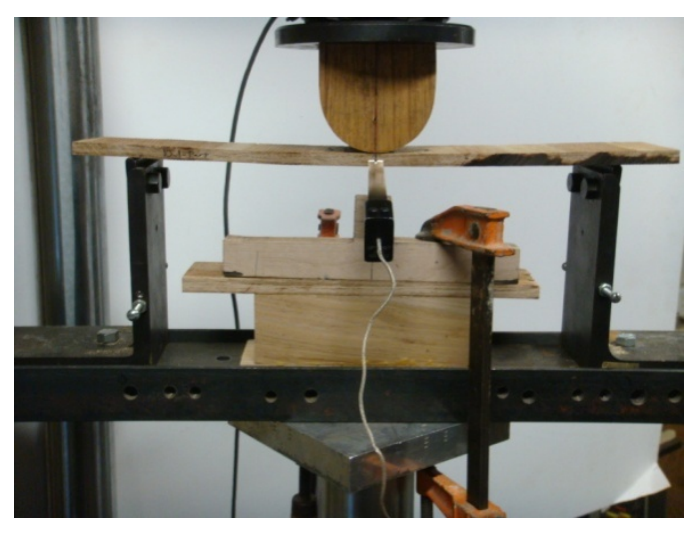

(a)

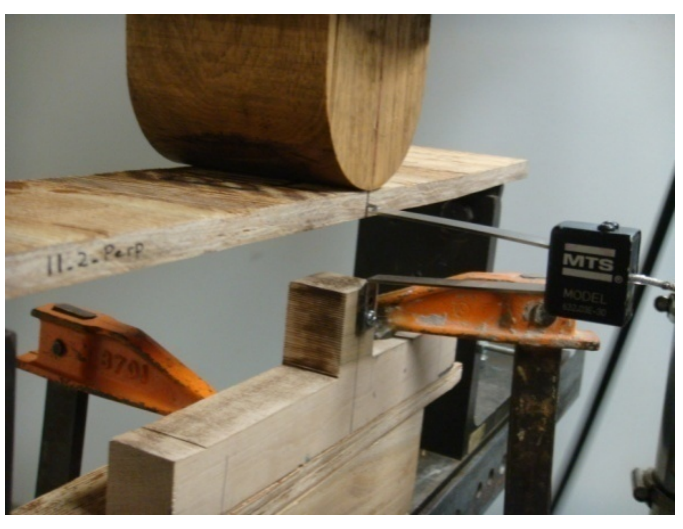

(b)

Figure 4.13 Static bending test setup (a) front view and (b) side view.

The loading was applied perpendicular to the surface of the panel directly at the midpoint. The load rate was based on the following formula given in ASTM D 1037 - 99:

$$
N=\frac{0.005 L^{2}}{6 t}
$$

Where:

$$
\begin{aligned}
& N=\text { Load rate }(\text { in } / \mathrm{min}) \\
& L=\text { Span (in) } \\
& t=\text { Thickness of specimen (in) }
\end{aligned}
$$

Flatwise panels were tested at a constant rate of $0.361 \mathrm{in} / \mathrm{min}$ and edgewise panels at $0.337 \mathrm{in} / \mathrm{min}$. For both the edgewise and flatwise panels in the parallel to strand alignment the $20,000 \mathrm{lb}$ load cell was used to measure the loading data. Due to 
much weaker strength in the perpendicular to strand alignment, the $500 \mathrm{lb}$ load cell was used. A clip on extensometer accurate to the nearest 0.00001 in. was used to measure displacement at the midpoint as shown in Figure 4.13. A digital caliper accurate to the nearest 0.001 inch was used to measure the cross sectional area of the samples.

When testing was completed and all data collected, the MOE and MOR could then be calculated. The modulus of rupture (MOR) was found using the following formulas:

$$
M_{M A X}=\frac{P_{M A X} L}{4}
$$

Where:

$$
\begin{aligned}
& M_{\text {MAX }}=\text { Maximum moment }(\mathrm{lb}-\mathrm{in}) \\
& P_{M A X}=\text { Maximum load }(\mathrm{lb}) \\
& L=\text { Span length }(\mathrm{in}) \\
& S_{x}=\frac{w t^{2}}{6}
\end{aligned}
$$

Where:

$$
\begin{aligned}
& S_{x}=\text { Section modulus }\left(\mathrm{in}^{3}\right) \\
& w=\text { Width of specimen (in) } \\
& t=\text { Thickness of specimen (in) }
\end{aligned}
$$




$$
M O R=\frac{M_{M A X}}{S_{x}}
$$

Where:

$$
\begin{aligned}
& \text { MOR }=\text { Modulus of rupture }(\mathrm{psi}) \\
& M_{M A X}=\text { Maximum moment }(\mathrm{lb}-\mathrm{in}) \\
& S_{X}=\text { Section modulus }\left(\mathrm{in}^{3}\right)
\end{aligned}
$$

To calculate the modulus of elasticity (MOE) the load vs. displacement was graphed using a simple scatter plot. The linear elastic region of the graph was found and outlying data removed. A quick regression analysis was run and the data was corrected so that the regression line passed through the origin. The apparent MOE was calculated using the following equations:

$$
I_{x}=\frac{w t^{3}}{12}
$$

Where:

$$
\begin{aligned}
& I_{x}=\text { Moment of inertia }\left(\mathrm{in}^{4}\right) \\
& w=\text { Width of specimen (in) } \\
& t=\text { Thickness of specimen (in) }
\end{aligned}
$$




$$
M O E_{A P P}=\frac{P L^{3}}{48 I_{x} \Delta}
$$

Where:

$$
\begin{aligned}
& M O E_{A P P}=\text { Apparent modulus of elasticity (psi) } \\
& P=\text { Load in the linear elastic region (lb) } \\
& L=\text { Span length (in) } \\
& I_{x}=\text { Moment of inertia }\left(\mathrm{in}^{4}\right) \\
& \Delta=\text { Deflection (in) }
\end{aligned}
$$

The MOE was calculated at each data pair in the linear elastic region for the corrected data set using Equation 7 and the average of the individual calculations was taken to be the apparent MOE.

\subsubsection{Compression}

Compression testing was performed in accordance with ASTM D 1037-99 Procedure A. This procedure states that the nominal size of the specimen should be 1" inch $^{2}$ by 4 " (with the 4 in. direction running parallel to the applied compressive load). In order to reach an approximately 1 inch $^{2}$ base, three 1 " $x 4$ " strips were required. Compressive strength in both the parallel and perpendicular to strand alignment orientations was tested, with 20 specimens manufactured for each direction.

The compressive load was applied using a self-aligning spherical loading block seen in Figure 4.14. The speed of the crosshead was applied at a rate of $0.005 \mathrm{in} / \mathrm{in}$ 
of length/min. Therefore, for the 4 " long specimens tested in the direction parallel to strands, the load rate was $0.20 \mathrm{in} / \mathrm{min}$. For specimens tested perpendicular to the direction of strands, where the strength is much lower, the rate of crosshead movement was slowed to $0.15 \mathrm{in} / \mathrm{min}$.

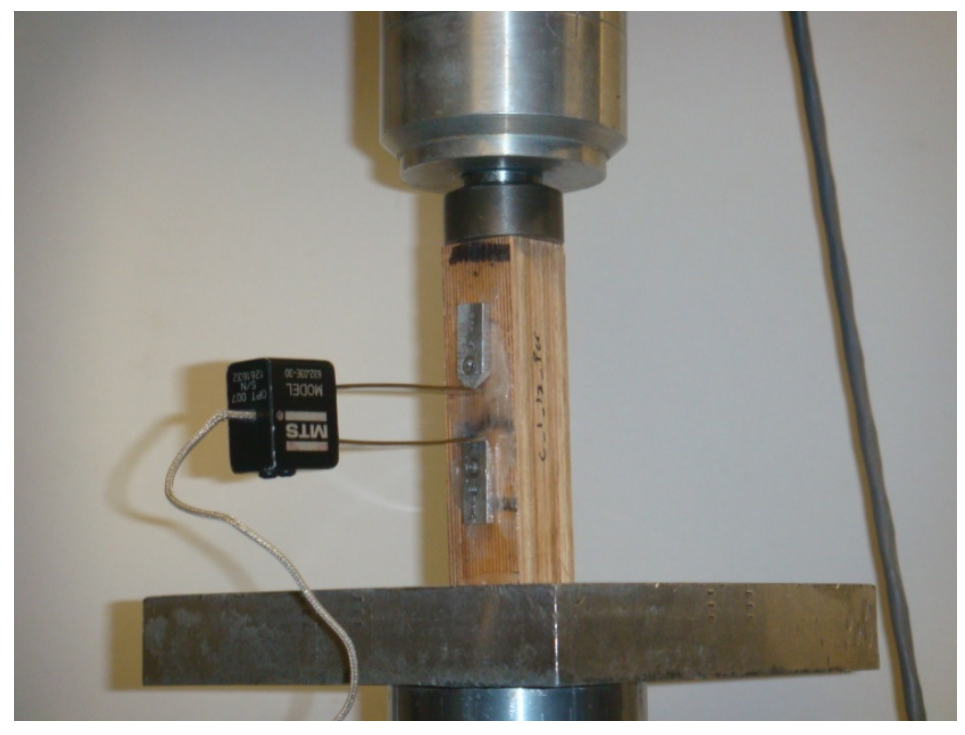

Figure 4.14 Compression strength test setup.

Twenty samples in each the parallel to strand alignment and perpendicular to strand alignment directions were tested. To measure the cross sectional area a digital caliper with a sensitivity of 0.001 inch was used. An extensometer accurate to the nearest 0.00001 in was used to measure deformation over the midpoint. A 20,000 lb load cell was used to measure the loading data for both sets of tests.

The compressive stress was calculated using Equation 1. MOE was calculated by first plotting the stress vs. strain data using a simple scatter plot. Strain was calculated with the following equation: 


$$
\epsilon=\frac{\delta}{l_{0}}
$$

Where:

$$
\begin{aligned}
& \epsilon=\text { strain (in/in) } \\
& \delta=\text { displacement (in) } \\
& I_{0}=\text { initial gauge length (in) }
\end{aligned}
$$

The linear elastic region of the graph was determined and all outlying data removed. A line was fit through the data and the MOE was determined by taking the slope of this line according to Hooke's law.

\subsubsection{Tension}

Tension testing was performed in accordence with ASTM D 3500-99 Procedure A. Due to equipment restraints in the tesing facility ASTM D 1037-99 tension testing could not be performed. The MTS used only had tension grips that could accommodate samples 1" in width rather than the 2" required for ASTM D 1037-99.

Specimens parallel to strand alignment were cut into the "dogbone" shape as

seen in the standard. Specimens perpindicular to the grain were rectangular shape with dimension of 1 " wide by 16 " long. Attempts were made to cut these samples into the "dogbone" shape using a router. But, this almost always resulted in destruction of the sample. 23 samples were tested in each parallel and perperndicular to to strand aligment orientations. 
The tensile strength test setup can be seen in Figure 4.15. Instron lever operated mechanical wedge action T-grips with a capacity $20,000 \mathrm{lbs}$ were used to hold the specimens during testing. A 20,000 lb load cell was used for specimens tested in the parallel to strand alignment orientation. For perpendicular to strand alignment specimens a $500 \mathrm{lb}$ load cell was used to measure the loading data. The cross sectional area of the center of the specimens length was measured using digital calipers accurate to 0.001 inches. A clip-on extensometer accurate to 0.00001 inches was used to measure deformation over the center of the samples. The initial gauge length of the extensometer was measured using the same digital calipers. A rate of motion of the crosshead of $0.035 \mathrm{in} / \mathrm{min}$ is suggested in the standard. Specimen failure must occur betwwen a 3 to 10 -min time span. A crosshead speed of $0.035 \mathrm{in} / \mathrm{min}$ was satisfactory for the specimens tested in the parallel to strand alignment configuration but had to be lowered to $0.0275 \mathrm{in} / \mathrm{min}$ for specimens perpendicular to strand alignment.

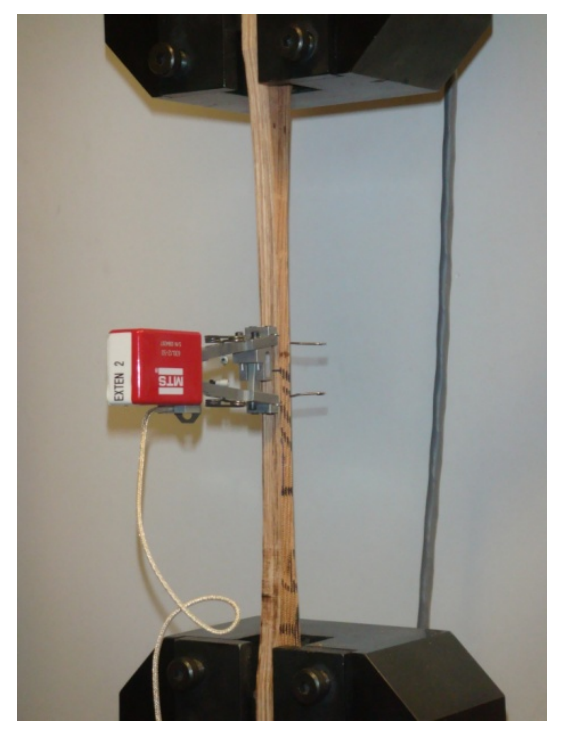

Figure 4.15 Tensile strength test setup 
Using Equation 1 the tensile stress was calculated for each test. MOE could then be determined by plotting the stress vs. strain data using a simple scatter plot. Strain was calculated using Equation 8. The linear elastic region of the graph was determined and all outlying data removed. The MOE was determined by calculating the slope of the stress vs. strain plot in the linear elastic region according to Hooke's law.

\subsubsection{Shear}

Shear blocks were manufactured with dimensions in accordance with ASTM D 1037 - 99. Five $2 " \times 2.5$ " strips were glued together to produce the test samples. The shear plane was cut midway between the glue lines so that the failure was in the plane of the board and not in the plane of the glue line.

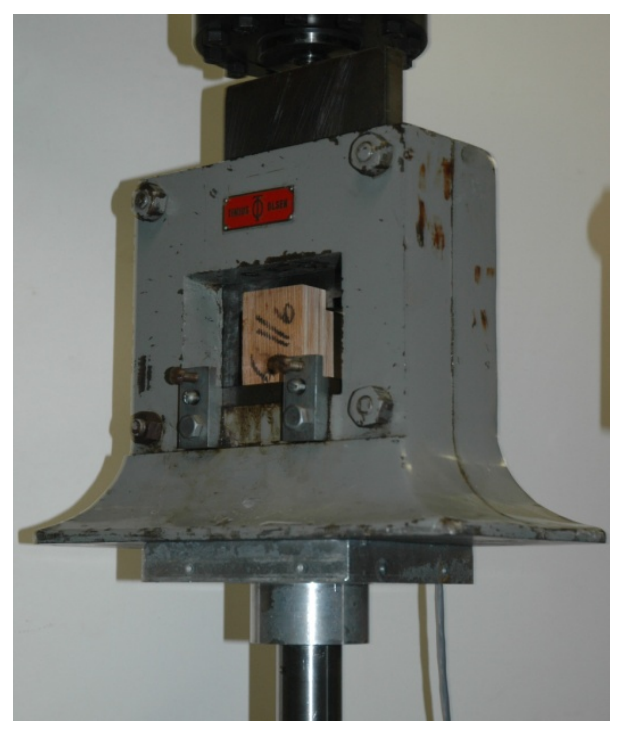

Figure 4.16 Shear strength in the plane of the board test setup. 
The shear tool shown in Figure 4.16 was used to test the specimens. In accordance with ASTM D 1037 - 99 the shear tool provided a 0.125 in. offset between the inner edge of the supporting surface and loaded plane. Also, the speed of the crosshead was fixed at $0.024 \mathrm{in} / \mathrm{min}$. A $20,000 \mathrm{lb}$ load cell was used for both parallel and perpendicular to strand alignment tests. The shear area was measured to the nearest 0.001 inch using a digital caliper. The maximum shear stress was calculated using the following equation:

$$
\tau_{M A X}=\frac{P_{M A X}}{A}
$$

Where:

$$
\begin{aligned}
& \tau_{\text {MAX }}=\text { Maximum shear stress }(\mathrm{psi}) \\
& P_{\text {MAX }}=\text { Maximum load }(\mathrm{lbs}) \\
& A=\text { Sheared area }\left(\mathrm{in}^{2}\right)
\end{aligned}
$$

\subsubsection{Water Absorption and Thickness Swell}

To test the water absorption properties of these panels the methods specified in ASTM D 1037-99 were followed. Method A: 2 hour plus 22 hour soaking was used. Ten samples were cut into 6" $\times 6$ " specimens. Four points approximately 1 " in from the sides on all corners and a point in the center of the specimens were chosen to evaluate thickness swell. The length width and thickness at each of the five points were measured using a digital caliper accurate to the nearest $0.001 \mathrm{in}$. Also, the weight of each of the specimens was recorded using a scale measuring to the nearest $0.001 \mathrm{lb}$. 
The specimens were submerged horizontally under water for 2 hours, then removed and weighed. The thickness at each of the 5 points was also measured again. Then, the samples were submerged for 22 more hours and the process was repeated. For each the 2 hour and subsequent 22 hour soak periods the water absorption as a percentage of volume and as a percentage of weight was calculated using the following formulas:

$$
\% V=\frac{\left(V_{\text {final }}-V_{\text {initial }}\right)}{V_{\text {initial }}} \times 100 \%
$$

Where:

$$
\begin{aligned}
& \% V=\text { Percent of water absorbed by volume } \\
& V_{\text {final }}=\text { Volume after soak }\left(\mathrm{lb} / \mathrm{in}^{3}\right) \\
& V_{\text {initial }}=\text { Volume before soak }\left(\mathrm{Ib} / \mathrm{in}^{3}\right)
\end{aligned}
$$

and as a percentage of weight:

$$
\% W=\frac{\left(W_{\text {final }}-W_{\text {initial }}\right)}{W_{\text {initial }}} \times 100 \%
$$

Where:

$$
\begin{aligned}
& \% W=\text { Percent of water absorbed by weight } \\
& W_{\text {final }}=\text { Weight after soak }(\mathrm{lb}) \\
& W_{\text {initial }}=\text { Weight before soak }(\mathrm{lb})
\end{aligned}
$$


The thickness swelling as a percentage of the original thickness was also calculated. The following formula was used:

$$
T S=\frac{\left(t_{\text {final }}-t_{\text {initial }}\right)}{t_{\text {initial }}} \times 100 \%
$$

Where:

$$
\begin{aligned}
& T S=\text { Thickness swell } \\
& t_{\text {final }}=\text { Thickness after soak (in) } \\
& t_{\text {initial }}=\text { Thickness before soak (in) }
\end{aligned}
$$

\subsection{Web-to-Web Joint Tensile Strength}

A modified version of ASTM D 3500-99 Method B was used to evaluate the joint strength of the web-to-web connections. Two joint types, finger joints and dovetails joints, were evaluated. Tests on solid panels cut into a "dogbone" shape to ensure failure in the middle of the specimen were also performed to compare to the strength of the joints.

The tensile strength of the joints was determined from flat panel specimens 6-8" wide. The width of the solid specimens was 8" with a radius cut out of the middle of the panel so the width in the desired area of failure was equal to 6". See Figure 4.17 for test setup and solid panel specimen. Striated steel plates with dimension of 8 " wide by 4" long were manufactured to hold the specimens during testing. To fix the samples to the grips eight bolts were used at both ends of the specimen. The net length of the specimens range from $20-24$ " due to manufacturing restraints. 


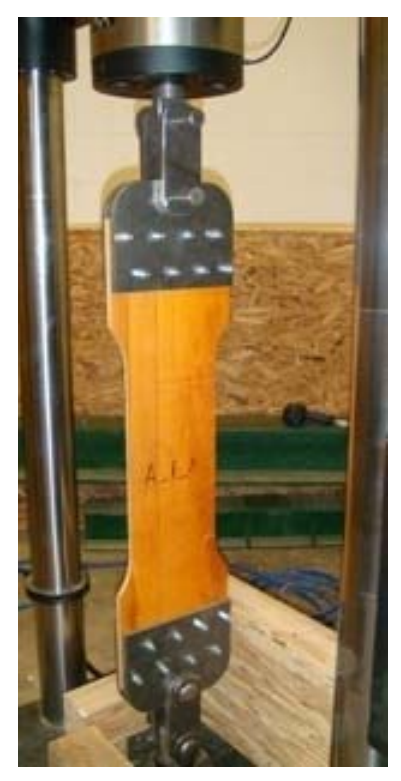

Figure 4.17 Web-to-web joint tensile strength test setup.

An Instron Satec Series $300 \mathrm{kN}(\approx 67,400 \mathrm{lb})$ universal testing machine was used to investigate the strength of the specimens. This machine was equipped with a load cell, which was the same capacity as the testing machine, which was used to measure the loading data in real time. The rate of motion of the crosshead was set at 0.025 in/min. The tensile strength was evaluated using Equation 1. 


\subsection{Flange-to-Web Shear Strength}

The shear strength of two types of flange-to-web joints was evaluated. Six samples with finger joints and six with tongue and groove joints were tested. Also, for comparison nine trials using commercial I-joists were performed.

To prepare the samples, a template made from solid wood was glued to the web (Figure 4.18). This was to prevent crushing of the web when the specimen was loaded. Because there were some gaps in the glued surfaces between the template and the sine wave shaped web, two bolts were also inserted through the middle of the web to ensure that the template remained in place (Figure 4.19).

The sample was loaded using a steel bar equal to the length of the web with an 1/8" gap on either side. The depth of the web of all samples tested was approximately 9.5 inches. The flanges were supported directly above the flange-to-web connection on the opposite end. The test setup for the shear strength of the joint is shown in Figure 4.19. The specimens were loaded at a constant speed of $0.1 \mathrm{in} / \mathrm{min}$. 


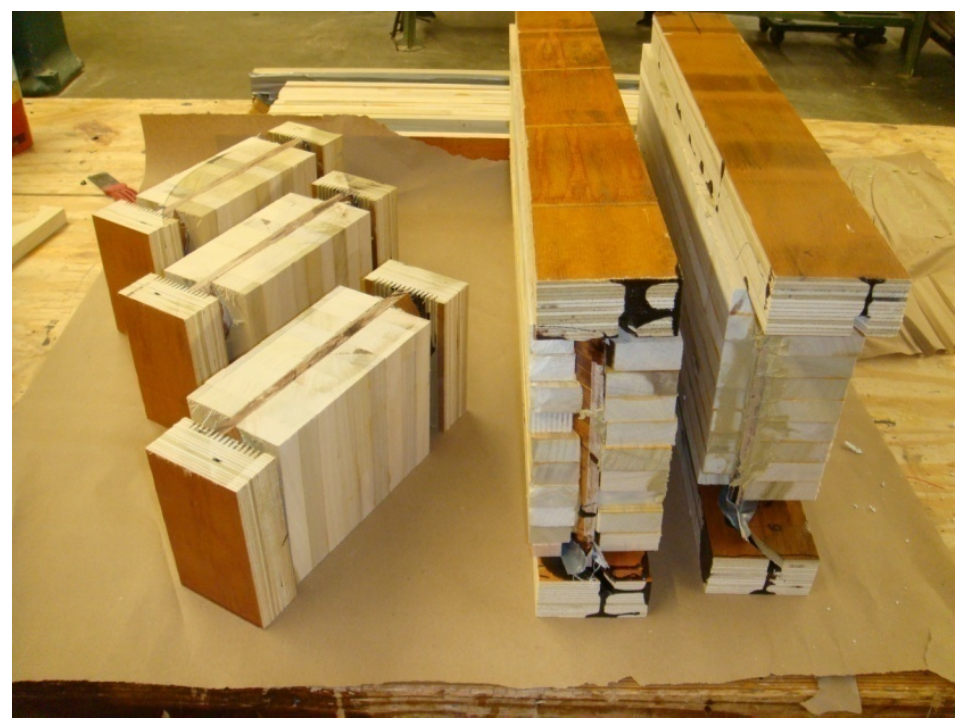

Figure 4.18 Flange-to-web shear strength test specimens.

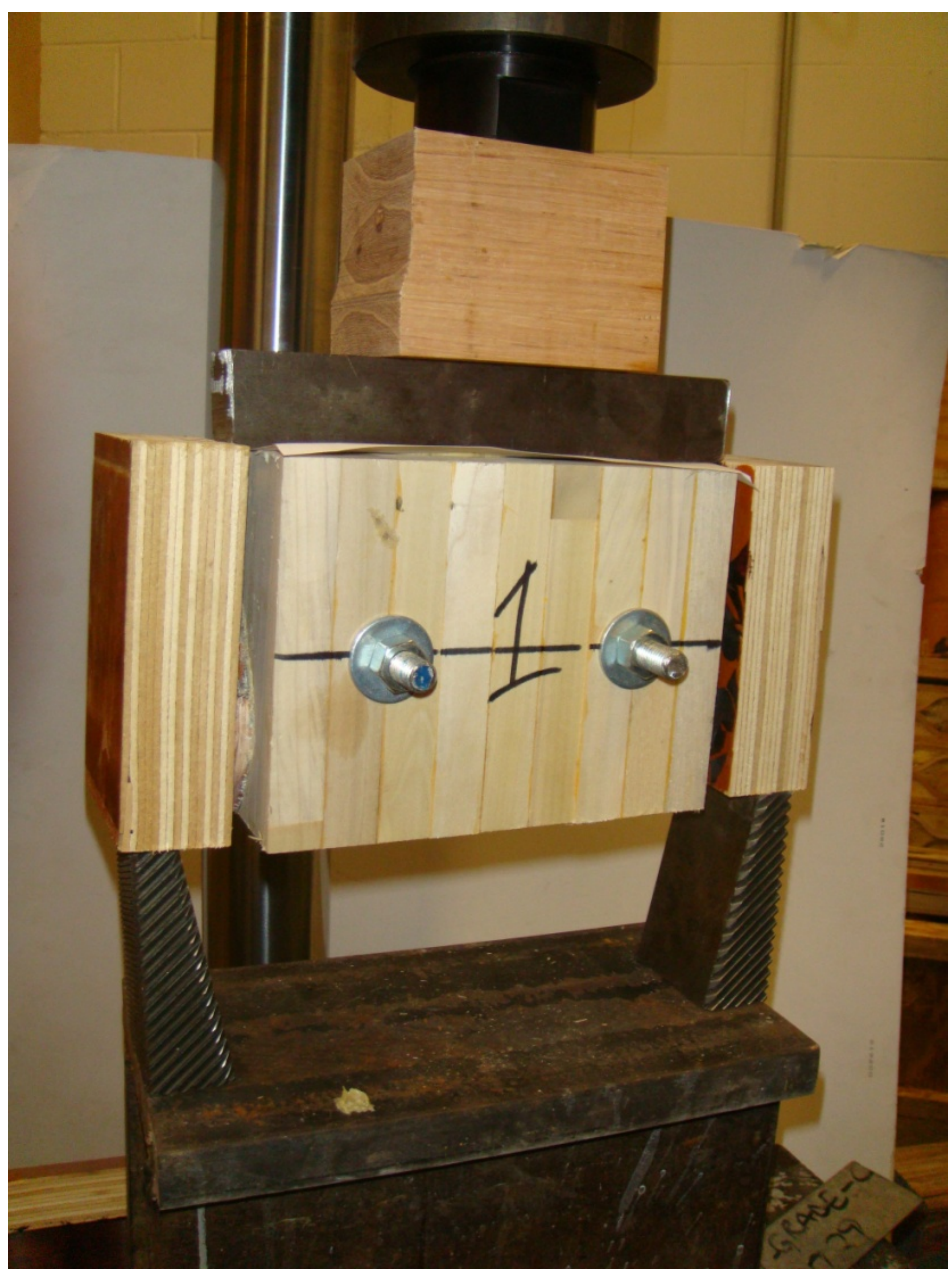

Figure 4.19 Flange-to-web shear strength test configuration. 
Using the data collected the maximum load and shear strength of each specimen was determined. The shear strength was calculated using the following equations:

$$
b_{\boldsymbol{w}}=\frac{34.774}{30} \times b_{w-a c t u a l}
$$

Where:

$$
\begin{aligned}
& b_{w}=\text { Adjusted web thickness (in) } \\
& b_{w-a c t u a l}=\text { Actual web thickness (in) } \\
& A_{\boldsymbol{a}}=b_{w} \times l
\end{aligned}
$$

Where:

$$
\begin{aligned}
& A_{a}=\text { Adjusted shear area }\left(\mathrm{in}^{2}\right) \\
& b_{w}=\text { Adjusted web thickness (in) } \\
& I=\text { Length of the flange-to-web connection (in) } \\
& \tau_{M A X}=\frac{P_{M A X}}{A_{a}}
\end{aligned}
$$

Where:

$$
\begin{aligned}
& \tau_{M A X}=\text { Maximum shear stress }(\mathrm{psi}) \\
& P_{\text {MAX }}=\text { Maximum load }(\mathrm{lbs}) \\
& A_{a}=\text { Adjusted shear area }\left(\mathrm{in}^{2}\right)
\end{aligned}
$$




\subsection{I-Joist Bending}

Full scale I-joist bending tests followed the specifications described by ASTM D 198-99. Nine joists were manufactured in 8 and 12 foot lengths at different depths using various $S C L$ as flange material. Two flange-to-web joint types were evaluated, finger joints and tongue and groove joints. The span-to-depth ratio recommended by the standard is 17-21:1. In comparison, due to differing specimen lengths and depths, the span-to-depth ratio of the $12 \mathrm{ft}$ joists was $12-15: 1$ and for the $8 \mathrm{ft}$ joists 6-10:1.

Appropriate lateral support was provided for both the 8 and 12 foot beams. The load was applied using an Instron Satec Series universal testing machine. For specimens to fail in the specified 6-10 min range the crosshead speed was applied at $0.1 \mathrm{in} / \mathrm{min}$. Load data was measured with a $300 \mathrm{kN}(\approx 67,400 \mathrm{lb})$ load cell. Using a linear displacement transducer, accurate to the nearest 0.000001 inch, the midpoint deflection between the two load points was measured. Test setup was as shown in Figure 4.20.

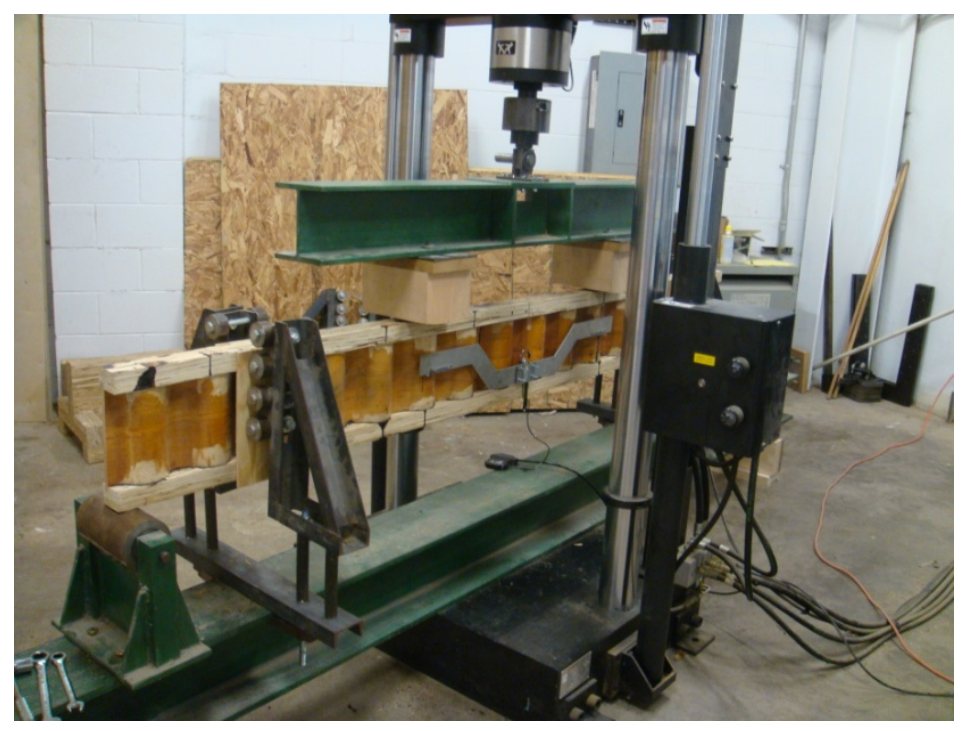

Figure 4.20 I-joist bending test setup. 
Using the data collected the bending strength, modulus of elasticity, and moment capacity of the beams were calculated. The moment capacity was calculated using the following equation.

$$
M_{M A X}=\frac{P_{M A X} L}{6}
$$

Where:

$$
\begin{aligned}
& M_{\text {MAX }}=\text { Maximum moment }(\mathrm{lb}-\mathrm{in}) \\
& P_{M A X}=\text { Maximum load }(\mathrm{lb}) \\
& L=\text { Span length between the supports (in) }
\end{aligned}
$$

The moment of inertia was found using the parallel axis theorem:

$$
I_{x}=I_{w}+2\left(I_{f}+A_{f} d^{2}\right)
$$

Where:

$I_{x}=$ Moment of inertia $\left(\mathrm{in}^{4}\right)$

$I_{c}=$ Moment of inertia of the axis parallel to and passing through the centriod, i.e. the web $\left(\mathrm{in}^{4}\right)$

$A=$ Cross sectional area of the members not passing through the centroid, i.e. the flanges $\left(\mathrm{in}^{2}\right)$

$d=$ Distance between the $\mathrm{x}$-axis and the centroidal axis (in) 
Or Equation 17 can be written as:

$$
I_{x}=\frac{b_{w} h_{w}^{3}}{12}+2\left[\frac{b_{f} h_{f}^{3}}{12}+\left(b_{f} h_{f}\right) d^{2}\right]
$$

Where:

$$
\begin{aligned}
& I_{x}=\text { Moment of inertia }\left(\mathrm{in}^{4}\right) \\
& b_{w}=\text { Width of the web (in) } \\
& h_{w}=\text { Height of the web (in) } \\
& b_{f}=\text { Width of the flange (in) } \\
& h_{f}=\text { Height of the flange (in) } \\
& d=\text { Distance between the x-axis and the centroidal axis (in) }
\end{aligned}
$$

It should be noted that in the calculation of moment of inertia web thickness was adjusted by using a ratio of the equivalent length of the corrugated web to that of a flat web at a length of 30 inches using Equation 13.

The modulus of rupture was calculated using the following equations:

$$
c=\frac{h}{2}
$$

Where:

$$
\begin{aligned}
c= & \text { Height of centroidal axis, i.e. distance from the outer fiber to the } \\
& \text { centroidal axis (in) } \\
h= & \text { total height of beam (in) }
\end{aligned}
$$


Or Equation 19 can be written as:

$$
c=\frac{h_{w}+\left(2 h_{f}\right)}{2}
$$

Where:

$$
\begin{aligned}
& c= \text { Height of centroidal axis, i.e. distance from the outer fiber to the } \\
& \text { centroidal axis (in) } \\
& h_{w}= \text { Height of the web (in) } \\
& h_{f}=\text { Height of the flange (in) }
\end{aligned}
$$

$$
S_{x}=\frac{I_{x}}{c}
$$

Where:

$$
\begin{aligned}
& S_{x}=\text { Section modulus }\left(\mathrm{in}^{3}\right) \\
& I_{x}=\text { Moment of inertia }\left(\mathrm{in}^{4}\right) \\
& c=\text { Height of centroidal axis (in) }
\end{aligned}
$$

The modulus of rupture was finally calculated using Equation 5.

To calculate MOE load vs. displacement data was graphed using a simple scatter plot. The linear elastic region of the plot was found and outlying data removed. A regression analysis was run and the data corrected so that the regression line passed through the origin. Modulus of elasticity was calculated using Equation 22. Taking the average of all the MOE values over the linear elastic region was taken to be the apparent MOE for the sample. 


$$
M O E=\frac{M_{M A X} l^{2}}{8 I_{x} \Delta}
$$

Where:

$$
\begin{aligned}
& \text { MOE }=\text { Modulus of elasticity (psi) } \\
& M_{M A X}=\text { Maximum moment (lb in) } \\
& I=\text { Length between the points where the load is applied (in) } \\
& I_{X}=\text { Moment of inertia }\left(\mathrm{in}^{4}\right) \\
& \Delta=\text { Deflection (in) }
\end{aligned}
$$




\section{RESULTS AND DISCUSSION}

\subsection{Mechanical Testing of Small Scale Specimens}

Small scale coupon testing was performed to evaluate the mechanical and physical properties of flat panels in both the $\|$ and $\mid$ configurations. With the exception of thickness swell all mechanical tests had a sample size of at least 20 specimens for each orientation.

\subsubsection{Internal Bond}

The internal bond strength of 20 samples manufactured cherry veneer-mill residues was evaluated. A summary of the results are shown in Table 5.1. A mean of 152 psi was calculated with a minimum of 65 psi and a maximum of 289 psi. The standard deviation was high and this is most likely due to areas of low density in the panels. The internal bond strength of OSB ranges from 30 to 70 psi (Georgia Pacific Wood Products 2008). Compared to OSB this product has significantly higher strength. 
Table 5.1 Summary of internal bond strength tests.

\begin{tabular}{lr} 
Internal Bond Test Results & \\
\hline \hline Sample Size & 20 \\
Mean (psi) & 152.3 \\
Std. Dev. (psi) & 56.3 \\
Minimum (psi) & 64.7 \\
Maximum (psi) & 288.8 \\
\hline \hline
\end{tabular}

\subsubsection{Water Absorption and Thickness Swell}

Ten different specimens with five points on each specimen were observed. The results of the testing are shown in Table 5.2. Wood is a hydroscopic material and moisture is always an area of concern. After just 2 hours the weight of the specimens increased by an average of $20 \%$. The thickness only increased by $5 \%$. But after the total 24 hours the weight increased by over $40 \%$, volume by $20 \%$, and thickness by $15 \%$. These results show that caution should be taken and the increase in thickness should be compensated for if these panels are to come in contact with excessive moisture. 
Table 5.2 Summary of water absorption and thickness swell testing.

\begin{tabular}{llccc}
\hline \hline & & \% Weight & \% Volume & Thickness Swell (\%) \\
\hline \hline \multirow{3}{*}{ 2 hour soak } & Mean & 19.2 & 11.7 & 5.5 \\
& Std. Dev. & 6.4 & 4.5 & 1.9 \\
& Minimum & 12.6 & 8.3 & 2.9 \\
& Maximum & 33.5 & 23.1 & 9.6 \\
\hline \multirow{2}{*}{ 24 hour soak } & Mean & 41.1 & 19.3 & 14.6 \\
& Std. Dev. & 9.2 & 6.8 & 2.9 \\
& Minimum & 29.2 & 11.5 & 11.1 \\
& Maximum & 58.4 & 33.1 & 19.1 \\
\hline \hline
\end{tabular}

\subsubsection{Static Bending}

Three-point bending tests were performed in order to calculate the MOE and MOR about 4 different planes. With 20 samples tested in each $\|\left._{\text {Flatwise, }}\right|_{\text {Flatwise, }}$ and LEdgewise $_{\text {Orientations and } 24 \text { in the }} \|_{\text {Edgewise }}$ direction. A statistical summary of the flatwise and edgewise bending tests are presented in Table 5.3. In which the mean, standard deviation, minimum, and maximum values are listed by testing orientation. 
Table 5.3 Flatwise and edgewise bending summary.

\begin{tabular}{|c|c|c|c|c|c|}
\hline & & $\mathbf{P}_{\text {MAX }}$ & $\mathrm{M}_{\text {MAX }}$ in) & $\begin{array}{c}\text { MOR } \\
\left(\times 10^{3} \text { psi) }\right.\end{array}$ & $\begin{array}{c}\text { MOE }_{\text {APP }} \\
\left(\times 10^{6} \mathrm{psi}\right)\end{array}$ \\
\hline \multirow{4}{*}{$\|_{\text {Flat }}$} & Mean & 459.4 & 1464.2 & 19.22 & 2.26 \\
\hline & Std. Dev. & 69.7 & 222.0 & 3.38 & 0.28 \\
\hline & Minimum & 339.4 & 1081.7 & 13.67 & 1.74 \\
\hline & Maximum & 558.0 & 1778.6 & 25.62 & 2.86 \\
\hline \multirow{4}{*}{$\|_{\text {Edge }}$} & Mean & 385.6 & 1229.0 & 16.02 & 1.94 \\
\hline & Std. Dev. & 46.2 & 147.3 & 1.57 & 0.15 \\
\hline & Minimum & 310.6 & 990.1 & 13.34 & 1.54 \\
\hline & Maximum & 474.0 & 1510.8 & 19.27 & 2.12 \\
\hline \multirow{4}{*}{ I Flat } & Mean & 28.9 & 92.0 & 1.26 & 0.18 \\
\hline & Std. Dev. & 9.2 & 29.5 & 0.39 & 0.04 \\
\hline & Minimum & 16.3 & 51.9 & 0.74 & 0.11 \\
\hline & Maximum & 52.0 & 165.8 & 2.14 & 0.29 \\
\hline \multirow{4}{*}{ I Edge } & Mean & 25.7 & 81.9 & 1.05 & 0.17 \\
\hline & Std. Dev. & 6.4 & 20.4 & 0.24 & 0.04 \\
\hline & Minimum & 15.1 & 48.0 & 0.62 & 0.11 \\
\hline & Maximum & 38.7 & 123.4 & 1.54 & 0.23 \\
\hline
\end{tabular}

II - Parallel to Strand Alignment

1 - Perpendicular to Strand Alignment 


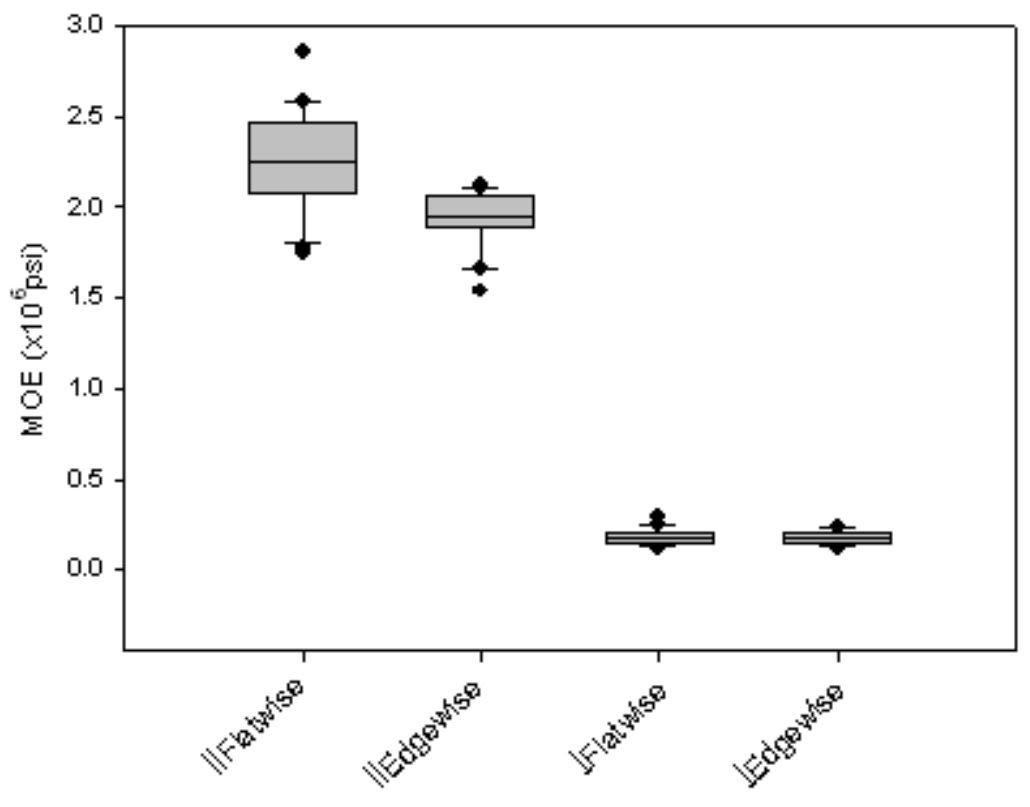

Figure 5.1 Comparison of flatwise and edgewise MOE about both the $\|$ and $\rfloor$ planes.

As expected the MOE about the parallel to strand alignment orientation was significantly higher than that of the perpendicular to strand alignment orientation (Figure 5.1). This is due to the natural orthotropic behavior of wood, where the strength along the grain is much higher than the strength perpendicular to the grain. In the flatwise orientiation the MOE in the perpendicular to strand alignment direction is only $8 \%$ of the MOE in the direction parallel to strand alignment. In the edgewise orientation, the MOE about the perpendicular to strand alignment direction is only $9 \%$ of the MOE parallel to strand alignment.

Pair wise t-tests showed significant difference between $\|_{\text {Flatwise }}$ and $\|_{\text {Edgewise }}$ MOE, while showing no significant difference in $\left.\right|_{\text {Flatwise }}$ and $\left.\right|_{E d g e w i s e}$ MOE. The difference in the flatwise and edgewise parallel to strand alignment MOE are most likely due to 2 
factors. First, edgewise samples are loaded perpendicular to the glued surfaces. Weaknesses in the glued bonds between individual lamina and LPF bonds between the strands themselves could cause the lower MOE seen in the $\|_{\text {Edgewise }}$ samples. Also, the consolidation process causes a density profile in the panel where the outer layers are densely compacted than the center of the panel. When these samples were tested in the edgewise orientation these areas of lower density were directly exposed to the loading. In other words for the flatwise samples, the bottom surface was better consolidated providing higher strength. The $\left.\right|_{\text {Flatwise }}$ and $\left.\right|_{\text {Edgewise }}$ bending tests showed no significant differences in MOE because the strength is so much less perpendicular to the grain that the strength of the wood controlled and the glued surfaces and density profile had little effect. 


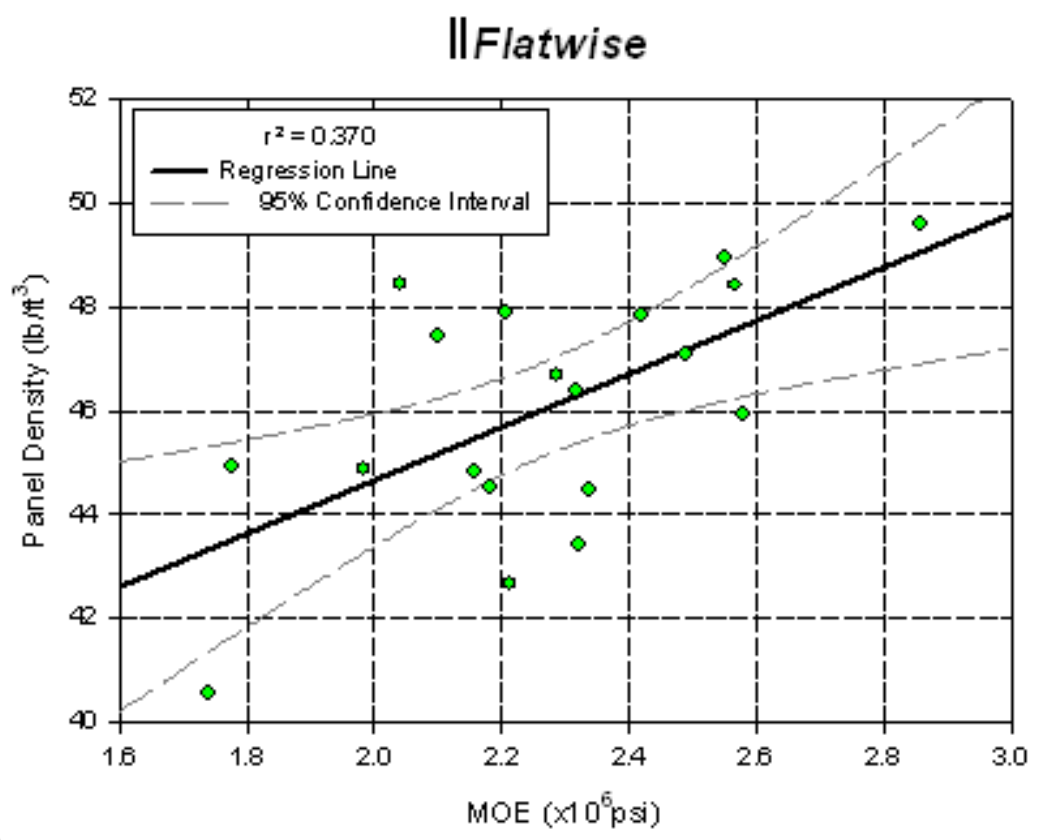

(a)

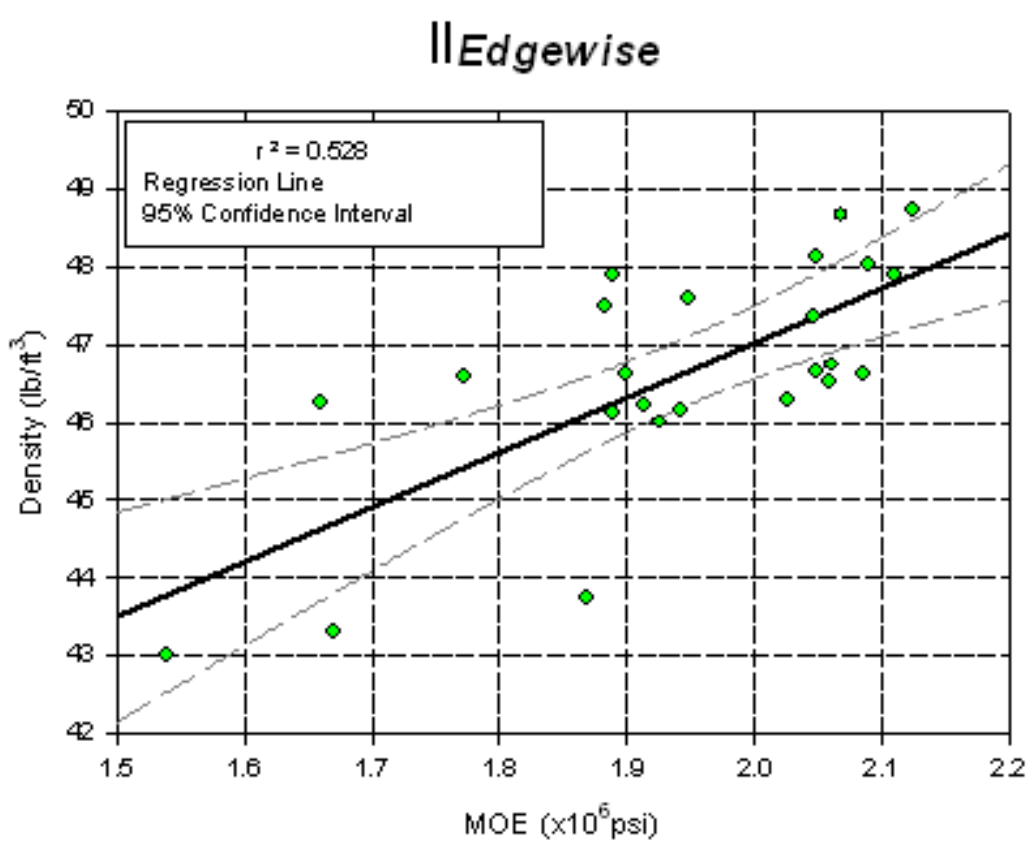

(b)

Figure 5.2 Relationship between density and the bending MOE about (a) $\|_{\text {Flatwise }}$ and (b) $\|_{\text {Edgewise }}$ 


\section{IFlatwise}

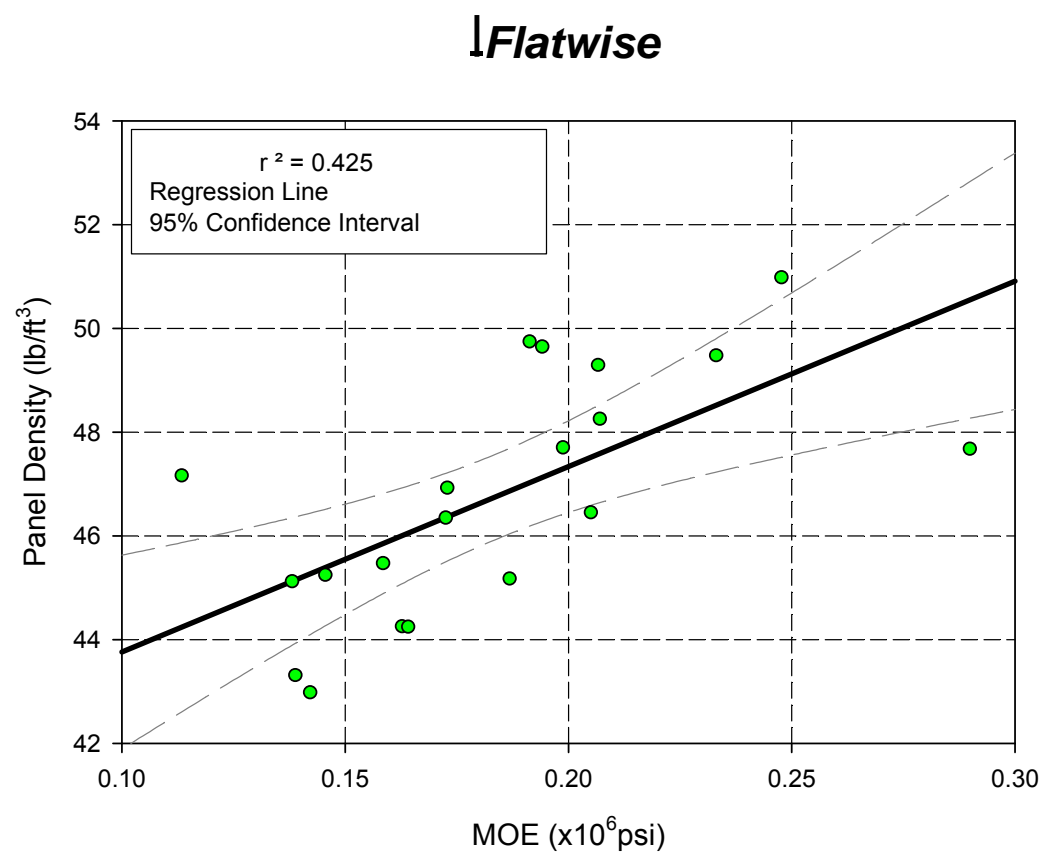

(a)

IEdgewise

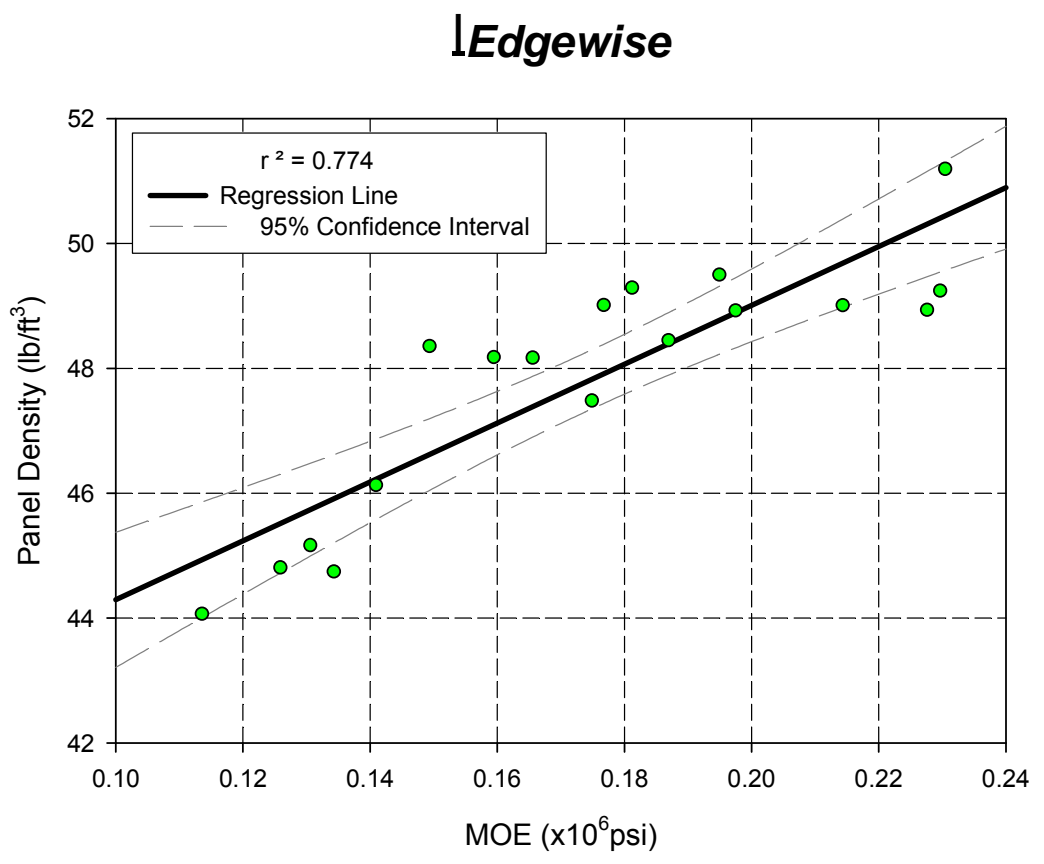

(b)

Figure 5.3 Relationship between density and the bending MOE about (a) IFlatwise and

(b) lEdgewise. 
The relationship between density and MOE was investigated for the four different orientations tested. Regression analysis was performed using a 95\% confidence interval. It was found that a linear relationship exists for the samples tested in the edgewise configuration. The results showed that $\|_{\text {Edgewise }} \mathrm{MOE}$ and density had an $\mathrm{r}^{2}$ value of 0.528 while $\left.\right|_{\text {Edgewise }}$ MOE and density had a stronger linear relationship with $r^{2}=$ 0.774. However in the flatwise orientation density and MOE had little correlation.

\subsubsection{Compression}

Compressive tests were performed on coupon samples to determine compressive strength and compressive MOE. 20 samples were tested in both the parallel and perpendicular to strand alignment configurations. A list of the results can be seen in Table 5.4 .

Table 5.4 Compression testing summary.

\begin{tabular}{|c|c|c|c|c|}
\hline & & $\mathbf{P}_{\text {MAX }}$ & $\begin{array}{l}\sigma_{\mathrm{MAX}} \\
(\mathrm{psi})\end{array}$ & $\begin{array}{c}\text { MOE }_{c} \\
\left(\times 10^{6} \mathrm{psi}\right)\end{array}$ \\
\hline \multirow{4}{*}{ II } & Mean & 12590 & 10685 & 1.66 \\
\hline & Std. Dev. & 1829 & 1513 & 0.40 \\
\hline & Minimum & 8464 & 7055 & 1.06 \\
\hline & Maximum & 14622 & 12737 & 2.53 \\
\hline \multirow{4}{*}{1} & Mean & 2797 & 2301 & 0.16 \\
\hline & Std. Dev. & 895 & 707 & 0.06 \\
\hline & Minimum & 1187 & 996 & 0.08 \\
\hline & Maximum & 4581 & 3736 & 0.32 \\
\hline
\end{tabular}




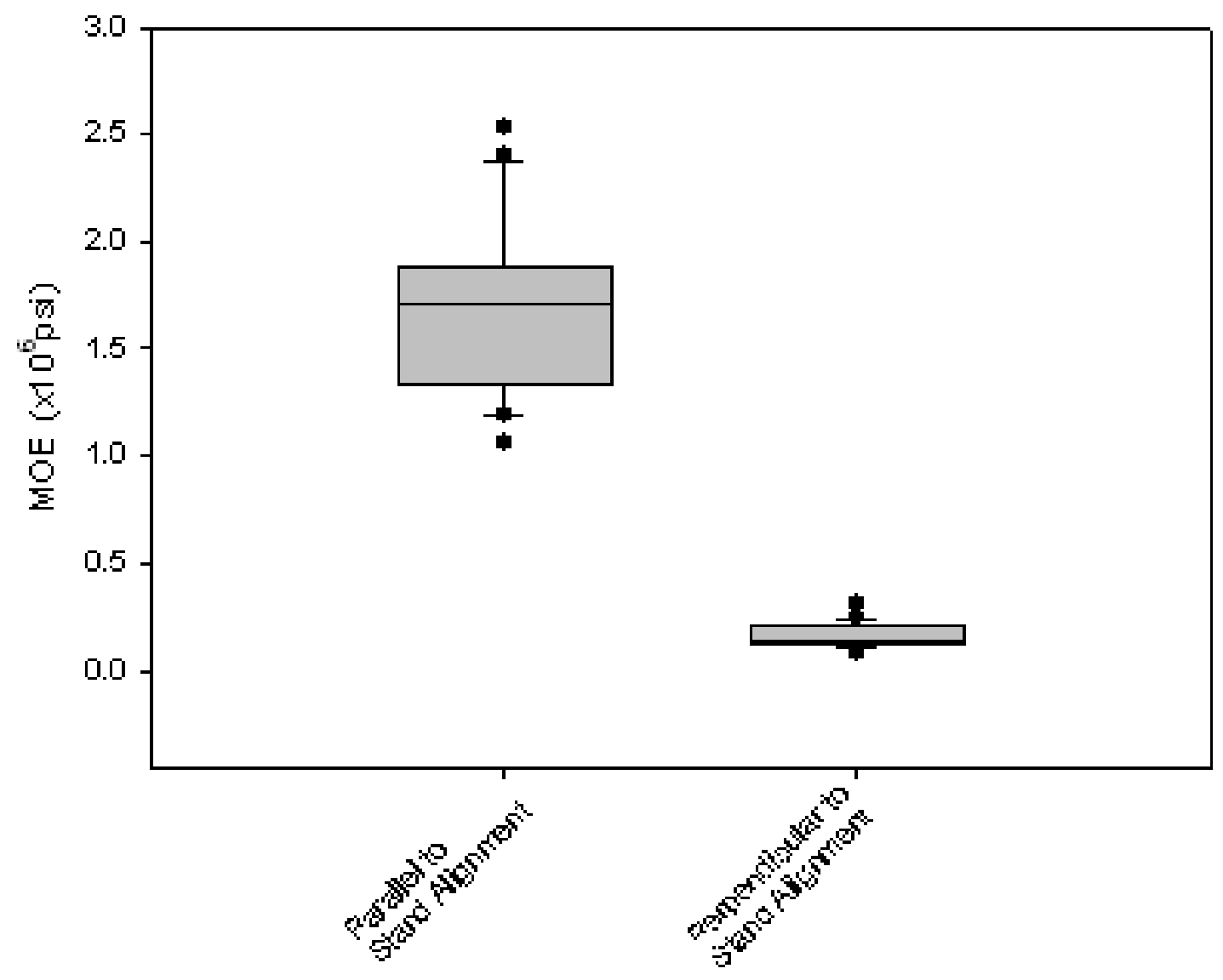

Figure 5.4 Comparison of the compressive MOE about the $\|$ and $\rfloor$ planes.

The MOE values in the parallel to strand alignment direction are once again significantly higher than that of the perpendicular to strand direction (see Figure 5.4). The MOE about the $\rfloor$ plane is only $10 \%$ of the MOE about the $\|$ plane. 


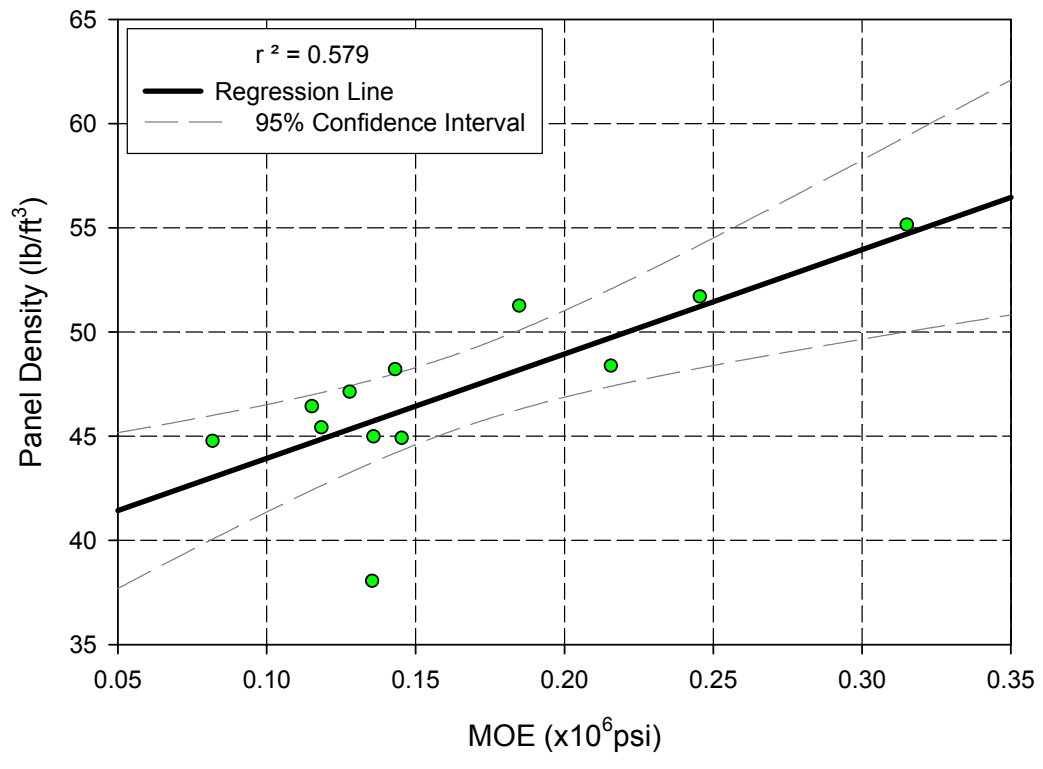

(a)

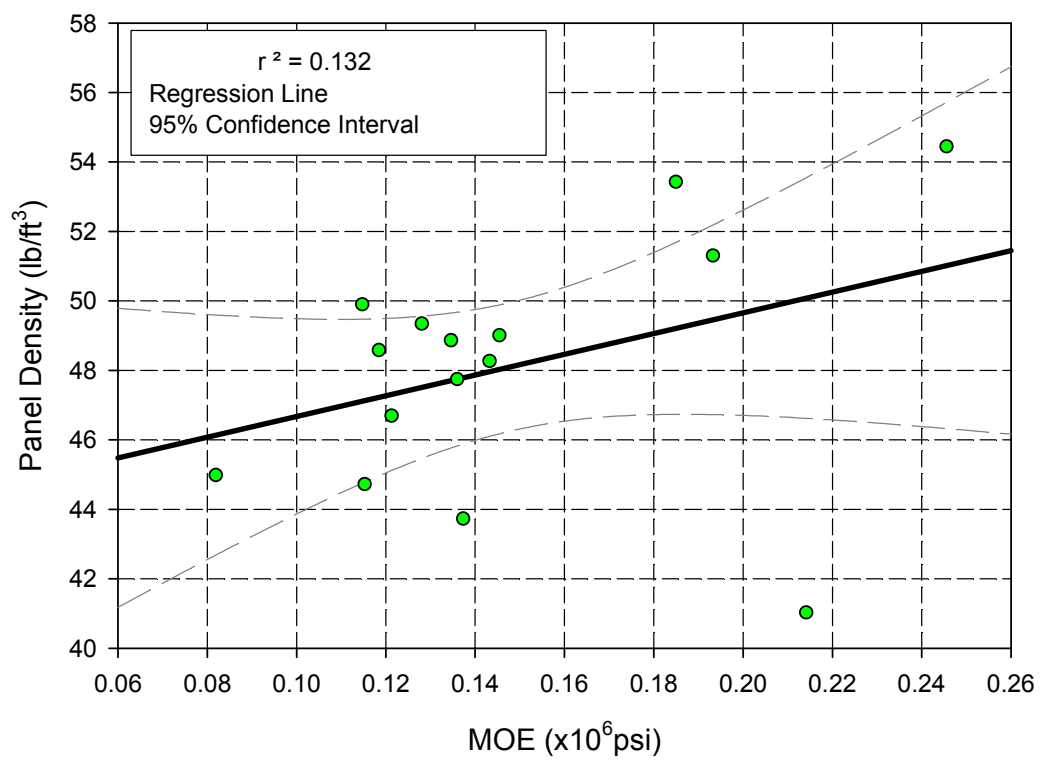

Figure 5.5 Relationship between density and the compressive MOE about the (a) ॥ and (b) \ planes. 
Regression analysis was used to examine the correlation between compressive MOE and density. A 95\% confidence interval was used in the analysis. The results showed that a linear relationship exists between density and compressive MOE about the $\|$ plane $\left(r^{2}=0.579\right)$ but there is not a relationship between density and MOE about the \plane $\left(r^{2}=0.132\right)$.

\subsubsection{Tension}

The tensile strength and MOE about both the $\|$ and $\mid$ directions were evaluated, with 23 tests performed in each direction. When the specimens failed within the grips the tests were disregarded. This only occurred with tests in the perpendicular to strand alignment direction where the specimens were rectangular in shape. The result was that 6 tests failed within the grips and the data was disregarded.

A summary of the testing is shown in Table 5.5. The MOE perpendicular to strand alignment is $7 \%$ of that in the parallel direction. The boxplot in Figure 5.6 shows the comparison of the MOE in these two directions. The variance in the data about the $\|$ direction is quite high. The lower outliers are most likely due to insufficient consolidation in sections of the panels. 
Table 5.5 Summary of tensile tests.

\begin{tabular}{|c|c|c|c|c|}
\hline & & $\mathbf{P}_{\text {MAX }}$ & $\begin{array}{l}\sigma_{\mathrm{MAX}} \\
(\mathrm{psi})\end{array}$ & $\begin{array}{c}\text { MOE }_{\mathrm{T}} \\
\left(\times 10^{6} \mathrm{psi}\right)\end{array}$ \\
\hline \multirow{4}{*}{ II } & Mean & 1720 & 14449 & 2.61 \\
\hline & Std. Dev. & 425 & 4310 & 0.48 \\
\hline & Minimum & 753 & 1567 & 1.65 \\
\hline & Maximum & 2442 & 20104 & 3.33 \\
\hline \multirow{4}{*}{1} & Mean & 216 & 585 & 0.18 \\
\hline & Std. Dev. & 100 & 227 & 0.04 \\
\hline & Minimum & 61 & 162 & 0.12 \\
\hline & Maximum & 374 & 939 & 0.27 \\
\hline
\end{tabular}

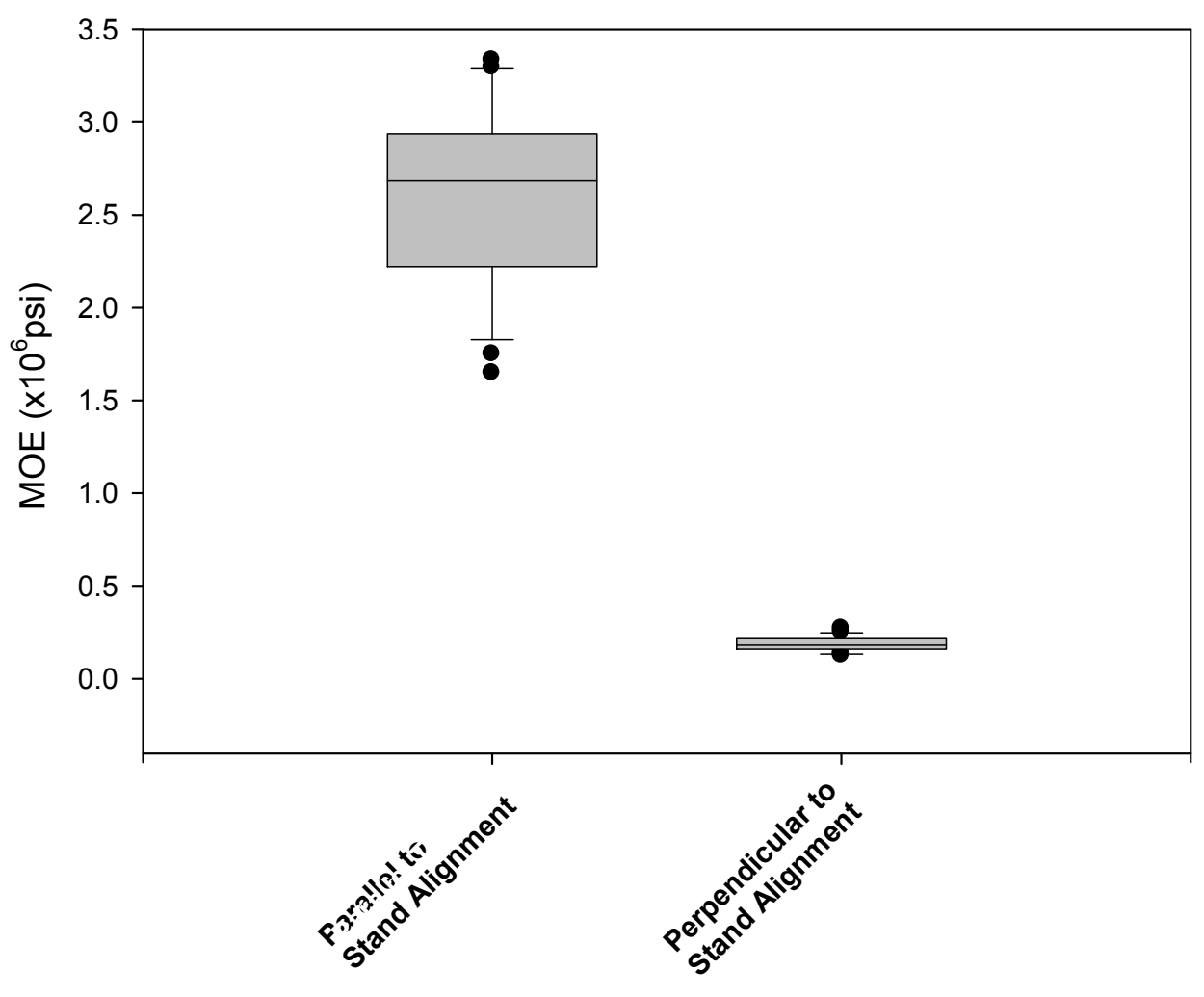

Figure 5.6 Comparison of the tensile MOE about the $\|$ and $\rfloor$ planes. 


\subsubsection{Shear}

The shear strength of 20 specimens in each the $\|$ and $\mid$ directions were investigated. Failures that occurred at the base of the sample on the supporting surface were disregarded. The results of the testing are shown in Table 5.6. The average strength in the perpendicular to strand alignment direction was $62 \%$ of that in the parallel direction. Figure 5.7 shows a comparison of the shear strength about each of these planes. The shear strength was higher in the $\|$ direction. The reason for this phenomenon is uncertain and requires further investigation.

Table 5.6 Summary of shear strength testing.

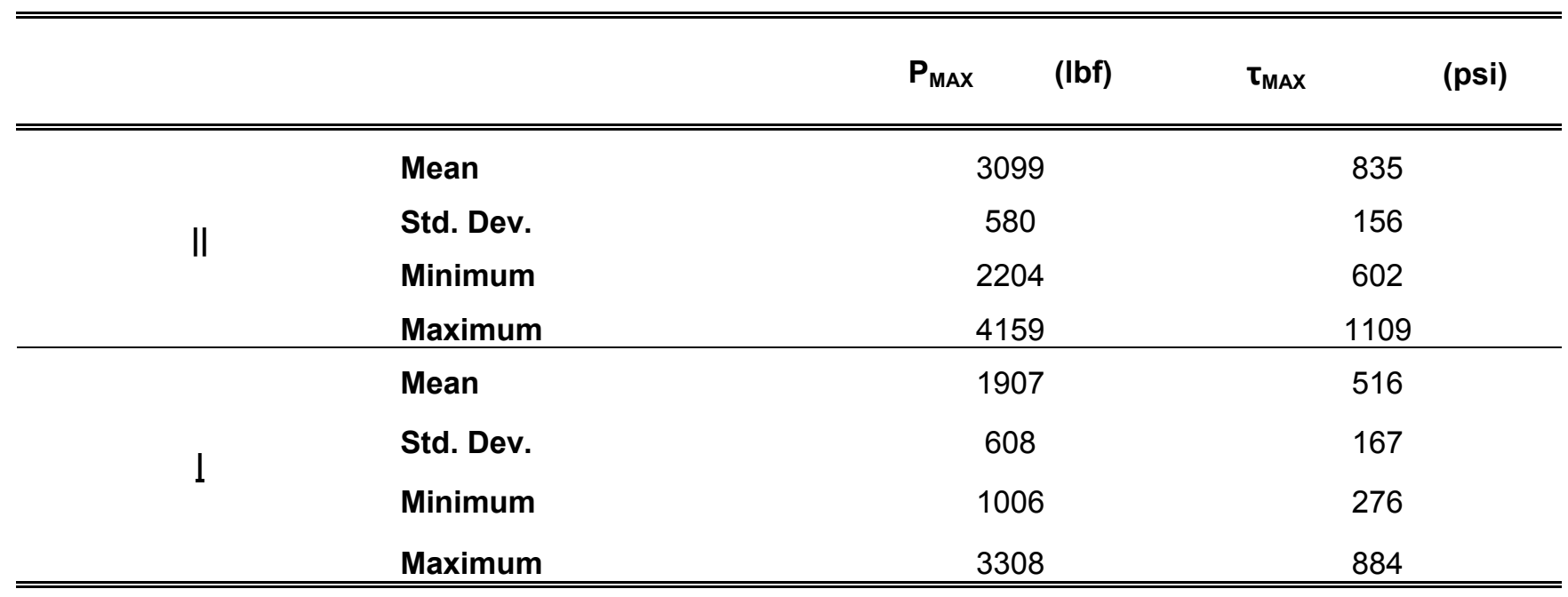




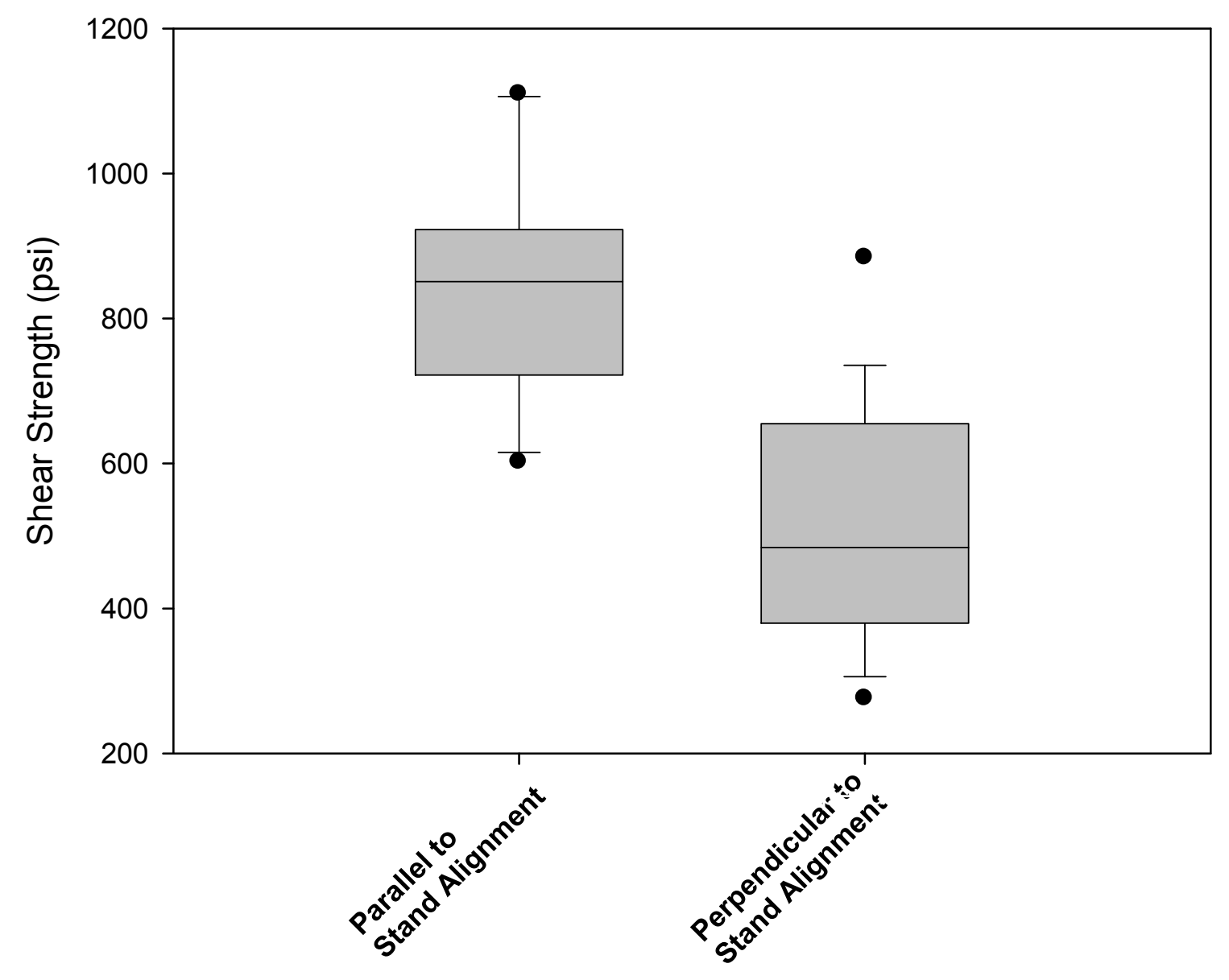

Figure 5.7 Comparison of the shear strength in the $\|$ and $\mid$ planes. 


\subsection{Comparison to Solid Cherry}

One of the major advantages of wood composites is that they can typically outperform solid wood. Table 5.7 shows a comparison of the mechanical properties of solid cherry to the veneer strand composite (VSC) panels manufactured from the same species.

Table 5.7 Comparison of the mechanical properties of the veneer strand composite to solid cherry.

\begin{tabular}{|c|c|c|}
\hline Property & vsc $^{1}$ & Solid Cherry ${ }^{2}$ \\
\hline \multicolumn{3}{|l|}{ Static Bending: } \\
\hline MOR (x10 $\left.30^{3} \mathrm{si}\right)$ & $19.22^{3}$ & 12.33 \\
\hline MOE (x106 psi) & $2.26^{3}$ & 1.49 \\
\hline Compression $\|^{4}$ (psi) & 10600 & 7100 \\
\hline Compression $\left.\right|^{5}$ (psi) & 2301 & 690 \\
\hline Tension | (psi) & 580 & 570 \\
\hline Shear \|| (psi) & 770 & 1700 \\
\hline
\end{tabular}

${ }^{1}$ Veneer strand composite

${ }^{2}$ Values from Forest Products Laboratory (2004 )in the dry condition

${ }^{3}$ Values from || flatwise bending, apparent MOE some shear effect included

${ }^{4} \|$ = parallel to grain for solid cherry and $\|=$ parallel to strand alignment for VSC

${ }^{5} \mathrm{I}=$ perpendicular to grain for solid cherry and $\mathrm{l}=$ perpendicular to strand alignment for VSC

With the exception of shear, the composite has higher mechanical properties than solid cherry. MOR, MOE, and compressive strength parallel to the grain (or strand alignment for the composite) were all roughly $50 \%$ higher for the veneer strand composite. Compression perpendicular to the grain (or strand alignment for the composite) was $200 \%$ higher than that of solid wood. The tension perpendicular to the grain and tension perpendicular to the strand alignment were basically equal. The $\|$ 
shear strength was $45 \%$ higher for solid wood, showing that the shear strength of the bonds between strands could not compare to solid wood.

\subsection{Comparison to Structural Wood Panels}

Structural wood panels, generally, plywood and OSB are used as web material in prefabricated I-joists. A comparison of the mechanical properties of composite panels made from veneer-mill residues and common sheathing-grade structural wood panels is shown in Table 5.8.

Table 5.8 Comparison of the mechanical properties of the veneer strand composite to sheathing-grade OSB and plywood.

\begin{tabular}{|c|c|c|c|}
\hline Property & vsc $^{1}$ & OSB $^{2}$ & Plywood $^{3}$ \\
\hline \multicolumn{4}{|l|}{ Flexure: } \\
\hline MOR (x10 $\left.{ }^{3} \mathrm{psi}\right)$ & 19.22 & 4.00 & 7.00 \\
\hline MOE (x10 $\left.{ }^{6} \mathrm{psi}\right)$ & $2.26^{4}$ & 1.20 & 1.90 \\
\hline Compressive Strength (psi) & 10700 & 2500 & 5000 \\
\hline Tensile Strength (psi) & 14500 & 1500 & 4000 \\
\hline Shear Strength (rolling shear, psi) & 835 & 300 & 300 \\
\hline
\end{tabular}

${ }^{1}$ Veneer strand composite with stress applied to the parallel to strand alignment direction.

${ }^{2}$ Values from Forest Products Laboratory (2004) with stress applied parallel to panel major axis.

${ }^{3}$ Values from Forest Products Laboratory (2004) with stress applied parallel to grain direction of the face plies.

${ }^{4}$ Value of apparent MOE from flatwise bending, some shear effect included.

While the properties of OSB and plywood are comparable the composite made from veneer strands significantly outperforms both. The MOR of plywood and OSB is only $20 \%$ and $30 \%$ that of the VSC respectively (Figure 5.8). A graph comparing the 
MOE of these three composites is shown in Figure 5.9. The MOE of OSB is approximately half that of the composite panels made from veneer-mill residues. The tensile and compressive strengths of the VSC are also much higher than that of standard structural wood panels (Figure 5.10).

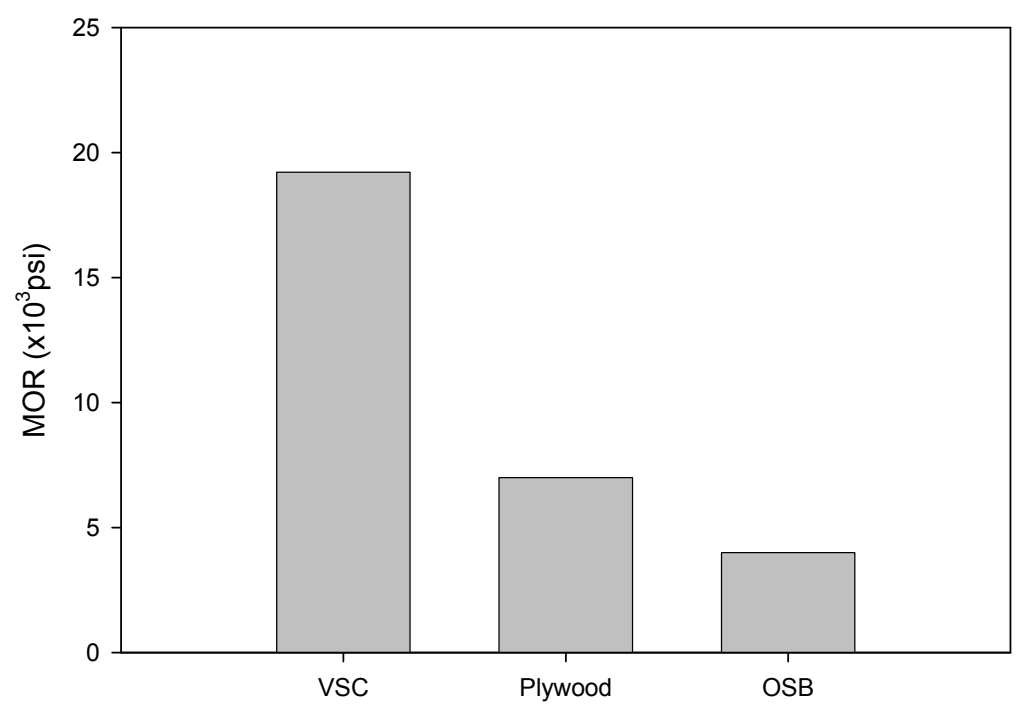

Figure 5.8 Comparison of MOR in flexure of the veneer strand composite, plywood, and OSB. 


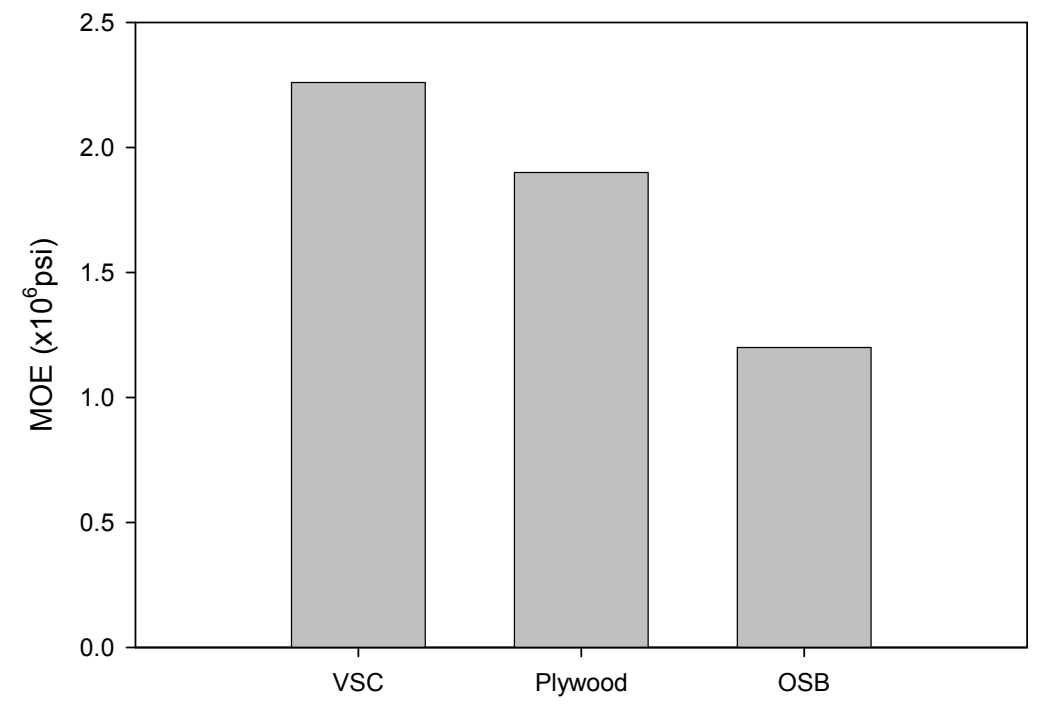

Figure 5.9 Comparison of MOE in flexure of the veneer strand composite, plywood, and OSB.

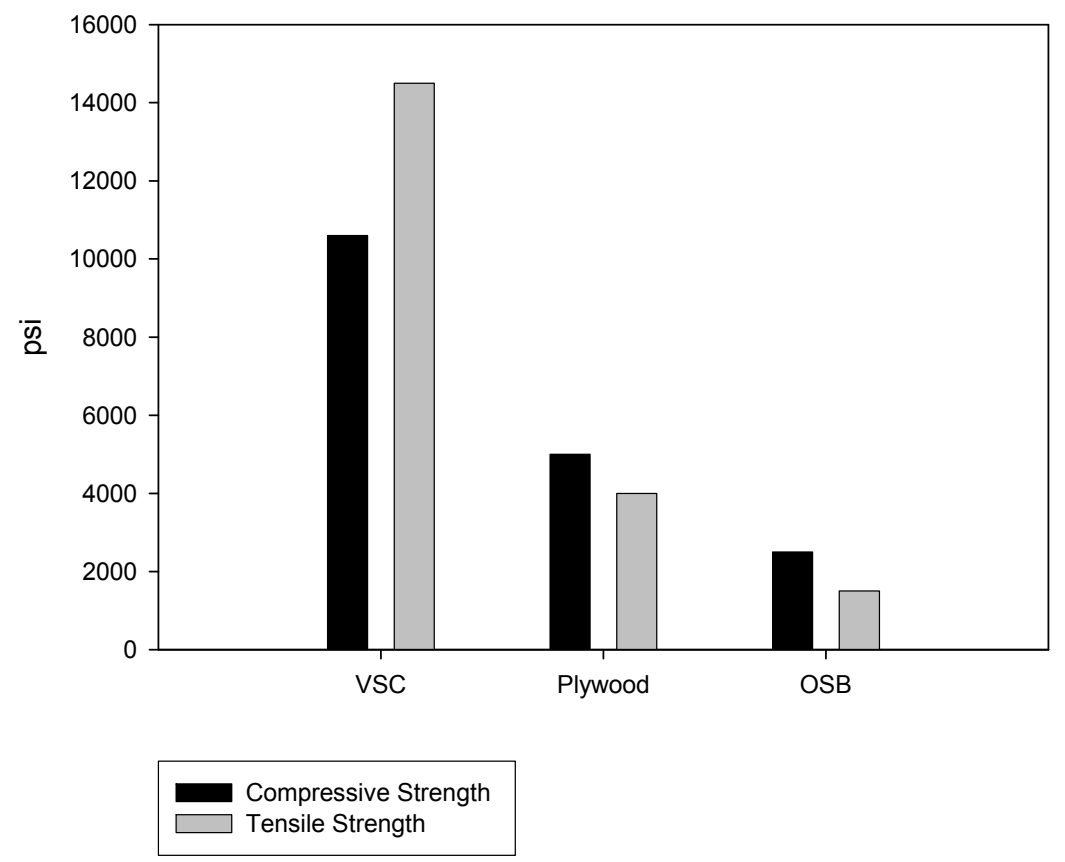

Figure 5.10 Comparison of tensile and compressive strength of the veneer strand composite, plywood, and OSB. 


\subsection{Comparison to Structural Composite Lumber}

This composite product made from veneer-mill residues would better fit in the category of SCL than structural wood panel. Table 5.9 shows a comparison of the mechanical properties of panels manufacture from veneer mill residues and two common structural composite lumber products, LVL and PSL.

Table 5.9 Comparison of the mechanical properties of the veneer strand composite to LVL and PSL.

\begin{tabular}{|c|c|c|c|}
\hline Property & vsc $^{1}$ & $\mathrm{LVL}^{2}$ & $\mathrm{PSL}^{3}$ \\
\hline Flatwise Bending MOE (x10 $\left.0^{6} \mathrm{psi}\right)$ & $2.26^{4}$ & 1.94 & 1.82 \\
\hline Edgewise Bending MOE (x10 $\left.10^{6}\right)$ & 1.94 & 1.92 & 1.86 \\
\hline Compressive MOE $\|\left(\times 10^{6} \mathrm{psi}\right)^{5}$ & 1.66 & 1.72 & 1.91 \\
\hline Compressive MOE $\mid\left(\times 10^{6} \mathrm{psi}\right)^{6}$ & 0.16 & 0.06 & 0.07 \\
\hline Shear Strength || (psi) & 835 & 980 & 960 \\
\hline Shear Strength [ (psi) & 515 & 405 & 310 \\
\hline
\end{tabular}

${ }^{1}$ Veneer strand composite

${ }^{2}$ Values from Bejo (2001), 15-layer yellow-poplar LVL, manufactured from 1/8" thick peeled veneer sheets

${ }^{3}$ Values from Bejo (2001), PSL with a mixture of $75 \%$ yellow-poplar and $25 \%$ southern yellow pine

${ }^{4}$ Value of apparent MOEs for VSC, some shear effect included.

${ }^{5} \|$ = parallel to strand alignment direction

${ }^{6} \mathrm{I}=$ perpendicular to strand alignment direction

While the edgewise bending MOE of the three products is nearly identical the flatwise bending MOE of the VSC is $15 \%$ and $25 \%$ higher than that of LVL and PSL respectively (Figure 5.11). The compressive MOE (Figure 5.12) as well as the shear strength (Figure 5.13) of the three products in both the parallel and perpendicular to strand alignment directions are comparable. 


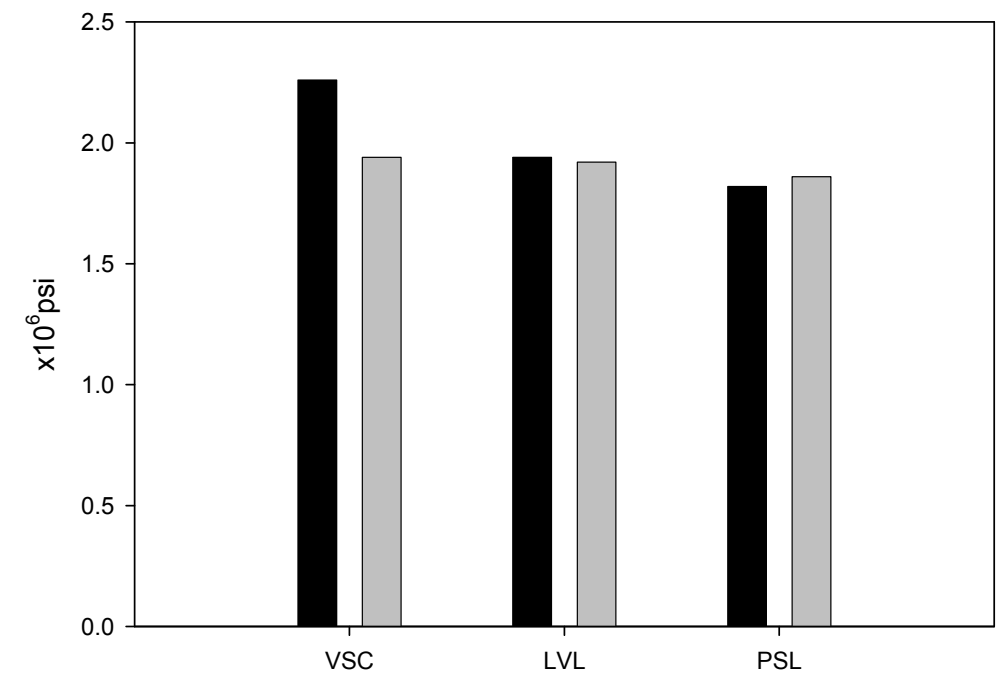

MOE Flatwise

MOE Edgewise

Figure 5.11 Comparison of flatwise and edgewise MOE parallel to strand alignment of the veneer strand composite, LVL, and PSL.

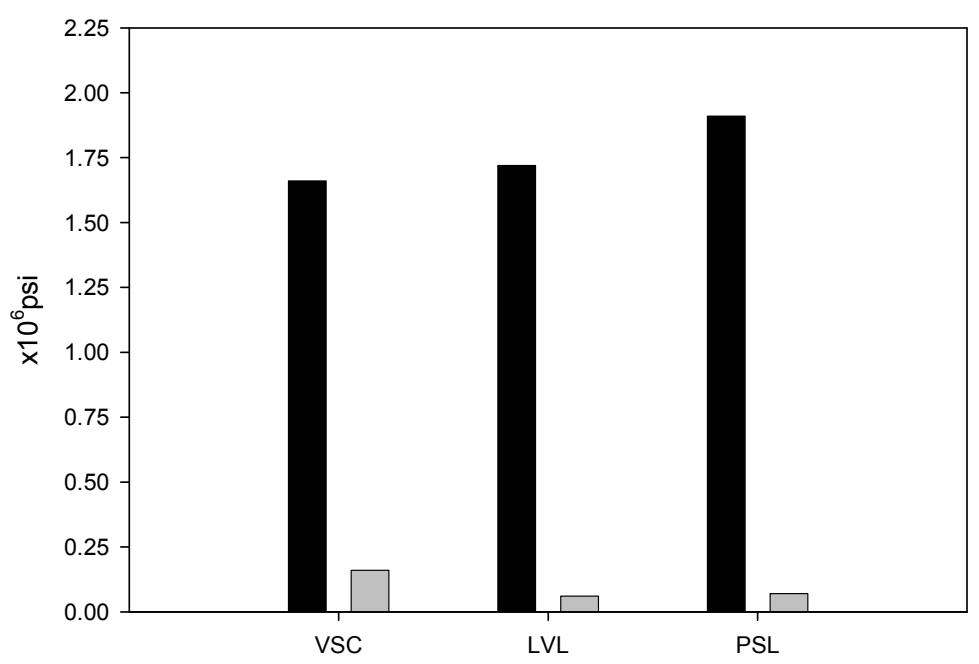

Compressive MOE parallel to strand alignment Compressive MOE perpendicular to strand alignment

Figure 5.12 Comparison of compressive MOE parallel and perpendicular to strand alignment of the veneer strand composite, LVL, and PSL. 


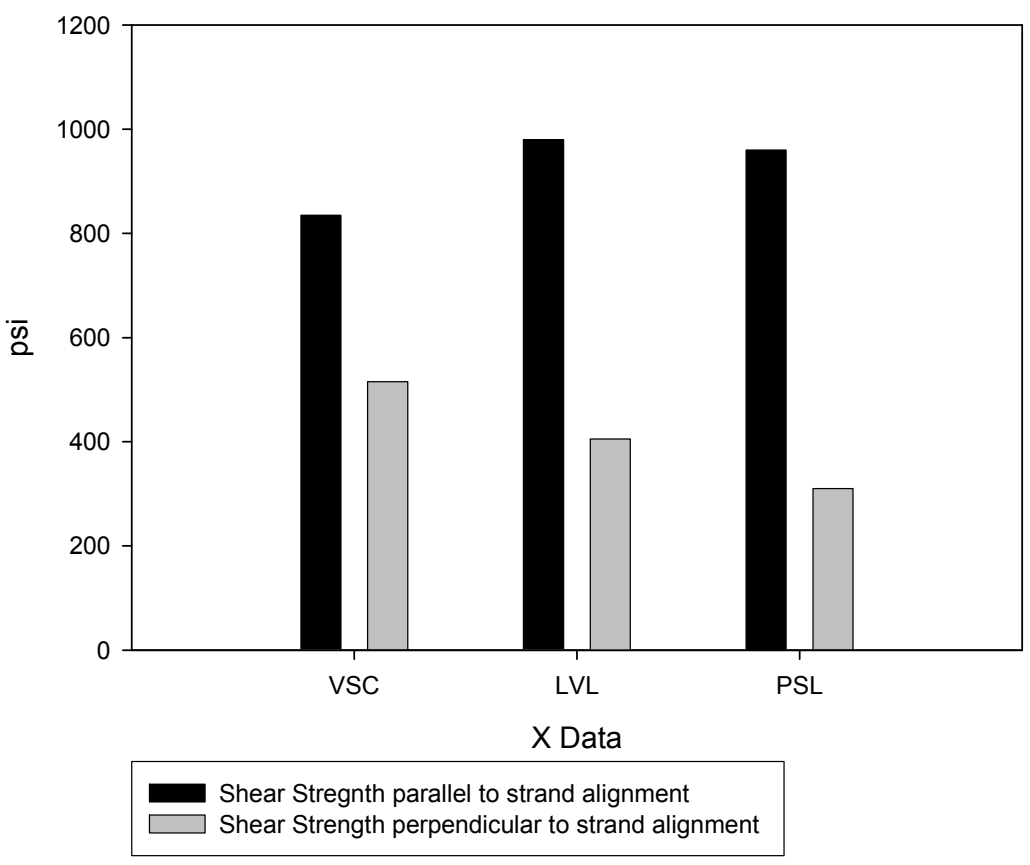

Figure 5.13 Comparison of shear strength parallel and perpendicular to strand alignment of the veneer strand composite, LVL, and PSL.

\subsection{Web-to-Web Tension}

Preliminary tests were performed using panels made from Ash veneer-mill residues. Two different joints were tested, finger joints and dovetail joints. Solid panels were also tested for comparison. The results of the preliminary testing show that finger joints have over twice the strength of dovetail joints (Table 5.10). Finger jointing the panels reduces the tensile strength by $60 \%$ while dovetail joints reduce the strength by $85 \%$. Even though joining the panels in length reduces the strength by $60 \%$ the joints can withstand nearly $9000 \mathrm{lbs}$. 
Table 5.10 Summary of preliminary web-to-web joint tensile strength tests with panels made from Ash.

\begin{tabular}{lccccc}
\hline \hline Joint Type & $\mathbf{n}$ & \multicolumn{2}{c}{$\mathbf{P}_{\mathrm{MAX}}$} & \multicolumn{2}{c}{$\boldsymbol{\sigma}_{\mathrm{MAX}}$} \\
\hline & & Mean (lbf) & $\mathbf{C}_{\mathrm{v}}(\%)$ & Mean (psi) & $\mathbf{C}_{\mathrm{v}}(\%)$ \\
\cline { 3 - 6 } Without Joint & 9 & 14183 & 0.30 & 9639 & 0.18 \\
Finger Joint & 13 & 8976 & 0.26 & 3672 & 0.25 \\
Dovetail Joint & 10 & 3356 & 0.32 & 1337 & 0.20 \\
\hline \hline
\end{tabular}

The preliminary tests showed that using a finger joint was preferable to a dovetail. Therefore, tests on Cherry panels only compared finger joints to the tensile strength of solid panels. The results are shown in Table 5.11. The tensile was only reduce by $30 \%$ showing much improvement over the trials made with Ash. A comparison between the Ash and Cherry specimens is shown in Figure 5.14.

Table 5.11 Summary of web-to-web joint tensile strength tests with panels made from Cherry.

\begin{tabular}{|c|c|c|c|c|c|}
\hline \multirow[t]{2}{*}{ Joint Type } & \multirow[t]{2}{*}{$n$} & \multicolumn{2}{|c|}{$\mathbf{P}_{\text {MAX }}$} & \multicolumn{2}{|c|}{$\sigma_{\operatorname{MAX}}$} \\
\hline & & Mean (Ibf) & $C_{v}(\%)$ & Mean (psi) & $\mathrm{C}_{\mathrm{v}}(\%)$ \\
\hline Without Joint & 5 & 20385 & 0.11 & 10031 & 0.09 \\
\hline Finger Joint & 5 & 13051 & 0.16 & 6745 & 0.14 \\
\hline
\end{tabular}




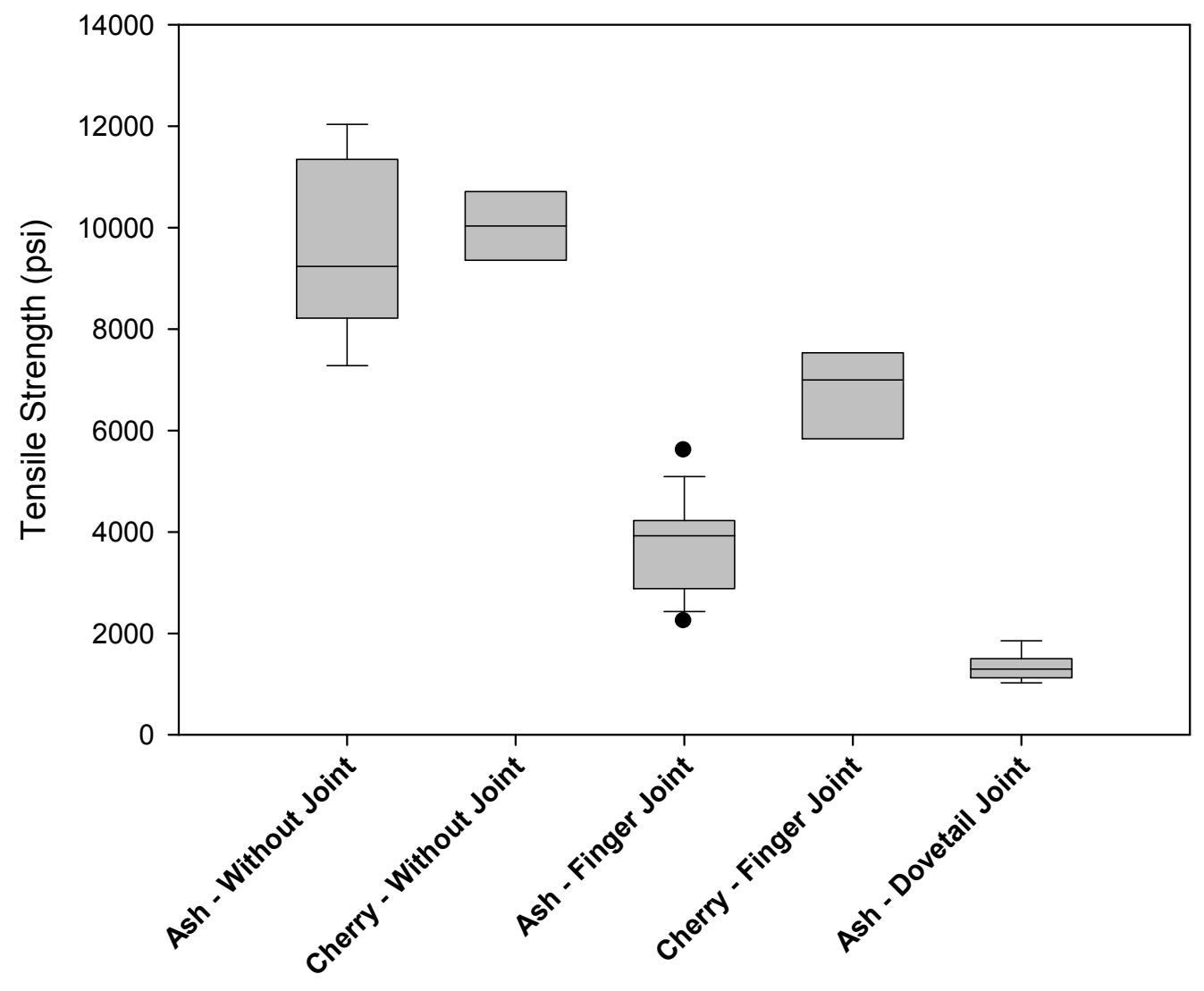

Figure 5.14 Comparison of tensile strength of solid panels and panels joined in length using Ash and Cherry.

The tensile strength of the solid panels made from Cherry was slightly higher than those made from Ash. The strength of the finger jointed panels was much higher than the dovetail joint. With finger joining there is more contact area and therefore has higher strength. Of the two joint types tested, finger jointing is the best method to connect the web. 


\subsection{Flange-to-Web Shear}

The shear strength of two flange-to-web joint types was evaluated. Six specimens each were tested with finger joints and tongue and groove joints. Eight specimens using a commercial I-joist, Trus Joist Silent Floor TJI $^{\circledR} /{ }^{\circledR} R O{ }^{\text {TM }} 130$ TS, with and 3/8" OSB web and tongue and grove flange-to-web connection were also tested for comparison. Table $\mathbf{5 . 1 2}$ shows a summary of the test results.

Table 5.12 Summary of flange-to-web shear strength testing.

\begin{tabular}{lccccc}
\hline \hline \multicolumn{1}{c}{ Joint Type } & $\mathbf{n}$ & \multicolumn{2}{c}{$\mathbf{P}_{\mathrm{MAX}}$} & \multicolumn{2}{c}{$\boldsymbol{\tau}_{\text {MAX }}$} \\
\hline & & Mean (lbf) & $\mathbf{C}_{\mathrm{v}}(\%)$ & Mean (psi) & $\mathbf{C}_{\mathrm{v}}(\%)$ \\
\cline { 3 - 6 } Finger Joint & 6 & 3671 & 0.18 & 1323 & 0.21 \\
Tongue and Groove Joint & 6 & 3595 & 0.29 & 1264 & 0.20 \\
Commercial Joist $^{1}$ & 8 & 5542 & 0.25 & 2523 & 0.25 \\
\hline \hline
\end{tabular}

${ }^{1}$ Commercial I-joist with 3/8" thick OSB web and tongue and groove joint

There was no significant difference in the strength of the tongue and groove and fingerjoints. The failures of 4 of the 6 tests for both joint types were through the web (Figure 5.15 a and c). The other 2 tests of each joint type failed through the panel (Figure $5.15 \mathrm{~b}$ and $\mathbf{d}$ ). In the case of the commercial joists tests, 3 of the 8 samples tested sheared through the web.

For the tests with corrugated webs, the results show that the strength of the joint was approximately the same as the strength of the panel. This is most likely due to tearing and crushing of the fingers in the manufacturing of finger joint specimens. For tongue and groove specimens, there was not adequate bonding between the faces of 
the panel which were covered with impregnated paper and the cold setting resin. If the paper had been removed prior to production of the tests specimens the tongue and groove joint would have had a higher strength capacity. Therefore, in the case of tongue and groove joints the critical shear strength is most likely the strength of the panel and not the connection.
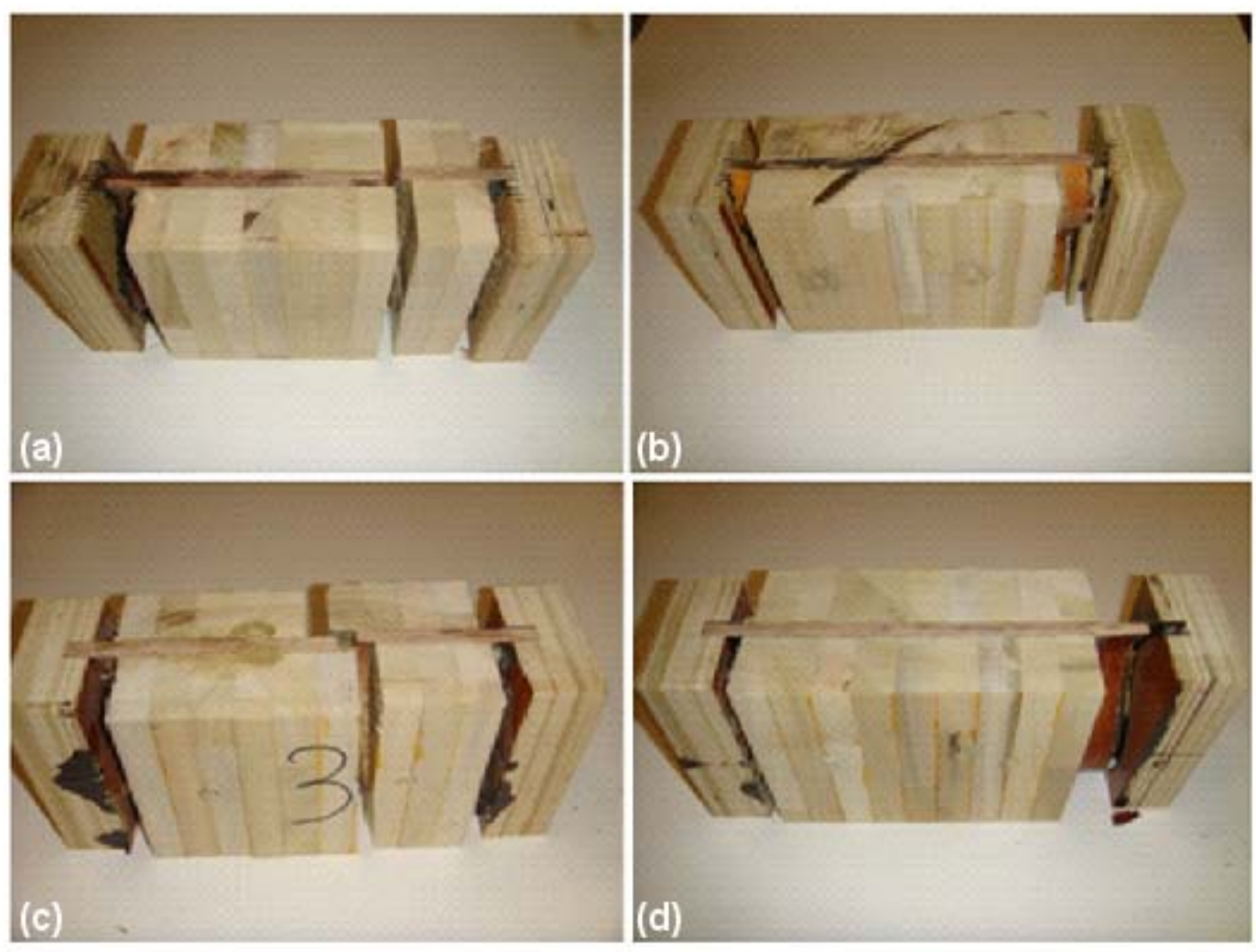

Figure 5.15 Typical failure modes of flange-to-web shear tests. 


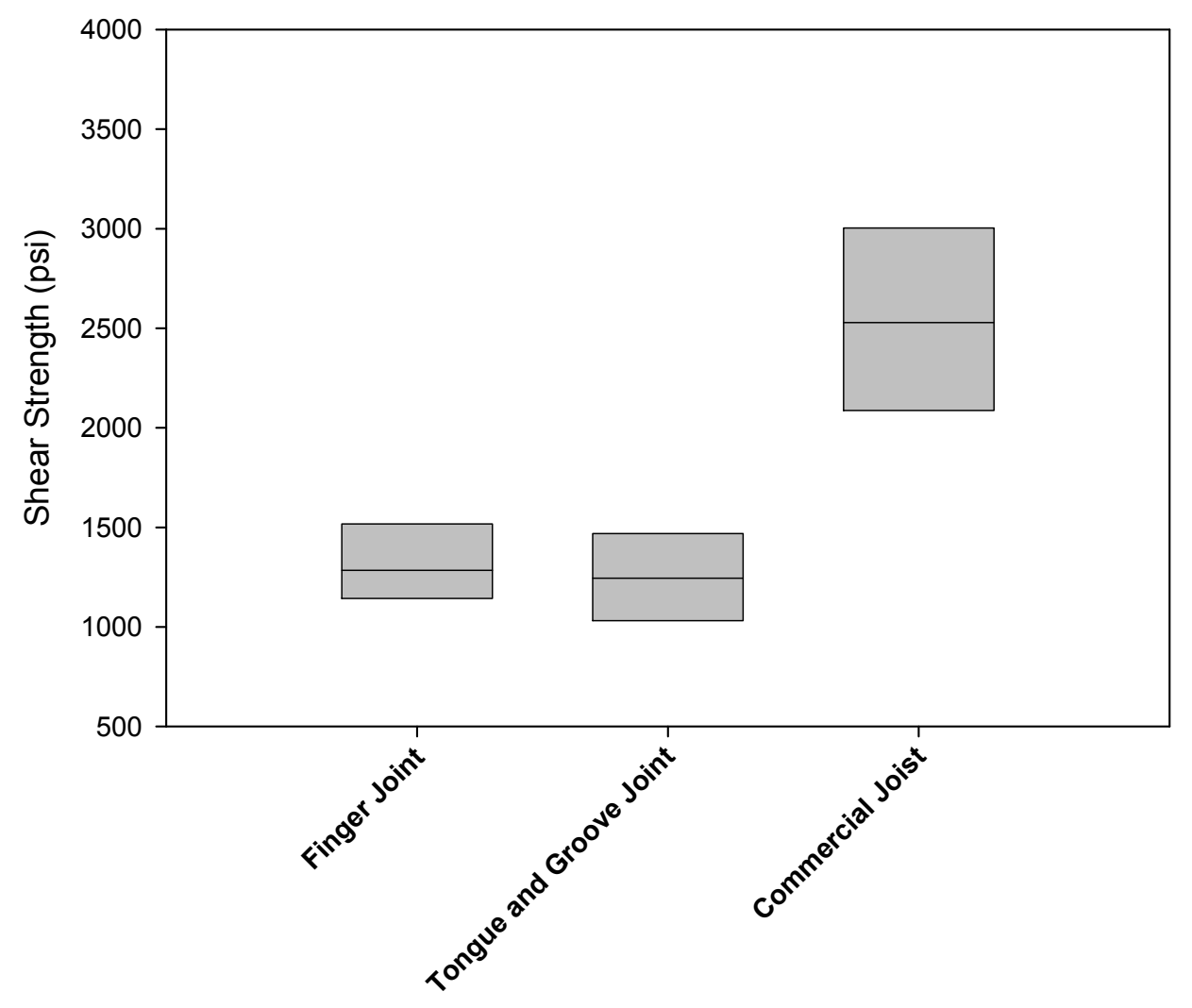

Figure 5.16 Comparison of shear strength of flange-to-web joints.

As seen in Figure 5.16 the flange-to-web connection of the commercial joist outperformed that of the joists with corrugated webs. This is due to the lower shear strength of the web of the veneer strand composites panels. The strands were all aligned along the length of the web and most specimens sheared through the bonds between strands created during the consoldation process. The OSB web of the commercial joist is manufactured with cross layers improving the shear strength of the product. 


\subsection{I-Joist Bending}

Nine I-joists were tested in bending. These joist were all manufactured using a web of corrugated panels made from veneer-mill residues of different depths and thicknesses. To make full scale I-joists the panels were finger jointed in length. LVL, PSL, and LSL were used as flange materials. A basic description of each joist can be seen in Table 5.13.

Table 5.13 Description of prefabricated l-joists.

\begin{tabular}{cccccccc}
\hline \hline Specimen & $\begin{array}{c}\text { Flange } \\
\text { Material }\end{array}$ & $\begin{array}{c}\text { Joint } \\
\text { Type }\end{array}$ & $\begin{array}{c}\text { Length } \\
\text { (ft) }\end{array}$ & $\begin{array}{c}\text { Depth } \\
\text { (in) }\end{array}$ & $\begin{array}{c}\text { Flange } \\
\text { Width (in) }\end{array}$ & $\begin{array}{c}\text { Flange Height } \\
\text { (in) }\end{array}$ & $\begin{array}{c}\text { Web } \\
\text { Thickness }^{\mathbf{3}} \text { (in) }\end{array}$ \\
\hline \hline $\mathbf{1}$ & PSL & FJ $^{1}$ & 12 & 8.88 & 1.69 & 1.31 & 0.20 \\
$\mathbf{2}$ & LVL & FJ & 12 & 10.94 & 1.75 & 1.69 & 0.31 \\
$\mathbf{3}$ & PSL & TG $^{2}$ & 12 & 11.75 & 2.19 & 1.56 & 0.25 \\
$\mathbf{4}$ & LVL & FJ & 12 & 11.25 & 2.00 & 1.38 & 0.31 \\
$\mathbf{5}$ & PSL & FJ & 12 & 11.38 & 2.00 & 1.38 & 0.45 \\
$\mathbf{6}$ & LVL & TG & 12 & 12.13 & 2.25 & 1.75 & 0.18 \\
$\mathbf{7}$ & LVL & TG & 8 & 9.25 & 2.25 & 1.75 & 0.50 \\
$\mathbf{8}$ & PSL & TG & 8 & 10.13 & 2.25 & 1.50 & 0.36 \\
$\mathbf{9}$ & LSL & TG & 8 & 16.25 & 3.38 & 1.38 & 0.40 \\
\hline \hline
\end{tabular}

\footnotetext{
${ }^{1}$ Finger joint

${ }^{2}$ Tongue and groove joint

${ }^{3}$ Values of actual web thickness (not adjusted equivalent values)
} 
Table 5.14 Mechanical properties of prefabricated I-joists.

\begin{tabular}{ccccccc}
\hline \hline Specimen & $\mathbf{I}_{\mathbf{x}}\left(\mathbf{i n}^{4}\right)$ & $\mathbf{P}_{\text {MAX }}(\mathbf{l b f})$ & $\mathbf{M}_{\text {MAX }}\left(\mathbf{l b}^{*} \mathbf{i n}\right)$ & $\mathbf{S}_{\mathbf{x}}\left(\mathbf{i n}^{3}\right)$ & $\begin{array}{c}\text { MOR } \\
\left(\mathbf{x} 10^{3} \mathbf{p s i}\right)\end{array}$ & $\begin{array}{c}\text { MOE } \\
\left(\mathbf{x} 10^{6} \mathbf{p s i}\right)\end{array}$ \\
\hline \hline $\mathbf{1}$ & 68.75 & 1484 & 34132 & 15.49 & 2.20 & 1.82 \\
$\mathbf{2}$ & 140.69 & 1856 & 42688 & 25.73 & 1.66 & 1.26 \\
$\mathbf{4}$ & 194.25 & 3990 & 91770 & 33.06 & 2.78 & 1.91 \\
$\mathbf{5}$ & 153.34 & 1479 & 34017 & 27.26 & 1.25 & 1.86 \\
$\mathbf{6}$ & 166.26 & 1856 & 42688 & 29.23 & 1.46 & 1.74 \\
$\mathbf{7}$ & 224.77 & 1997 & 45931 & 37.08 & 24 & 1.88 \\
$\mathbf{8}$ & 121.93 & 5725 & 89692 & 26.36 & 3.40 & - \\
$\mathbf{9}$ & 139.38 & 4958 & 77675 & 27.53 & 2.82 & - \\
\hline \hline
\end{tabular}

The moment capacity, modulus of rupture, and modulus of elasticity of each beam is listed in Table 5.14. The moment of inertia was based on an equivalent web thickness (see Equation 17). Though different beam geometries were tested, the MOE and MOE values are fair consistent with the exception of one outlier MOE value. It should be noted that MOE could not be accurately calculated for the 8 foot specimens because the displacement data recorded by the transducer was not consistent.

The joists with a tongue and groove flange-to-web connection showed significantly higher moment capacities. This phenomenon could be due to the fact that in manufacturing the finger jointed specimens the cutter head destroyed some of the fingers running along the length of the corrugated web when cutting perpendicular to the grain. I-joists made with the finger joints failed in rolling shear along the top or bottom flanges followed by failure of the web-to-web connection (Figure 5.17 a and b). For the joist with tongue and groove connection the failure was typically horizontal shear along 
the corrugated panels as seen in Figure $5.17 \mathrm{c}$ and $\mathrm{d}$. Specimen 3 failed in a combination of shear through the web-to-web joint and tension in the joint of the bottom flange (Figure $5.17 \mathrm{~d}$ and e).
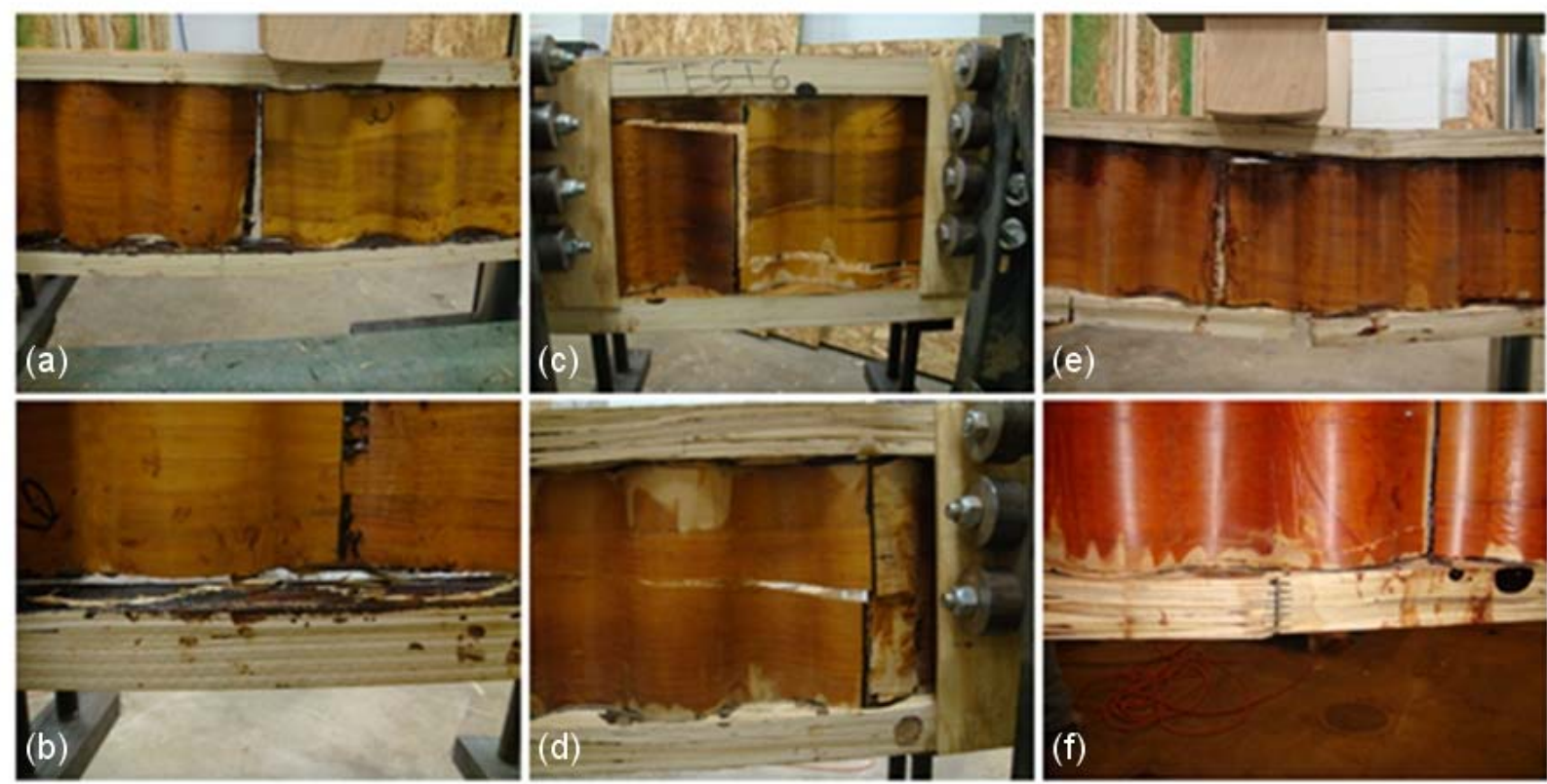

Figure 5.17 Typical failure modes of I-joists. 


\section{SUMMARY AND CONCLUSIONS}

The objective of this research was to investigate the physical and mechanical properties of a new composite produced from veneer-mill residues of underutilized hardwood species. This research also included a preliminary investigation into utilization of these panels as a corrugated web material in I-joists.

The results show that high quality composites can be produced from this waste material. When compared to solid wood, this veneer strand product demonstrated more higher strength and stiffness and more consistent mechanical properties. Comparisons to OSB and plywood showed that this new composite produce had higher bending, compression, tension, and shear properties. The panels showed similar mechanical properties to structural composite lumber products.

The results also show that these hardwood veneer clippings can be successfully consolidated into corrugated panels and used as web material in prefabricated I-joists. Testing was conducted on two different web-to-web connections. Finger jointing showed the most promising results, with the tensile strength of the joint having approximately half the strength of solid panels. Testing on the shear strength of the flange-to-web connection showed that shear strength of the panel connection. With adequate bonding of the joint the tongue and groove connection, this would produce a joint that would prove to have higher shear strength than that of the panel. Theoretically, finger jointing should produce a stronger joint because there is a higher bonded surface area. Due to 
manufacturing constraints the router and cutter head used to finger joint the web panels resulted in tearing out and chipping many of the fingers. However, an investigation into improving finger jointing techniques of the web panels could produce a higher quality joint that may outperform the tongue and groove.

The flexural properties of the composite joists are comparable to those of commercial prefabricated I-joists. The joists with finger jointed flange-to-web connection typically sheared through the connection while joists with tongue and groove connection failed through horizontal web shear. Efforts into improving the through-thethickness shear strength of the panels should be made. This could be achieved by orienting the strands perpendicular to the length of the joist or by adding cross layers to the mat before the panel is consolidated.

With the increasing need for construction materials and rising cost and decreasing availability of high quality lumber the wood composites industry is only going to grow. The results of this research have shown that this waste material can be manufactured into composites with improved physical and mechanical properties. Making use of these hardwood decorative veneer residues as value added composites could prove beneficial to both the veneer-mill and construction industry. 


\section{REFERENCES}

American Standard for Testing and Materials. 1999. Standard Test Methods of Static Tests of Lumber in Structural Sizes. ASTM 198-05a. ASTM, West Conshohocken, PA.

American Standard for Testing and Materials. 1999. Standard Test Methods for Evaluating Properties of Wood-Base Fiber and Particle Panel Materials. ASTM 1037-99. ASTM, West Conshohocken, PA.

American Standard for Testing and Materials. 1999. Standard Test Methods for Structural Panels in Tension. ASTM 3500-90. ASTM, West Conshohocken, PA.

Barnes, Derek. 2000. An integrated model of the effect of processing parameters on the strength properties of oriented strand wood products. Forest Products Journal. $50(11 / 12): 33-42$.

Barnes, Derek. 2002. A model of the effect of strand angle and grain angle on the strength properties of oriented veneer and strand wood composites. Forest Products Journal. 52(4):39-47.

Bejo, Laszlo. 2001. Simulation based modeling of the elastic properties of structural wood based composite lumber. Dissertation, West Virginia University, Morgantown, West Virginia. 224 pp. 
Cai, Z., J. Muehl, and J. Winandy. 2006. Effects of panel density and mat moisture content on processing medium density fiberboard. Forest Products Journal. 56(10):2025.

Denes, L., E. Lang, and Z. Kovacs. 2006. Product development from veneer-mill residues: an application of the Taguchi's method. Wood and Fiber Science 37(1): 36-48.

Edgar, Russell. 2003. Effects of strand geometry of selected properties of long-strand structural composite lumber made from northeastern hardwoods. Master Thesis, University of Maine, Orono, Maine. 177 pp.

Forest Products Laboratory. 1962. The manufacture of veneer. USDA Forest Products Laboratory, Madison, WI.

Forest Products Laboratory. 1999. Wood Handbook: Wood as an Engineering Material. FPL-GTR-113. USDA Forest Products Laboratory, Madison, WI.

Forest Products Laboratory. 2004. Fundamentals of composite processing. Technical report. FPL-GTR-149. USDA Forest Products Laboratory, Madison, WI.

Georgia Pacific Wood Products. 2008. Oriented Strand Board. June 23, 2009. $\underline{w w w . g p . c o m / B U I L D / D o c u m e n t V i e w e r . a s p x ? r e p o s i t o r y=B P \& e l e m e n t i d=3188 ~}$ 
Heebink, B., W. Lehmann, and F. Hefty. 1972. Reducing particleboard pressing time: Exploratory study. Research Paper. FPL 180. USDA Forest Products Laboratory, Madison, WI.

Lang, E., J. Davalos, and L. Denes. 2008. Hybrid structural wood composites engineered from underutilized hardwood species combined with reformulated waste materials. 2007 Annual Wood Utilization Research Report to the WVU WURC. West Virginia University, Division of Forestry and Natural Resources. Morgantown, WV. pp 61-66.

Leichti, R., R. Falk, and T. Laufenberg. 1990. Prefabricated wood composite I-beams: a literature review. Wood and Fiber Science 2(1):62-79.

Mercker, D. and G. Harper. Quality hardwood veneer. Agricultural Extension Service. University of Tennessee.

Nishimura, T., J. Amin, and M. Ansell. 2004. Image analysis and bending properties of model OSB panels as a function of strand distribution, shape, and size. Wood Science and Technology. 38:297-309.

Temperate Forest Foundation. 2001. Engineered wood products. Eco-Link 11(4). 
Wiedenbeck, J., M. Wiemman, D. Alderman, J. Baumgras, W. Luppold. 2003. Defining hardwood veneer log quality attributes. Technical Report to the USDA, Forest Service. NE-313. Northeastern Research Station, Newton Square, PA.

Xu, W. and O. Suchsland. 1998. Variability of particleboard properties from single- and mixed-species processes. Forest Products Journal. 48(9):68-74. 


\section{APPENDIX}

Comparison of $\|_{\text {Flatwise }}$ and $\|_{\text {Edgwise }}$ bending MOEs.

t-test

Monday, June 15, 2009, 2:51:13 PM

Data source: Data 1 in Par bending - flat vs. edge

Normality Test: $\quad$ Passed $(P>0.050)$

Equal Variance Test: Failed $(P=0.026)$

Test execution ended by user request, Rank Sum Test begun

Mann-Whitney Rank Sum Test

Monday, June 15, 2009, 2:51:14 PM

Data source: Data 1 in Par bending - flat vs. edge

$\begin{array}{llcccc}\text { Group } & \mathbf{N} & \text { Missing } & \text { Median } & \mathbf{2 5 \%} & \mathbf{7 5 \%} \\ \text { Flatwise } & 20 & 0 & 2250.172 & 2086.104 & 2454.332 \\ \text { Edgewise } & 24 & 0 & 1945.742 & 1886.421 & 2059.654\end{array}$

$\mathrm{T}=622.000 \mathrm{n}($ small $)=20 \mathrm{n}(\mathrm{big})=24 \quad(\mathrm{P}=<0.001)$

The difference in the median values between the two groups is greater than would be expected by chance; there is a statistically significant difference $(P=<0.001)$

Comparison of $\left.\right|_{\text {Flatwise }}$ and lEdgwise $_{\text {bending MOEs. }}$

t-test

Monday, June 15, 2009, 3:21:33 PM

Data source: Data 1 in Perp bending - flat vs. edge

Normality Test: $\quad$ Passed $(P>0.050)$

Equal Variance Test: Passed $(P=0.807)$

$\begin{array}{llccrc}\text { Group Name } & \text { N } & \text { Missing } & \text { Mean } & \text { Std Dev } & \text { SEM } \\ \text { Flatwise } & 20 & 0 & 183.728 & 42.094 & 9.413 \\ \text { Edgewise } & 19 & 0 & 174.882 & 36.160 & 8.296 \\ \text { Difference } & 8.846 & & & & \end{array}$

$t=0.702$ with 37 degrees of freedom. $(P=0.487)$

95 percent confidence interval for difference of means: -16.677 to 34.368 
The difference in the mean values of the two groups is not great enough to reject the possibility that the difference is due to random sampling variability. There is not a statistically significant difference between the input groups $(P=0.487)$.

Power of performed test with alpha $=0.050: 0.050$

The power of the performed test (0.050) is below the desired power of 0.800 .

You should interpret the negative findings cautiously.

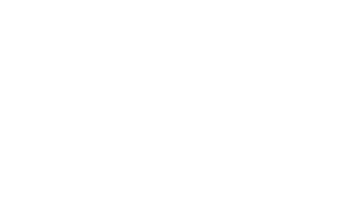

Hagen 